\title{
Immunomodulatory Effects Mediated by Dopamine
}

\author{
Rodrigo Arreola, ${ }^{1}$ Samantha Alvarez-Herrera, ${ }^{2}$ Gilberto Pérez-Sánchez, ${ }^{2}$ \\ Enrique Becerril-Villanueva, ${ }^{2}$ Carlos Cruz-Fuentes, ${ }^{1}$ Enrique Octavio Flores-Gutierrez, ${ }^{3}$ \\ María Eugenia Garcés-Alvarez, ${ }^{2}$ Dora Luz de la Cruz-Aguilera, ${ }^{4}$ Emilio Medina-Rivero, ${ }^{5}$ \\ Gabriela Hurtado-Alvarado, ${ }^{6}$ Saray Quintero-Fabián, ${ }^{7}$ and Lenin Pavón ${ }^{2}$
}

\author{
${ }^{1}$ Psychiatric Genetics Department, National Institute of Psychiatry "Ramón de la Fuente", Clinical Research Branch, \\ Calzada México-Xochimilco 101, Colonia San Lorenzo Huipulco, Tlalpan, 14370 Mexico City, Mexico \\ ${ }^{2}$ Department of Psychoimmunology, National Institute of Psychiatry "Ramón de la Fuente", Calzada México-Xochimilco 101, \\ Colonia San Lorenzo Huipulco, Tlalpan, 14370 Mexico City, Mexico \\ ${ }^{3}$ National Institute of Psychiatry "Ramón de la Fuente", Clinical Research Branch, Calzada México-Xochimilco 101, \\ Colonia San Lorenzo Huipulco, Tlalpan, 14370 Mexico City, Mexico \\ ${ }^{4}$ Laboratory of Neuroimmunoendocrinology, National Institute of Neurology and Neurosurgery "Manuel Velasco Suárez", \\ Avenida Insurgentes Sur 3877, La Fama, Tlalpan, 14269 Mexico City, Mexico \\ ${ }^{5}$ Unidad de Investigación y Desarrollo, Probiomed S.A. de C.V. Cruce de Carreteras Acatzingo-Zumpahuacán S/N, \\ 52400 Tenancingo, MEX, Mexico \\ ${ }^{6}$ Area of Neurosciences, Department of Biology of Reproduction, CBS, Universidad Autonoma Metropolitana, \\ Unidad Iztapalapa, Avenida San Rafael Atlixco No. 186, Colonia Vicentina, Iztapalapa, 09340 Mexico City, Mexico \\ ${ }^{7}$ Unidad de Genética de la Nutrición, Instituto de Investigaciones Biomédicas, Universidad Nacional Autónoma de México, \\ Instituto Nacional de Pediatría, Av. del Iman No. 1, Cuarto Piso, 04530 Mexico City, Mexico
}

Correspondence should be addressed to Lenin Pavón; lkuriaki@imp.edu.mx

Received 15 March 2016; Revised 29 July 2016; Accepted 8 August 2016

Academic Editor: Peirong Jiao

Copyright (C) 2016 Rodrigo Arreola et al. This is an open access article distributed under the Creative Commons Attribution License, which permits unrestricted use, distribution, and reproduction in any medium, provided the original work is properly cited.

Dopamine (DA), a neurotransmitter in the central nervous system (CNS), has modulatory functions at the systemic level. The peripheral and central nervous systems have independent dopaminergic system (DAS) that share mechanisms and molecular machinery. In the past century, experimental evidence has accumulated on the proteins knowledge that is involved in the synthesis, reuptake, and transportation of DA in leukocytes and the differential expression of the D1-like (D1R and D5R) and D2-like receptors (D2R, D3R, and D4R). The expression of these components depends on the state of cellular activation and the concentration and time of exposure to DA. Receptors that are expressed in leukocytes are linked to signaling pathways that are mediated by changes in cAMP concentration, which in turn triggers changes in phenotype and cellular function. According to the leukocyte lineage, the effects of DA are associated with such processes as respiratory burst, cytokine and antibody secretion, chemotaxis, apoptosis, and cytotoxicity. In clinical conditions such as schizophrenia, Parkinson disease, Tourette syndrome, and multiple sclerosis (MS), there are evident alterations during immune responses in leukocytes, in which changes in DA receptor density have been observed. Several groups have proposed that these findings are useful in establishing clinical status and clinical markers.

\section{Introduction}

Dopamine (DA) is a monoamine that is best known for its neurotransmitter function, and like other neurotransmitters, its effects are not limited to the central nervous system (CNS). Several studies support the notion that DA is a coregulator of the immune system (IS) [1-7], tissues and organs, such as adipose tissue and kidney [8, 9]. Alterations in the DAS have been associated with many health problems, including high blood pressure [10], psychiatric disorders (e.g., schizophrenia), and neurodegenerative diseases (e.g., Parkinson disease).

Based on the involvement of DA in behavioral and cognitive processes, many studies have focused on the nervous 
system [11-14], describing the general mechanisms, physiological issues, and signaling pathways of the DAS $[15,16]$. The existence of DA in the bloodstream suggests the presence of the dopaminergic components that modulate functions in the immune system [17], as in other systems [18]. Studies on monoamines, such as serotonin, DA and its derivatives, and neuropeptides, have become increasingly significant since the 1980s, given their neuroimmunoregulatory functions [1922].

The CNS and immune system are the main adaptive systems, participating in continuous and functional crosstalk to ensure homeostasis. DA and other catecholamines, such as noradrenaline, function as neuroimmunotransmitters in the sympathetic-adrenergic terminals of the autonomic nervous system, which innervates the primary and secondary lymphoid organs - in addition to the direct local effects that nonsynaptic varicosity secretions have on immune cells [1, 2 , 23, 24].

This review focuses on the function of the DAS in the immune system and the function of DA as an immunoregulatory molecule and on the communication between the CNS and IS, based mainly on studies in human cells. We also discuss the clinical aspects of disturbances in the DAS in mental disorders, such as schizophrenia, Parkinson disease, and other clinical conditions that are related to cancer, viral infections, and autoimmunity.

\section{The Early History of DA and Its Receptors}

DA (3-hydroxytyramine; 3,4-dihydroxyphenethylamine; $\mathrm{C}_{8} \mathrm{H}_{11} \mathrm{NO}_{2}$ ) was first synthesized in 1910 [25-27]. The initial experiments on DA, in the same year, evaluated its biological effects as a weak sympathomimetic [26, 28]. After nearly 30 years, in 1938, Peter Holtz and colleagues identified LDOPA decarboxylase in mammals, which uses L-DOPA as a substrate to obtain DA. One year later, Hermann Blaschko in 1939 postulated the biosynthetic pathway of catecholamines, which remains valid and places DA as a precursor of adrenaline and noradrenaline [29].

In subsequent years, observations of small concentrations of DA in several peripheral tissues were reported. Curiously, the name "dopamine" was not adopted until 1952, when a shorter name was proposed by Henry Dale [29]. In the 1950 s, the participation of DA in biological processes became recognized, in addition to it being a precursor of adrenaline and noradrenaline, with significant physiological function in the mammalian brain. Arvid Carlsson and colleagues (19571959) found that DA has a fundamental function and unique distribution throughout the brain and other tissues [30, 31]. Bertler and Rosengren (Carlsson's students) reported that DA was present in the brains of all of the mammals that they studied but its distribution in the brain differed [32].

This difference, combined with results from other studies that used reserpine, an inhibitor of chromaffin granule amine transporter and synaptic vesicular amine transporter $[33,34]$, and L-DOPA prompted speculation that DA was involved in the modulation of motor function. Early reports on the distribution of dopamine in animals and humans showed that DA exists primarily in the caudate nucleus in significant amounts [32, 35-37]. At the beginning of the 1960s, the initial studies on Parkinson disease were performed using human tissue from autopsies, demonstrating the absence of DA in the striatum [38].

The idea of providing L-DOPA to patients with Parkinson disease and psychotic disorders arose soon thereafter, leading to the first clinical trials on L-DOPA to mitigate Parkinsonian symptoms [39]. After an extended trial period, L-DOPA was commercialized in 1973 with benserazide, a DOPA decarboxylase inhibitor [40-43].

Moreover, several studies already reported the relevance of DA as a modulator of motor function [45]; the biochemical study of DA receptors (DRs) in the CNS began with Greengard's research, just like the discovery that DA stimulates adenylyl cyclase in the cervical sympathetic ganglia and rat caudate nucleus $[46,47]$. The results on stimulation with DA led to the classification of two types of receptors for the second messenger cAMP: stimulatory (alpha-type) and inhibitory (beta-type) [48, 49]. cAMP function depends on the coupling of its receptor (DR) to the heterotrimeric $G$ proteins $\mathrm{G} \alpha$-s/olf and $\mathrm{G} \alpha$-i/o. The subtypes of receptors are the D1-like subtype (D1-like), which includes D1R and D5R, and the D2-like subtype (D2-like), comprising $\mathrm{D} 2 \mathrm{R}$ receptor longer, D2R receptor short, D3R, and D4R [16]. Another important component of the DAS is sodium-dependent dopamine transporter (DAT; gene SLC6A3), which was cloned from rat and cow by several groups in 1991 [50-53] and in humans in 1992 [54].

Arvid Carlsson, Paul Greengard, and Eric Kandel were awarded the Nobel Prize in Physiology or Medicine in 2000 for their work on signal transduction in the nervous system [55]. The function of DA as a neurotransmitter precedes its importance in the immune system, based on the many processes in which it participates in the CNS. However, the history of DA and its functions in the IS and other tissues has recently begun.

\section{Dopaminergic System}

The DAS is a vast protein assembly that synthesizes, releases, senses, and metabolizes DA in various cell types in mammals. It also modulates a vast set of neuronal processes. Several examples of brain functions in which DA participates are cognition, motor control, mood, reward systems, pain perception, and sexual behavior $[11,12]$.

The function of DA outside of the nervous system has only recently been studied. For instance, DA mediates stem cell-mediated dental repair with platelets, regulates salt excretion by the kidney, and modulates blood pressure [56, 57]. DA is unable to cross the blood-brain barrier; thus, signaling in the neuronal DAS should be independent of that of the DAS in peripheral systems [11].

3.1. DA Concentrations in the Peripheral Region Outside of the CNS. DA in peripheral systems originates from the nervous system and mesenteric region. The concentration of DA in peripheral plasma in humans is approximately $0.1 \mathrm{nmol} / \mathrm{L}$ $(0.1 \mathrm{pmol} / \mathrm{mL})$ and is derived primarily from sympathetic noradrenergic nerve fibers. This concentration can vary by 
up to nearly 50 -fold for derivatives, such as DA sulfate, after ingestion of a standard meal and according to the region of the circulatory system [58].

The concentration of DA has been assessed in the mesenteric region in samples from abdominal surgeries for gastric adenocarcinoma and pancreatic neoplasm. Abdominal DA concentrations in arterial plasma (samples from the radial and hepatic arteries) and venous plasma (from the right hepatic and portal veins) are approximately $0.312 \mathrm{pmol} / \mathrm{mL}$ and $0.937 \mathrm{pmol} / \mathrm{mL}$, respectively (estimated from Figure 1 of Eisenhofer 1997). In addition, by immunoreactivity, tyrosine hydroxylase has been detected in human gastrointestinal mucosa, as have its catalytic activity and the presence of DRs $[59,60]$. The concentration of DA and its metabolites in plasma of the portal vein with respect to arterial plasma has demonstrated greater production of DA in the mesenteric organs $(12 \mathrm{nmol} / \mathrm{min})$, representing approximately $50 \%$ of the DA that is produced in the human body [59].

\subsection{Dopaminergic System Expressed in Various Tissues and} Leukocytes. The physiological mechanisms of the cell signaling and pharmacology of DRs and DA metabolism have been described extensively in the murine CNS $[15,61]$. The mechanisms and protein components of this system are likely to be shared between CNS cells and all other tissues in mammals. However, the genes of the DAS in each tissue type are differently expressed differentially, and the protein components must be specifically modulated, based on the function of the cell type. Thus, the genes and proteins of the DAS, such as DRs and DAT, are expressed in a wide range of tissues (e.g., adipose tissue, perivascular adipose tissue, kidney, heart, pituitary, the gastrointestinal tract, and pancreatic beta cells) that regulate processes that differ from those that the CNS governs (e.g., blood pressure regulation, sight process regulation in the retina, vascular permeability regulation in the epithelium, and insulin release) $[9,10$, 13, 18, 62-68]. However, many of these studies have been performed primarily in murine models and cell lines (human and murine), potentially creating variations in the results.

The DAS has been observed in murine immune cells [6973] and human platelets [74]. Recent studies have described its effects on the activation and proliferation of certain cells [75]. The expression of all DRs has been studied in all types of human leukocytes (Table 1). Although their mRNA and protein levels vary between human cell lines, DRs expression is lowest in T lymphocytes and monocytes among all leukocytes, whereas B lymphocyte and NK cell membranes bear the highest levels.

3.3. Metabolic Pathways of DA. In the CNS, DA is synthesized through an anabolic pathway that is shared with other catecholamines, such as L-noradrenaline (NE) and adrenaline (E) [61]. Catecholamine metabolism serves as a source of intracellular ROS (reactive oxygen species) production, which occurs in Parkinson disease, along with mitochondrial dysfunction [138]. The catecholamine pathway has been proposed to be particularly crucial in the reductionoxidation (REDOX) homeostasis in cells. It might mediate the overproduction of ROS in neurons, which can compromise the integrity of dopaminergic cells [61]. The effects of DA metabolism in leukocytes, the modulation of the REDOX balance, and the function of DA in mitochondria remain poorly documented [24].

In other tissues, such as the murine kidney, study of the relationship between DRs, oxidative stress, and the REDOX balance has provided information on high blood pressure [10]. The degradation of catecholamines, particularly DA, generates subproducts at low abundance, the concentrations of which depend strongly on the tissue and cell type [61].

A recent mathematical model of DA metabolism in Parkinson disease shows a certain degree of predictability with respect to pharmacological and genetic changes. The authors of this model propose its application in silico in the search for molecular approximations that allow the imbalance in DA contents to be restored and changes in oxidative stress to be detected. This model is a preliminary effort, and the authors have commented on future developments and extensions [139]. It would be desirable for such extensions to include peripheral DA systems-for example, studying the metabolism of adrenergic-sympathetic terminals in lymphoid organs and determining their predictive value in human immune system cells.

3.3.1. Anabolism. The classical pathway of DA synthesis begins with the production of L-tyrosine from L-phenylalanine by phenylalanine 4-hydroxylase (PAH) (EC: 1.14.16.1; $P A H$ gene). DA is synthesized in the catecholamine pathway (Figure 1), the first enzymatic step of which is the transformation of L-tyrosine into L-DOPA by tyrosine 3hydroxylase (TH) (EC: 1.14.16.2; TH gene). Both enzymes use molecular oxygen and tetrahydrobiopterin as cofactors of oxidation, rendering them two strongly regulated enzymes. Next, L-DOPA is converted to DA by DOPA decarboxylase (DDC) (EC: 4.1.1.28; DDC gene). DA is the precursor of $\mathrm{L}-$ noradrenaline, mediated by DA betahydroxylase DBH (EC: 1.14.17.1; $D B H$ gene). Finally, L-noradrenaline is converted into adrenaline by phenylethanolamine $\mathrm{N}$-methyltransferase (PNMTase) (EC: 2.1.1.28; PNMT gene) [61, 111].

Two alternative pathways of DA synthesis have been identified in the rat brain and human hepatic microsomes. In the first mechanism, DDC transforms L-phenylalanine into phenylethylamine, which in turn is converted into tyramine by PAH; in the second pathway, DDC uses L-tyrosine to produce tyramine. In both cases, tyramine is converted into DA by the cytochrome p-450 CYP2D6 isoform (EC: 1.14.14.1; CYP2, CYP2D genes) $[140,141]$.

The enzymatic activity of TH and PAH in human leukocytes has been detected since the 1980s [112-114]. In addition, the expression and immunodetection of TH in human and mouse leukocytes have been widely reported $[77,79,83,106$, 107]. On the other hand, DDC expression in human cells has also been documented $[79,109,110]$ (Table 1).

In human lymphocytes, the presence and synthesis of certain catecholamines, such as L-DOPA and noradrenaline, the synthesis of which appears to be linked to cholinergic stimulation, have been measured, but they are differentially synthesized between B and T lymphocytes; L-DOPA exists 


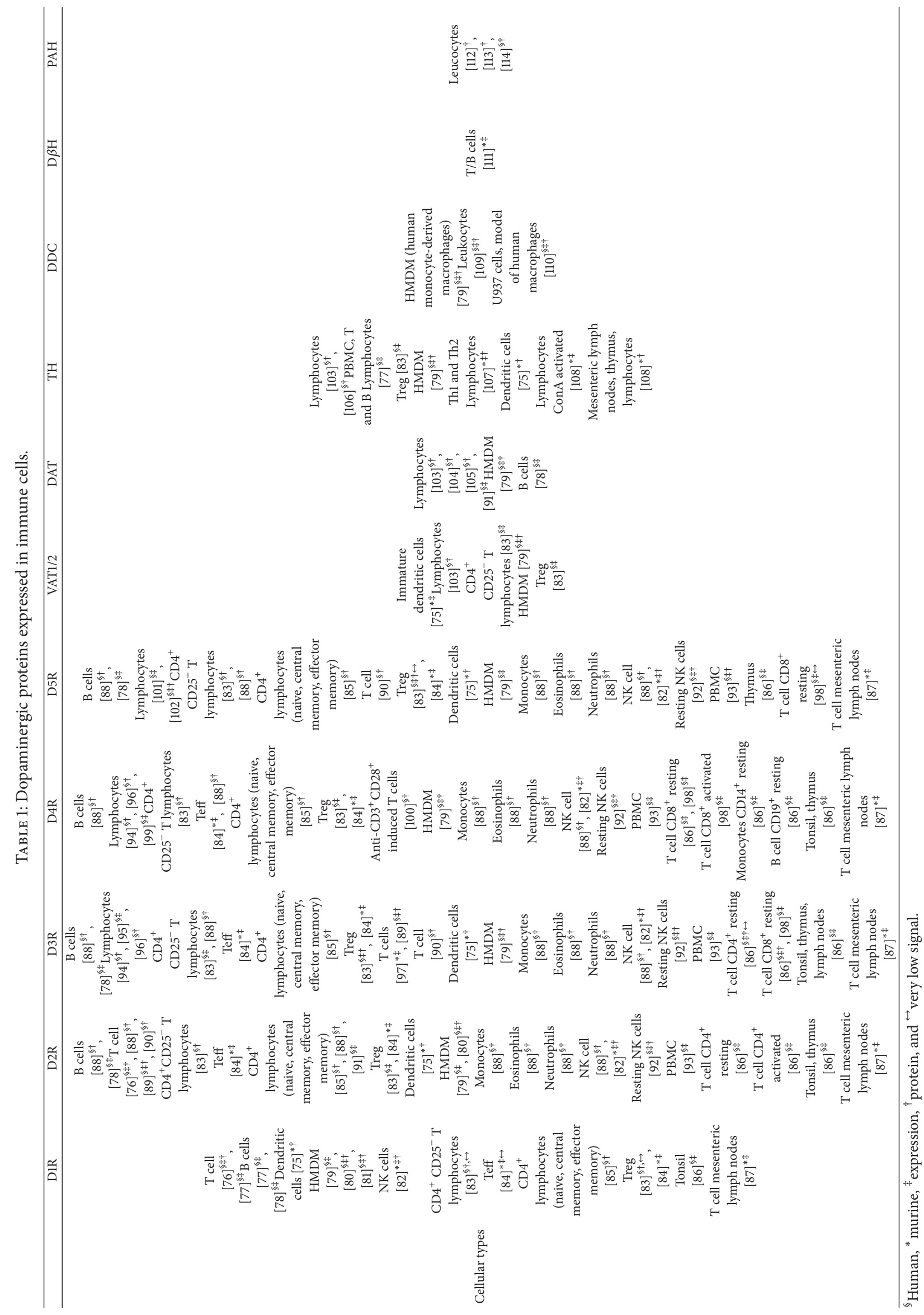




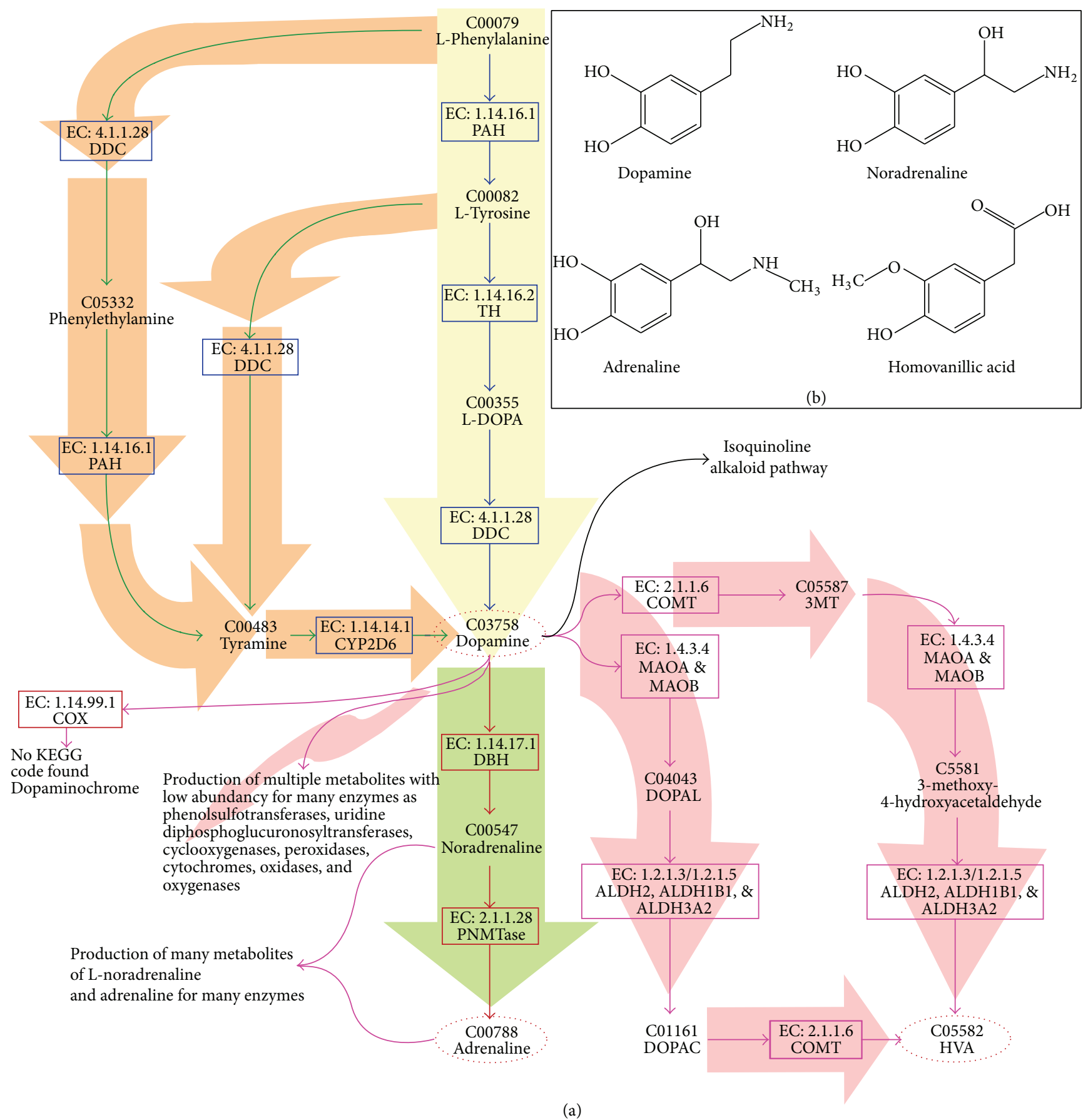

FIGURE 1: Metabolic pathways associated with DA. The metabolic pathways branching from the catabolism of L-phenylalanine are shown. (a) The dark blue arrows (over light yellow branches) indicate the DA generation pathway, and the red arrows (over light green branches) represent the noradrenaline and adrenaline pathway. Green arrows (over orange branches) show the alternative synthesis pathways to dopamine. The magenta arrows (over pink branches) show dopamine catabolism; the right side shows the normal pathways converging on HVA; the left side shows the catabolic pathways when dopamine concentrations are high in the cytoplasm. Many enzymes can transform dopamine and metabolites, such as COX enzymes (cyclooxygenases), producing dopaminochrome and dopamine quinone [44]. Other enzymes can produce sulfur and glucuronide derivatives. (b) The inset shows the most important products (circled with dotted lines) of metabolic pathways associated with DA. The compounds in these pathways are denoted by Kyoto Encyclopedia of Genes and Genomes (KEGG) code (http://www.genome.jp/kegg/). Enzymes with their classification codes (EC, http://www.chem.qmul.ac.uk/iubmb/enzyme/) and UNIPROT gene names are shown in squares. 
in both cell types, but noradrenaline is only found in $\mathrm{T}$ cells [142]. The incubation of human lymphocytes with L-tyrosine and acetylcholine increases L-DOPA and DA levels. In human and murine lymphocytes, incubation with L-tyrosine and L-DOPA increases L-DOPA, DA, and noradrenaline $[122,142,143]$.

3.3.2. Catabolism. In neurons, DA is recovered from the synaptic cleft by DAT and accumulates in the cytosol, where it is carried to synaptic storage vesicles by synaptic vesicular amine transporter (VAT2). The excess of DA in the neuronal cytosol is degraded by an enzymatic set (Figure 1), comprising monoamine oxidases (MAO-A and MAO-B) (EC: 1.4.3.4; genes $M A O A$ and $M A O B$ ), catechol o-methyltransferase (COMT) (EC: 2.1.1.6; gene COMT), aldehyde dehydrogenases (ALDHs) (EC: 1.2.1.3/1.2.1.5; gene type $A L D H s$ ), alcohol dehydrogenases (ADHs) (EC: 1.1.1.1; gene $A D H$ ), and aldehyde reductases (ARs) (EC: 1.1.1.21; gene type $A K R$ ).

Using DA, COMT produces 3-methoxytyramine (3MT), which MAO-A and MAO-B acquire to produce 3-methoxy4-hydroxyacetaldehyde, which is then used by ALDH to generate homovanillic acid (HVA). Alternatively, MAO-A and MAO-B can act on DA to synthesize 3,4-dihydroxyphenylacetaldehyde (DOPAL), which is then transformed into 3,4-dihydroxyphenylacetate (DOPAC) by ALDH. DOPAC is converted to HVA by COMT. DOPAC and HVA are the final principal metabolites of the degradation pathway of DA [61]. However, other subproducts have been observed in the CNS, based on the activity of phenolsulfotransferases (PSTs) and uridine diphosphoglucuronosyltransferases (PAPS), which produce other derivatives with sulfate and glucuronic acid, respectively [144-146]. Cyclooxygenases, peroxidases, cytochromes, oxidases, and oxygenases can also oxidize DA. For instance, prostaglandin $\mathrm{H}$ synthase (COX) (EC: 1.14.99.1) produces prostaglandin $\mathrm{H}$ using DA as a cofactor; subsequently, DA is transformed to generate dopaminochrome. Other examples of low-abundance metabolites that are derived from the catabolism of DA, the functions of which have not been examined, are discussed in Sulzer 1999 and Muñoz 2012 [147, 148].

Other compounds have been detected by spontaneous oxidation of the catechol group of DA and L-DOPA by ROS and amino acids that are derived from cysteine. These compounds are the corresponding quinones, which are associated with oxidative stress, such as DOPA quinone, dopamine quinone, and 6-hydroxydopamine quinone. Beginning with these compounds, a series of oxidation steps with ROS and cysteines occur to generate thioester derivatives and cysteine adducts $[44,61,147,149]$. These events regarding the catabolism and oxidation of DA and other catecholamines demonstrate that the classical enzymatic degradation pathway of DA must be tightly regulated under regular conditions to produce DOPAC and HVA (waste products). Otherwise, the excess of DA and its metabolites in the cytosol can lead to the formation of cumulative compounds, such neuromelanin, in the lysosomes and cause severe damage to cells. In Parkinson disease, excess production and accumulation of DA and its catabolites in the cytosol can effect mitochondrial dysfunction, oxidative stress, the formation of neurotoxic $\alpha$-synuclein protofibrils, and impairments in protein degradation, which mediate the neurodegeneration of dopaminergic neurons in Parkinson disease [61, 148].

In the mesenteric system (the gastrointestinal tract, spleen, and pancreas), DOPA, DA, and DOPAC are metabolized in the kidneys, plasma, and primarily liver, increasing HVA levels in the portal vein [59]. DOPAC in the bloodstream originates primarily from sympathetic nerve endings and is the precursor of HVA through COMT activity [150].

Generally, the rise in certain metabolites from DA degradation might indicate that cells are damaged by oxidative stress, because when physiological DA concentrations are surpassed, the degradation catabolites (HVA, DOPAL, DOPAC, and 3MT) begin to generate reactive secondary catabolites through spontaneous oxidation by chemical interaction with ROS. Further, when the concentrations of all DA derivatives climb, other enzymes can use them as substrates to generate additional metabolites.

3.4. Dopamine Receptors: DRs. Most studies on DRs have been conducted in the CNS, but many reports in other tissues are being published. The human DAS comprises at least six membrane DRs: D1R, D2RL, D2RS, D3R, D4R, and D5R. D2DR has four isoforms that are generated by differential mRNA splicing and have varying functions and sizes. Whereas the two longer isoforms are 443 and 445 amino acids, the short isoforms have 29 and 31 fewer amino acids. The number of DRD3 and DRD4 isoforms has not been determined and is poorly documented in humans and animals [95, 151-155]. In addition, these isoforms have not been linked to any differential functions, unlike DRD2 isoforms.

Human lymphocytes express $D R D 5$ and two of its pseudogenes, $\psi D 5 D R-1$ and $\psi D 5 D R-2$, which are transcriptionally competent and the functions of which are unknown [101, 119, 120]. However, the pseudogenes peptides are likely to generate truncated and nonfunctional receptors [120]. $\psi D 5 D R$ 1 and $\psi D 5 D R-2$ are segmental duplicated chromosomal regions that are $95 \%$ identical to DRD5 that cover part of the transcribed region of DRD5 [120, 121, 156] (Table 2).

Human peripheral blood lymphocytes also express $D R D 3$ and DRD4 [95, 99, 101, 151, 152]. Although DRD1 and DRD2 were initially believed not to be expressed in these cells $[94,102,157]$, recent studies showed that DRD2 is expressed in $\mathrm{T}$ and $\mathrm{B}$ lymphocytes, whereas $D R D 1$ does not appear to be expressed in any leukocyte $[88,97]$. By flow cytometry, all DRs, except D1R, are differentially expressed in nearly all human leukocyte cell lineages. The most recent studies show that DRD1 and D1R are expressed in stimulated T lymphocytes and are linked to the negative regulation of the immune response [76]. In particular, D4R expression is low in all leukocyte subtypes, except NK cells. T lymphocytes and monocytes contain low amounts of all DRs, followed by neutrophils, which primarily express D3R and D5R but at lower levels. B lymphocytes and NK cells have the highest levels of DR [88]. Further, other techniques, such as radioligand binding assay (RBA), have been used to document DR expression in the membranes of immune system cells [94, $158,159]$. D1R, D2R, D3R, and D5R have been observed by 
TABLE 2: Dopaminergic system protein components expressed in immune system.

\begin{tabular}{lcc}
\hline Receptors of DRs & Genes names & References \\
\hline $\begin{array}{l}\text { D(1) receptor: D1R } \\
\text { (old name D1A receptor) }\end{array}$ & $D R D 1^{*}$ & {$[75-87]$} \\
$\begin{array}{l}\text { D1-like subtype } \\
\text { (2) receptor longer: D2R }\end{array}$ & DRD2 & {$[75,76,78-80,82-93]$} \\
$\begin{array}{l}\text { D2-like subtype } \\
\text { (3) receptor: D3R }\end{array}$ & DRD3 & {$[75,78,79,82-90,92-98]$} \\
$\begin{array}{l}\text { D2-like subtype } \\
\text { D(4) receptor: D4R }\end{array}$ & DRD4 & {$[79,82-88,92-94,96,98-100]$} \\
$\begin{array}{l}\text { D2-like subtype } \\
\text { D(5) receptor: D5R } \\
\text { (old name D1B receptor) }\end{array}$ & & {$[75,78,79,82-88,90,92,93,98,101,102]$} \\
$\begin{array}{l}\text { D1-like subtype } \\
\text { Sodium-dependent dopamine } \\
\text { transporter: DAT }\end{array}$ & DRD5 & {$[78,79,91,103-105,115,116]$} \\
\hline
\end{tabular}

Protein components shared with other

monoamines systems

Chromaffin granule amine transporter: $\quad$ SLC18A1 isoform 2

VAT1 (synonyms: VMAT1)

$[83,103,117,118]$

Synaptic vesicular amine transporter:

VAT2

SLC18A2 (synonyms: VMAT2)

$[75,79,83,103,116]$

Protein components with unknown

functions

Chromaffin granule amine transporter:

VAT1 $115 \leftrightarrow$

SLC18A1 isoform 2

(synonyms: VMAT1 15 )

$[117,118]$

Pseudogene $\mathrm{D}(5)$ receptor $^{\dagger}$

$\psi D R D 5-1$

[101, 119-121]

Pseudogene D(5) receptor ${ }^{\dagger}$

$\psi D R D 5-2$

$[101,119-121]$

${ }^{*}$ This gene expresses low levels of mRNA and translates low quantities of the protein.

${ }^{\dagger}$ Unknown peptide product but produces mRNA with unknown functions.

$\leftrightarrow$ This protein cannot transport serotonin.

immunodetection in mouse bone marrow-derived dendritic cells (BMDCs) [75].

3.4.1. DRs Are G Protein-Coupled Receptors (GPCR). DRs belong to a superfamily of membrane proteins, called the $G$ protein-coupled receptor (GPCR) family of class A seventransmembrane domain receptors (7TM) [160,161]. Dopaminergic GPCRs transmit signals toward two transducer-coupled systems: one using heterotrimeric $\mathrm{G}$ protein activation and the other using noncanonical $G$ protein-independent, $\beta$ arrestin-dependent mechanisms. The heterotrimeric $\mathrm{G}$ protein complex comprises three subunits $(\mathrm{G} \alpha, \mathrm{G} \beta$, and $\mathrm{G} \gamma)$ that are coupled to the $\mathrm{C}$-terminal end of dopaminergic GPCRs in the inner cell membrane. GPCRs and heterotrimeric G proteins conform two large coupled systems: the DR system and the dopaminergic signal transduction system. The receptor system is formed by a homodimer and sometimes a heterodimer, such as D1R/D2R. Thus, when a signal is received, it is transmitted to the intracellular region through the C-terminus of the receptor, which is coupled to heterotrimeric $G$ protein systems. $G$ proteins initiate signaling cascades by separating the $G \alpha$ and $G \beta / G \gamma$ subunits $[16,162]$.

DRs are functionally classified into the D1-like (D1R and D5R stimulatory receptors) and D2-like subtypes (D2RL, D2RS, D3R, and D4R inhibitory receptors), based on their ability to stimulate the formation or inhibition of cAMP $[48,49]$. The stimulation or inhibition of adenylate cyclases (ACs) (EC: 4.6.1.1) depends on the type of receptor that is coupled to heterotrimeric $\mathrm{G}$ proteins. Thus, D1R binds to the $\mathrm{G} \alpha_{\mathrm{s} / \mathrm{olf}}$ subunit; D5R binds to $\mathrm{G} \alpha_{\mathrm{s}}$, D2RL, D2RS, or D3R; and $\mathrm{D} 4 \mathrm{R}$ binds to $\mathrm{G} \alpha_{\mathrm{i} / \mathrm{o}}$. Nevertheless, reports on the putative $\mathrm{D} 1 \mathrm{R} / \mathrm{D} 2 \mathrm{R}$ heterodimer and D1R and D5R receptors indicate the activation of complexes with the $\mathrm{G} \alpha_{\mathrm{q} 11}$ subunit, which acts on phospholipase C (PLC) signaling [16].

The activation of heterotrimeric $\mathrm{G}$ proteins is complex, because even if a DR has been classified by AC activation or inhibition, the specific proteins that constitute the heterotrimeric $G$ protein complex are not accurately defined. This is evident when we consider the number of genes that encode for the $G \alpha, G \beta$, and $G \gamma$ subunits. In the human genome, $21 \mathrm{G} \alpha$ subunits are encoded by 16 genes, six $\mathrm{G} \beta$ subunits are encoded by five genes, and $12 \mathrm{G} \gamma$ subunits are encoded by 12 genes. The variations that arise by splicing increase the diversity of heterotrimers $[163,164]$. The potential combinations of heterotrimeric $G$ protein complexes suggest a delicate initiation of the signaling mechanism that is coupled to transduction in DR systems. In perspective, further study is needed to determine the specific subunits that form the trimeric complexes that are associated with $\mathrm{AC}$ activation or inhibition through the various DRs. These 
data might help us understand the complex network of interactions that regulate dopaminergic signals in the immune system and its relationship with the CNS.

The complexity of these interactions increases if we also consider that heterotrimeric $G$ proteins are divided into two complementary signaling systems. For D2R in striatal medium spine neurons, the activation of $G$ protein releases the $\mathrm{G} \alpha_{\mathrm{i}}$ subunit (AC activators) and the $\mathrm{G} \beta / \mathrm{G} \gamma$ subunits, which initiate the PLC activation cascade [165].

The other transducer system that is coupled to DRs is the noncanonical $\mathrm{G}$ protein-independent, $\beta$-arrestin-dependent mechanism, which, although studied less extensively, is just as important. D2R mediates the activation of the multifunctional adapter protein $\beta$-arrestin 2 ( $\beta$ Arr2) with phosphatase A2 (PP2A), which has slower and more persistent effects than the $G$ protein system. Moreover, signals from $G$ protein and $\beta$ Arr2-PP2A have different physiological purposes, demonstrating that the DAS modulates signals by space and time $[15,166]$. Further, D2R activation induces a signaling complex that comprises AKT1, PP2A, and $\beta$-arrestin 2 and downregulates PKA activity [167].

3.5. DA Transporter DAT and Synaptic Vesicular Transporters VAT1 and VAT2. The DAS has a plasma membranespecific DA transporter (SLC6A3 gene), called sodiumdependent dopamine transporter (DAT). Other transporters, such as chromaffin granule amine transporter (VAT1 protein; SLC18A1/VMAT1 gene) and synaptic vesicular amine transporter (VAT2 protein; SLC18A2/VMAT2 gene), participate as well. DAT and VAT2 have not been reported to have functional isoforms, but there are at least two isoforms of VAT1 (VMAT1 and VMAT1 15$)$ [117, 118].

VAT1 and VAT2, studied primarily in the brain, are general cytoplasmic amine transporter proteins that reside in the internal vesicular membranes of mammals [34, 168172]. SLC18A1/VMAT1 is preferentially expressed in neuroendocrine cells, whereas SLC18A2/VMAT2 is mainly expressed in CNS cells [173]. VAT1 15 has been observed in small amounts in the reticulum membrane and is unable to transport serotonin [118]. The function of this protein is yet unknown.

DA is captured and transported to the interior of the cell by DAT, a $\mathrm{Na}^{+} / \mathrm{Cl}^{-}$-dependent DA transporter. Also, SERT (serotonin transporter) is able to take DA to the inside of the cell, though at low rates $[115,173,174]$. In neuroendocrine and endocrine cells, once DA and other monoamines (serotonin, histamine, and norepinephrine) are found in the cytoplasm, they are stored in secretory vesicles by VAT1 and VAT2 through a capture system that is facilitated by a proton gradient that is generated by a vesicular protein, proton ATPase [175-178]. This vesicular confinement modulates monoamine degradation and reuse through a secretory system by exocytosis $[61,173]$.

DAT and VAT2 transporters are present in the membranes of human peripheral blood lymphocytes $[103,116]$, and the function and expression of DAT have been verified in leukocytes $[69,91,104,105,179,180]$. However, few studies have examined the expression and function of SLC18A1/VMAT1 and SLC18A2/VMAT1 genes and their protein products, VAT1 and VAT2, in immune cells in rodent models or human cells. This oversight represents an area of interest because mental and mood disorders have been linked to gene polymorphisms $[181,182]$ and because they might affect the function of the immune system.

Recently, the crystal structure of human DA D3R in complex with a D2R/D3R-specific antagonist, eticlopride, was solved at $2.89 \AA$ resolution and deposited into Protein Data Bank under ID 3PBL [183]. This structure has guided the search for new drugs (agonists and antagonists) against DRs using in silico techniques (molecular dynamics simulation and homology modeling) and the creation and redesign of new chemical libraries [184]. The combination of these tools can help discover new molecules with potential use as drugs that are specific and selective for each type of DR [185].

\section{The Effects of DA on Leukocytes}

The immune response is regulated by cytokines, hormones, and neurotransmitters; this regulation is possible because leukocytes have receptors for each one of these soluble factors (Table 3). DA is a neuroregulatory and immunoregulatory molecule that has significant effects on cells that are involved in the immune response. In leukocytes, there is a balance between internal DA, synthesized by DDC, and DA that is transported from blood plasma into the cell through DAT, the latter of which is the primary source of DA in leukocytes [186]. The protein components of the DAS are differentially expressed by leukocyte subtype and the state of cellular activation. One effect of DA is the regulation of leukocytes during activation and function in the immune response. These biological phenomena have recently begun to be examined in various cell types, such as granulocytes, monocytes/macrophages, dendritic cells, and lymphocytes. In this section, we will focus on the evidence showing the relationship of leukocytes with DA and how this catecholamine can regulate leukocyte populations.

4.1. Hematopoiesis. Bone marrow (BM) is innervated by autonomic sympathoadrenergic efferent nerve fibers, in which the local microenvironment is critical in the maintenance of hematopoietic stem cells (HSCs). Stem cells are characterized by their capacity for self-renewal throughout the life of an individual and respond to signals that are generated in the microenvironment and identified by cell surface markers, such as CD34 and CD38 [187]. Communication between the CNS and hematopoietic process is known as the "brain-boneblood triad" and is mediated by many molecules, including such neurotransmitters as DA [188].

Maestroni and colleagues reported the first study on the functions of monoamines in hematopoiesis, performing chemical sympathectomy with 6-hydroxydopamine (6OHDA) and observing a significantly higher peripheral blood leukocyte count in mice that underwent transplantation with BM [189].

Subsequently, Spiegel et al. demonstrated the expression of D3R and D5R in human CD34 ${ }^{+}$cells by flow cytometry. The more primitive $\mathrm{CD} 34^{+} \mathrm{CD} 38^{\text {lo }}$ cells had higher levels of D3R and D5R. However, D3R and D5R expression was 
TABLE 3: The DRs effect on cytokine production.

\begin{tabular}{|c|c|c|c|}
\hline Effect on cytokine production & Cellular types and stimuli & Receptors involved & References \\
\hline $\begin{array}{l}\uparrow \mathrm{IL}^{-6^{\ddagger \dagger}} \\
\uparrow \mathrm{CCL} 2^{\ddagger \dagger}\end{array}$ & $\mathrm{HMDM}+\mathrm{DA}$ & $\mathrm{D} 3 \mathrm{R}, \mathrm{D} 4 \mathrm{R}^{*}$ & [79] \\
\hline $\begin{array}{l}\uparrow \text { IL-6 }^{\ddagger} \\
\uparrow \text { CCL2 }^{\ddagger \dagger} \\
\uparrow \mathrm{CXCL}^{\ddagger \dagger} \\
\uparrow \mathrm{IL}^{\ddagger} 0^{\ddagger \dagger} \\
\downarrow \mathrm{TNF}-\alpha^{\ddagger \dagger}\end{array}$ & $\mathrm{HMDM}+\mathrm{DA}+\mathrm{LPS}$ & $\mathrm{D} 3 \mathrm{R}, \mathrm{D} 4 \mathrm{R}^{*}$ & {$[79]$} \\
\hline $\begin{array}{l}\uparrow \mathrm{IFN}-\gamma^{\ddagger} \\
\downarrow \mathrm{IL}-10^{\ddagger} \\
\downarrow \mathrm{IL}-4^{\ddagger}\end{array}$ & Human activated $\mathrm{T}$ cells + quinpirole & D3R & {$[97]$} \\
\hline $\begin{array}{l}\uparrow \mathrm{IFN}-\gamma^{\ddagger} \\
\downarrow \mathrm{IL}-10^{\ddagger} \\
\downarrow \mathrm{IL}-4^{\ddagger}\end{array}$ & Human activated CD4 T cells + quinpirole & D3R & [97] \\
\hline$\uparrow \mathrm{IFN}-\gamma^{\ddagger}$ & Human activated CD8 T cells + quinpirole & D3R & {$[97]$} \\
\hline$\uparrow \mathrm{IFN}-\gamma^{\ddagger}$ & Rats T cells + L-DOPA + carbidopa & D3R & {$[97]$} \\
\hline $\begin{array}{l}\downarrow \mathrm{IL}-12^{\dagger} \\
\downarrow \text { IL-23 }\end{array}$ & $\begin{array}{l}\text { D5RKO mice, mature bone marrow-derived } \\
\text { dendritic cells + LPS }\end{array}$ & D5R absence & {$[75]$} \\
\hline $\begin{array}{l}\downarrow \mathrm{IFN}-\gamma^{\dagger} \\
\downarrow \mathrm{IL}-2^{\dagger} \\
\downarrow \mathrm{IL}-4^{\dagger}\end{array}$ & $\begin{array}{c}\text { Anti-CD3-stimulated human T cells + DA } \\
\text { Anti-CD3-stimulated human T cells + SCH-23390 } \\
\text { Anti-CD3-stimulated human T cells + clozapine }\end{array}$ & $\begin{array}{l}\text { Not measured } \\
\text { D1R/D5R } \\
\text { D4R }\end{array}$ & [89] \\
\hline $\begin{array}{l}\downarrow \mathrm{IL}-10^{\dagger \ddagger} \\
\downarrow \text { TGF- } \beta^{\dagger \ddagger}\end{array}$ & $\begin{array}{c}\text { Human } \mathrm{CD}^{+}{ }^{+} \mathrm{CD} 25^{+} \text {regulatory T cells: } \\
\text { (a) + reserpine + L-741626 } \\
\text { (b) + reserpine + U-99194A } \\
\text { (c) + reserpine + L-741741 }\end{array}$ & $\begin{array}{l}\text { (a) D2R, D3R, D4R } \\
\text { (b) D3R } \\
\text { (c) D4R }\end{array}$ & {$[83]$} \\
\hline $\begin{array}{l} \\
\downarrow \mathrm{IL}^{\dagger} 2^{\dagger} \\
\downarrow \text { IFN- } \gamma^{\dagger} \\
\downarrow \text { IL-6 } \\
\downarrow \text { IL-2 } \\
\downarrow \text { IFN- } \gamma^{\dagger} \\
\downarrow \text { IL-6 }\end{array}$ & $\begin{array}{l}\text { Mouse activated lymphocytes + L-DOPA } \\
\text { Mouse activated lymphocytes + L-DOPA } \\
\text { Mouse activated lymphocytes + L-DOPA } \\
\text { Mouse activated lymphocytes + DA } \\
\text { Mouse activated lymphocytes + DA } \\
\text { Mouse activated lymphocytes + DA }\end{array}$ & Not measured & [122] \\
\hline $\begin{array}{l}\uparrow \mathrm{IL}^{\dagger} 4^{\dagger} \\
\uparrow \mathrm{IL}^{\dagger} 5^{\dagger}\end{array}$ & Naive $\mathrm{CD} 4^{+} \mathrm{T}$ cells $+\mathrm{DA}$ & $\mathrm{D} 1 \mathrm{R} / \mathrm{D} 5 \mathrm{R}$ & [123] \\
\hline$\downarrow$ IFN- $\gamma^{\dagger}$ & Human resting NK cells + DA & D5R & {$[92]$} \\
\hline $\begin{array}{l}\uparrow \text { IFN- } \gamma^{\ddagger \dagger} \\
\downarrow \text { IFN- } \gamma^{\ddagger}\end{array}$ & $\begin{array}{c}\text { Human rIL-2 activated NK cells + DA } \\
\text { Human rIL-2 activated NK cells + SKF-38393 }\end{array}$ & $\begin{array}{l}\text { D5R } \\
\text { D5R }\end{array}$ & {$[92]$} \\
\hline $\begin{array}{l}\uparrow{\mathrm{IL}-17^{\dagger}}^{\dagger} \\
\downarrow \text { IFN- } \gamma^{\dagger} \\
\downarrow \text { IL- } 7^{\dagger} \\
\uparrow \mathrm{IFN}-\gamma^{\dagger}\end{array}$ & $\begin{array}{c}\text { Immature human Mo-Dc + L75066 } \\
\text { Immature human Mo-Dc + L75066 } \\
\text { Immature human Mo-Dc + SHC23390 } \\
\text { Immature human Mo-Dc + SHC23390 }\end{array}$ & $\begin{array}{l}\text { D2-like } \\
\text { D2-like } \\
\text { D1R/D5R } \\
\text { D1R/D5R }\end{array}$ & [124] \\
\hline $\begin{array}{l}\uparrow \mathrm{IL}-10^{\ddagger \dagger} \\
\uparrow \mathrm{TNF}-\alpha^{\ddagger \dagger}\end{array}$ & $\begin{array}{l}\mathrm{T} \text { cells }+\mathrm{DA} \\
\mathrm{T} \text { cells }+\mathrm{DA}\end{array}$ & $\begin{array}{l}\text { D2R, D1-like } \\
\text { D3R, D1-like }\end{array}$ & {$[90]$} \\
\hline$\downarrow \mathrm{IL}_{-} 2^{\dagger}$ & $\begin{array}{l}\text { Anti-CD3/CD28 stimulated T lymphocytes + } \\
\text { PD168,077 }\end{array}$ & $\mathrm{D} 4 \mathrm{R}$ & {$[100]$} \\
\hline $\begin{array}{l}\downarrow \mathrm{IL}-2^{\dagger} \\
\downarrow \mathrm{IL}-10^{\dagger}\end{array}$ & $\begin{array}{c}\text { Anti-CD3/CD28 activated Treg lymphocytes + } \\
\text { DA } \\
\text { Anti-CD3 + IL-2 activated Treg lymphocytes + } \\
\text { DA }\end{array}$ & Not measured & {$[84]$} \\
\hline$\downarrow \mathrm{IL}-2^{\ddagger \dagger}$ & $\begin{array}{c}\text { Anti-CD3/CD28 activated T lymphocytes } \mathrm{CD}^{+}+ \\
\text {DA }\end{array}$ & Not measured & [98] \\
\hline $\begin{array}{l}\downarrow \text { IFN- } \gamma^{\dagger} \\
\downarrow \text { IL } 4-\gamma^{\dagger}\end{array}$ & Lymphocytes + DA & Not measured & {$[20,125]$} \\
\hline $\begin{array}{l}\downarrow \mathrm{IFN}-\gamma^{\dagger} \\
\downarrow \mathrm{IFN}-\gamma^{\dagger} \\
\uparrow \mathrm{IL}-4-\gamma^{\dagger}\end{array}$ & $\begin{array}{l}\text { T cell (mesenteric lymph nodes) + ConA + } \\
\text { SKF38393 } \\
\text { T cell (mesenteric lymph nodes) + ConA + } \\
\text { quinpirole } \\
\text { T cell (mesenteric lymph nodes) + ConA }+ \\
\text { quinpirole }\end{array}$ & $\begin{array}{l}\text { D1-like } \\
\text { D2-like } \\
\text { D2-like }\end{array}$ & [87] \\
\hline
\end{tabular}


TABLE 3: Continued.

\begin{tabular}{lcc}
\hline Effect on cytokine production & Cellular types and stimuli & Receptors involved \\
\hline$\uparrow \mathrm{TNF}-\alpha^{\dagger}$ & Macrophages DAT & References \\
$\uparrow \mathrm{IL}-10^{\dagger}$ & Macrophages DAT $^{-/-}$mice + LPS & \\
$\downarrow \mathrm{IFN}-\gamma^{\dagger}$ & Splenocytes DAT & \\
$\downarrow \mathrm{IL}-10^{\dagger}$ & mice activated & DAT absence \\
$\uparrow \mathrm{IgG}^{\dagger}$ & Splenocytes DAT & \\
\hline
\end{tabular}

${ }^{\ddagger}$ Expression.

${ }^{\dagger}$ Protein.

${ }^{*} \mathrm{D} 3 \mathrm{R}$ and $\mathrm{D} 4 \mathrm{R}$ were only detected by western blot.

lower in the more differentiated $\mathrm{CD} 3^{+} \mathrm{CD} 38^{\text {hi }}$ cells, and positive correlations existed between DA receptor and an increase in the migration of $\mathrm{CD} 34^{+}$cells cord blood that were pretreated with GM-CSF. Their results showed that DA is a chemoattractant that enhances the migration of immature $\mathrm{CD}^{+}{ }^{+}$cells [190]. As discussed, the function of DA in hematopoiesis, mediated by D3R and D5R, might be related to the elevation in circulating $\mathrm{CD} 3^{+}$and $\mathrm{CD} 4^{+}$lymphocytes, as suggested by the association of polymorphisms in DRD1 and DRD5 with these cell counts [191].

Additional work of the function of DA demonstrated the amelioration of neutropenia and the restoration of the number of colony-forming unit-granulocyte macrophage (CFU-GM) colonies in the bone marrow of mice that were treated with 5-fluorouracil (5FU). These results are consistent with reports that have indicated that DA can be used safely as an antiangiogenic drug for malignant tumors [192] (see Section 5).

4.2. Granulocytes. Granulocytes are fundamental immune cells, based on their abundance and rapid activation in the presence of foreign elements. Granulocytes contain granules in their cytoplasm that harbor various inflammatory and antimicrobial mediators that effect their defensive activities. Depending on the content of their granules, these cells are classified in eosinophils, basophils, and neutrophils [193].

Eosinophil function in immunity is related to the response against parasites [193]. These cells have a higher density of D3R and D5R receptors and a low density of $\mathrm{D} 2 \mathrm{R}$ and D4R, whereas D1R is not detected [88]. No study has reported the effects of DA on eosinophils. Similarly, it is unknown whether basophils, involved in the allergic response, express DRs or respond to DA.

Neutrophils are the most abundant leukocyte population and have a significant function at the beginning of an inflammatory response [193]. These cells contain intracellular catecholamines, such as DA, epinephrine (E), and norepinephrine (NE), and several of their metabolites, such as DOPAC, 3MT, HVA, DL-3,4-dihydroxyphenylglycol (DHPG), and metanephrine (MET). Further, neutrophils synthesize and degrade such amines. In vitro, incubation with $\alpha$-methyl- $p$-tyrosine, an inhibitor of TH, reduces the intracellular concentration of DA, NE, and its metabolite, DHPG. Similarly, reserpine, a VAT inhibitor, lowers intracellular concentrations of DA and NE, and desipramine, an inhibitor of NE transporter (NET), decreases intracellular
NE concentrations. These findings implicate the existence of catecholamine storage and catecholamine reuptake mechanisms in neutrophils [194].

Neutrophils express D3R and D5R DA receptors and, at lower densities, D2R and D4R [88], which allows DA to modulate neutrophil function. Neutrophils (from peripheral blood) that are incubated with DA reduce their phagocytic activity dose-dependently, just like the production of oxygen reactive species and chemotaxis, with the maximum effect at $100 \mathrm{ng} / \mathrm{mL}$ [195]. Further, at $10 \mu \mathrm{Mol} / \mathrm{L}$ and $100 \mu \mathrm{Mol} / \mathrm{L}$, DA influences the viability of neutrophils from healthy volunteers and patients with Systemic Inflammatory Response Syndrome (SIRS) inducing apoptosis after $12 \mathrm{~h}$ of incubation in healthy volunteers and $6 \mathrm{~h}$ in SIRS patients, whereas respiratory burst activity remains undisturbed [196].

DA also reduces the density of the adhesion molecules CD11b (Mac-1) and CD18 in neutrophils, decreasing endothelial adhesion. Even in neutrophils that have been stimulated with LPS or TNF- $\alpha$, DA $(10 \mathrm{nM}$ and $100 \mathrm{nM})$ slows transendothelial migration and impedes chemoattraction by IL- 8 versus cells that are stimulated in the absence of DA [197]. In that regard, neutrophils that are activated with FMLP (N-formyl-methionyl-leucyl-phenylalanine) and incubated with pharmacological concentrations of DA $(261 \mathrm{nM})$ increase their density of CD62l (L-selectin) and decrease the density of CD11b. In the same report, DA at physiological concentrations $(0.26 \mathrm{nM})$ had no effect on CD62I or CD11b [198].

4.3. Monocytes/Macrophages. Monocytes are found in peripheral blood, and on entering tissues, they complete their differentiation into macrophages. Macrophages have high phagocytic capacity toward microorganisms and dead cells, secrete large amounts of cytokines, and present antigen in the context of MHC II [193]. According to McKeena and colleagues, human monocytes bear a higher density of D2R and D3R compared with D4R and D5R [88]. There are few reports about the effects of DA on monocytes; resting peripheral blood $\mathrm{CD} 14^{+}$monocytes express $D R D 4$ but not other DA receptors [86]. Also, human $\mathrm{CD}^{+} 4^{+}$monocytes from peripheral blood and the U937 cell line (premonocytes) harbor intracellular DA, E, and NE, and $\mathrm{CD}_{1}{ }^{+}$monocytes also contain some metabolites, such as 3MT, DHPG, and MET [199].

DA modulates the phenotype and function of monocytes/macrophages. An in vitro study in chicken macrophages 
demonstrated that high DA concentrations $(1-5 \mu \mathrm{g} / \mathrm{mL})$ are cytotoxic, causing up to $53 \%$ of cells to die. Incubation with DA at 0.1 and $0.5 \mu \mathrm{g} / \mathrm{mL}$ for 1 hour improved their phagocytic activity, but extended exposure to DA (3h) lowered this activity, although the percentage of Fc receptorpositive macrophages increased due to DA [200]. Haskó and colleagues demonstrated in LPS-activated peritoneal macrophages of Swiss mice that D2R stimulation using agonists (bromocriptine and quinpirole) and antagonists (sulpiride) lowered TNF- $\alpha$ and nitric oxide (NO) secretion. In contrast, D1R stimulation with the antagonist SCH23390 only downregulated NO production compared with controls [201].

In an elegant study, Gómez and colleagues reported that macrophages from guinea pigs that were immunized in vivo for 7 days using DA agonists (bromocriptine, leuprolide, and pergolide) or DA antagonists (chlorpromazine, SCH23390, metoclopramide, sulpiride, veralipride, alizapride, and cisapride) and primary macrophage cultures from guinea pigs that were stimulated in vitro with these drugs had increased $\mathrm{F} c \gamma$ receptors expression. The DA agonists improved the clearance of IgG-sensitized RBCs (in vitro recognition of IgG-sensitized RBCs by splenic macrophages) and enhanced the membrane expression of $\mathrm{Fc} \gamma$ receptors in macrophages; in contrast, the DA antagonists impaired macrophage Fc $\gamma$ receptor expression. Thus, the disturbance in $\mathrm{Fc} \gamma$ receptor expression is more extensive when D1R is stimulated and less so on activation of D2R [202].

Bergquist and colleagues examined whether the binding of NF- $\kappa$ B to DNA was inhibited by DA in nontransformed human peripheral blood monocytes and transformed human monocyte cell lines that were activated with LPS $(10 \mathrm{ng} / \mathrm{mL})$. Cell proliferation declined at $10 \mu \mathrm{M}$ DA in peripheral blood monocytes and at $100 \mu \mathrm{M}$ in the monocyte cell line after $24 \mathrm{~h}$; however, the low concentrations $(1 \mu \mathrm{M}$ and $0.1 \mu \mathrm{M})$ had no effects. They also observed that DA suppressed LPSmediated activation of NF- $\kappa$ B and LPS-induced binding of NF- $\kappa$ B to the TNF- $\alpha$ promoter dose-dependently-an effect that might be attributed to the inhibition of NF- $\kappa \mathrm{B}$ translocation from the cytoplasm to nucleus by DA [203]. In 2002, Haskó and colleagues showed that DA has antiinflammatory effects by binding to its receptors and through other mechanisms. Using the J774.1 cell line and C57B1/6 mice peritoneal macrophages that were stimulated with LPS $(10 \mu \mathrm{g} / \mathrm{mL})$ and DA $(0.01 \mu \mathrm{M}-100 \mu \mathrm{M})$, they observed that IL-12 p40 secretion and mRNA decreased dose-dependently, whereas IL-10 secretion was increased. These effects were not caused by DR stimulation (addition of the DR antagonists SCH23390 and raclopride did not inhibit the effects) but by the stimulation of $\beta$-adrenergic receptors as determined by the addition of the $\beta$-adrenergic antagonist propranolol, which had partial inhibitory activity [204].

Human monocyte-derived macrophages (HMDMs) from healthy donors express the SLC6A3/DAT, SLC18A2/VMAT2, TH, DDC, DRD1 [79-81], DRD2, DRD3, DRD4, and DRD5 genes and the D1R, D2R, D3R, D4R, DAT, VAT2, TH, and DDC proteins on the cell surface and in the cytoplasm, suggesting that these cells contain the machinery for synthesis, reuptake, and response to DA [79]. Another report showed that DA modulates cytokine secretion in HMDMs with and without LPS stimulation; LPS-activated HMDMs that were stimulated with elevated concentrations of DA $(2 \mu \mathrm{M}$ and $20 \mu \mathrm{M}$ ) increased IL-6, CCL2, CXCL8, and IL-10 secretion while TNF- $\alpha$ secretion declined. Conversely, lower DA concentrations ( $20 \mathrm{nM}$ and $200 \mathrm{nM}$ ) affected only TNF- $\alpha$, IL-6, and CCL2 secretion and upregulated IL-10, albeit insignificantly. In cells without LPS stimulation, $2 \mu \mathrm{M}$ and $20 \mu \mathrm{M}$ DA enhanced IL- 6 and CCL2 secretion. These findings suggest that macrophages develop differential responses, depending on the microenvironment (inflammatory or homeostatic), that are modulated by DA [79].

4.3.1. DA Receptor Roll in HIV Infection in Macrophages. DA also has effects on macrophages with regard to D2R-mediated HIV replication. This effect has been observed in HMDMs of healthy donors that have been infected in vitro with the $\mathrm{HIV}_{\mathrm{ADA}}$ and $\mathrm{HIV}_{\mathrm{YU} 2}$ strains [80] and in Jurkat cells (T-cellderived line) that have been transfected with the HIV proviral genome-an effect that is mediated by the activation of NF$\kappa \mathrm{B}$ [205]. D2R activation by the agonist quinpirole stimulates ERK1 by phosphorylation and increases HIV replication dose-dependently compared with unstimulated infected cells and cells stimulated with the D1R agonist SKF82958 [80].

In macrophages, the entry of HIV via CD4 and CCR5 in the plasma membrane depends on gp120 binding [206], and an increase in the density of CCR5 and CD4 enhances HIV infectivity [207]. Incubation of HMDMs with IL-4 and IL-10 upregulates CCR5 and CD4, accelerating the infection $[207,208]$. Similarly, a recent study showed that DA facilitates HIV entry through CCR5 and that TAK779, a CCR5 inhibitor, impedes viral entry [209]. These data suggest that entry of the virus requires the activation of DRs and is inhibited by a global DR antagonist, such as flupenthixol, through effects that do not depend on viral concentration.

The average percentage of infected HMDMs rises with high concentrations of DA-between $10^{-5}$ and $10^{-8} \mathrm{M}-$ dose-dependently, with a "steep threshold" at approximately $10^{-8} \mathrm{M}$. This finding confirms that CCR5 and DA-mediated DRs activation are necessary for viral entry in HMDMs. Specifically, D1-like and D2-like are the receptors that are activated and involved in HIV entry, indicating that there is a common pathway of activation that depends on $\mathrm{Ca}^{2+}$ mobilization [209]. Methamphetamine enables infection in HMDMs and increases the activity of viral reverse transcriptase and CCR5 density, thus downregulating IFN- $\alpha$ and STAT1 protein expression. STAT1 is a signal transducer and transcriptional activator that mediates cellular responses to interferons, cytokines, and growth factors. However, the D1R antagonists SCH23390 and SKF83566c block HIV Bal $_{1}$ ineffectiveness [81]. These data suggest the participation of dopamine receptors during macrophage infection by HIV which might have clinical applicability but demands more clinical trials.

4.4. Dendritic Cells. Dendritic cells (DCs) are the most efficient antigen-presenting cells of the immune system, with key functions in the induction of adaptive immune responses, 
immune tolerance, and the modulation of immune responses [193]. Human monocyte-derived dendritic cells (Mo-DCs) express the D1-like and D2-like receptors in the membrane, of which the D2-like receptors predominate functionally [123, 124]. DCs synthesize DA and store it in vesicles near the cell membrane, as observed in Mo-DCs, in which DA synthesis and storage increase when intracellular cAMP levels rise. Further, Mo-DCs liberate DA during their interaction with naive $\mathrm{CD}^{+} \mathrm{T}$ lymphocytes, which promotes polarization toward the Th2 phenotype; antagonism of Mo-DCs D2-like receptors with sulpiride and nemonapride raises cAMP levels, releasing DA and influencing naive $\mathrm{CD} 4^{+} \mathrm{T}$ lymphocytes, for example, by increasing the Th2/Th1 ratio (through the IL-5:IFN- $\gamma$ relationship), upregulating CCR4 (a Th2-type receptor), and decreasing CXCR3 (a Th1-type receptor) expression [123].

DA also has effects on murine bone marrow-derived dendritic cells (BMDCs), which express the molecular components that are needed to respond to, synthesize, store, and degrade DA. BMDCs bear D1R, D2R, D3R, and D5R on the membrane and vary their expression profile according to their state of activation: mature (stimulated by LPS) and immature (without stimulus). In the mature state, the intracellular enzyme TH, low levels of Scl18a2/Vmat2 mRNA, Slc6a4/Sert, maoa, and maob have been observed without detectable Slc6a3/dat, Slc6a2/Net1 (NE transporter), or Dbh mRNA. The same results have been obtained for immature cells, but there was more Slc18a2/Vmat2 mRNA [75]. Although BMDCs do not express DAT in the membrane or have quantifiable mRNA levels, SERT is present, and this transporter can carry DA at a low velocity [174].

In BMDCs, D5R appears to participate in maturation and regulate signaling pathways and cytokine release, thus contributing to the activation and proliferation of $\mathrm{CD}^{+}$ $\mathrm{T}$ lymphocytes. BMDC activation with LPS significantly decreases the density of D5R in the membrane. On stimulation with SKF38393, a selective D1R/D2R agonist, the phosphorylation of ERK1/2 increases. Notably, D5R is linked to IL-12 and IL-23 production; it has been observed that mature Drd5 knockout (Drd5KO) cells express less $\mathrm{Il}-23 \mathrm{a}$ (IL-23) and secrete less IL-12. These reports implicate an autocrine regulatory mechanism during cell maturation in which the release of DA and D5R activation selectively promote the secretion of certain regulatory cytokines. Similarly, $\mathrm{CD}^{+} \mathrm{T}$ lymphocytes significantly decrease IL-2 secretion and proliferation when they are activated and incubated using Drd5KO cells versus WT cells. This effect is not observed in $\mathrm{CD}^{+} \mathrm{T}$ lymphocytes, suggesting that D5R expression in DCs facilitates the strong priming of $\mathrm{CD} 4^{+} \mathrm{T}$ lymphocytes [75].

4.5. Lymphocytes. Lymphocytes are primordial cells of the adaptive immune response that recognize antigens in their molecular context. Depending on their ligands, lymphocytes have many subpopulations with a wide variety of functions; these cells can modulate, regulate, and coordinate the activities of other leukocyte populations through cytokine secretion and at the same time, lymphocytes can respond to circulatory levels of cytokines, hormones, and neurotransmitters [193].
4.5.1. Synthesis of Dopamine and Receptors. In the late 20th century, lymphocytes were demonstrated to have the metabolic ability to synthesize catecholamines and their metabolites; they also release and recapture these molecules, responding to them by expressing catecholamine receptors. The initial reports on DA and DOPAC in lymphocytes were based on cerebrospinal fluid and human $\mathrm{T}$ and $\mathrm{B}$ lymphocyte cultures; these studies reported that intracellular catecholamine concentrations and the inhibition of $\mathrm{TH}$ with $\alpha$-methyl- $p$-tyrosine downregulated intracellular catecholamines, which rose on exposure of the cells to DA [20]. Later, the presence of DA, L-DOPA, and NE in lymphocytes was confirmed by electrospray ionization mass spectrometry [210].

Another study reported that human peripheral lymphocytes exhibit intracellular DA, L-DOPA, and NE at concentrations that are detectable by HPLC and that T lymphocytes only contain L-DOPA and NE. In vitro, T lymphocytes that have been incubated with L-tyrosine $\left(5 \times 10^{-5} \mathrm{M}\right)$ or L-DOPA $\left(10^{-8} \mathrm{M}-10^{-5} \mathrm{M}\right)$ increase their intracellular NE concentrations. This finding suggests the presence of catecholamine synthesis pathways in these cells [143]. Marino and colleagues noted that PBMCs contain DA, NE, E, and metabolites, such as DOPAC, 3MT, HVA, DHPG, MET, and VMA. This group reported that the addition of $\alpha$-methyl- $p$-tyrosine decreased DA and NE concentrations intracellularly and in the medium; further, incubation with desipramine or GBR12909, 2 catecholamine reuptake inhibitors, significantly increases DA and NE levels in the medium, indicating the existence of an active recapture mechanism [116].

In the late 1990s, a study in rats confirmed that lymph node, splenic, and thymic lymphocytes contain intracellular catecholamines (DA, NE, and E), observing $\mathrm{TH}$ mRNA and protein in these cells. Also, the authors found that ConAactivated (concanavalin A) $(5 \mu \mathrm{g} / \mathrm{mL})$ lymphocytes had higher intracellular catecholamine and $\mathrm{TH}$ concentrations than unstimulated cells $[108,211]$. $\mathrm{CD}^{+} \mathrm{CD} 25^{-}$Teff lymphocytes and $\mathrm{CD} 4^{+} \mathrm{CD} 25^{+}$Treg were proven to express TH and intracellular L-DOPA, DA, E, and NE and some catecholamines metabolites. Further, incubation of $\mathrm{CD}^{+}$ $\mathrm{CD}_{25}{ }^{+}$Treg with reserpine (an inhibitor of VAT1) downregulated intracellular catecholamine concentrations, whereas concentrations in the medium rose [83].

The first report on DAT in peripheral blood lymphocytes was performed using several techniques. By radiobinding assay (RBA) using a specific ligand for DAT, $\left[{ }^{3} \mathrm{H}\right]-\mathrm{GBR} 12935$, it demonstrated specific binding in the membrane of human lymphocytes. By western blot, DAT, VAT1, and VAT2 were expressed, whereas DA and VAT2 showed immunoreactivity in cytoplasmic areas, corresponding to vacuoles, by immunofluorescence. Finally, DAT and VAT1 were detected in the plasma membrane and cytoplasm, respectively [103]. Later, Marazziti and colleagues confirmed DAT expression by RBA using $\left[{ }^{3} \mathrm{H}\right]$-WIN35428 in human lymphocytes, 1 of the most DAT-selective radioligands. This group observed $\left[{ }^{3} \mathrm{H}\right]-\mathrm{DA}$ reuptake, suggesting the presence of a DA reuptake mechanism [179]. In addition, Ferrari and colleagues reported that DA modulates its synthesis in human $\mathrm{T}$ and 
B lymphocytes from peripheral blood through PKC activation using 12-O-tetradecanoylphorbol-13-acetate (TPA) at $100 \mathrm{ng} / \mathrm{mL}$. This activity increases TH mRNA levels and intracellular catecholamines-effects that are significantly inhibited with DA $(1 \mu \mathrm{M})$ and SKF30393, a D1-like agonist, demonstrating that the stimulation of D1-like receptors impedes catecholamine synthesis [77].

The search for DA receptors in lymphocyte has been a difficult task. Unstimulated human lymphocytes express D2R, D3R, D4R, and D5R, but the activation of these cells modifies the expression of the receptors. In 1991, the initial data on specific dopamine binding sites in human lymphocytes were obtained using $\left[{ }^{3} \mathrm{H}\right]-\mathrm{DA}$, the binding of which declines considerably in the presence of such substances as cocaine and other inhibitors of biogenic amine uptake [69]. Subsequently, D5R was detected in the membranes of human lymphocytes by RBA using the dopaminergic antagonist $\left[{ }^{3} \mathrm{H}\right]-\mathrm{SCH} 23390$, as were 3 DRD5 mRNA sequences (by RT-PCR) and the transcription of 2 pseudogenes [101]. Similarly, D3R expression was observed in the membrane using the specific ligand $\left[{ }^{3} \mathrm{H}\right]-7$-hydroxy-N,N-di- $n$-propyl-2aminotetralin $\left(\left[{ }^{3} \mathrm{H}\right]-7-\mathrm{OH}-\mathrm{DPAT}\right)[95,212]$, as were its fulllength mRNA sequence and a shorter variant transcript, generated by alternative splicing $[95,151]$.

Another study with $\left[{ }^{3} \mathrm{H}\right]$-sulpiride in human lymphocytes by RBA characterized the D2-like receptors in the membrane and their similarities with D2R and D4R and, to a lesser extent, D3R [158]. Conversely, the expression of D1like receptors was described in 2 studies by RBA using $\left[{ }^{3} \mathrm{H}\right]-$ SCH23390 [73, 102] and immunocytochemistry [102], in which the expression of D5R, but not D1R, was demonstrated. Other studies on D4R in human lymphocytes detected it by RT-PCR $[99,100]$ and by RBA using $\left[{ }^{3} \mathrm{H}\right]$-clozapine [159] and western blot [100].

In 1998, Ricci and colleagues measured the expression in membrane-bound D2-like receptors by RBA and immunocytochemistry with greater precision. They observed that the ligand $\left[{ }^{3} \mathrm{H}\right]-7-\mathrm{OH}-\mathrm{DPAT}$ is not specific for D3R, because, on incubation with anti-D3R and anti-D4R, the interaction decreases $53 \%$ and $32 \%$, respectively, whereas anti-D2R has no effect [96]. Another study measured D3R and D4R by RBA using the radioligands $\left[{ }^{3} \mathrm{H}\right]-7-\mathrm{OH}-\mathrm{DPAT},\left[{ }^{3} \mathrm{H}\right]$-spiperone, and $\left[{ }^{3} \mathrm{H}\right]$-nemonapride and immunocytochemistry [94]. Cosentino and colleagues showed that intracellular catecholamines fall when TH is inhibited with $\alpha$-methyl-ptyrosine and reserpine in primary human PBMC cultures; reserpine also decreases catecholamine concentrations in the medium. This study also demonstrated that cell lines from hematopoietic precursors, such as NALM-B (pre-B), Jurkat (T lymphoblastoid), and U937 (promonocytic), synthesize catecholamines, because their intracellular DA, E, and NE decrease on incubation with $\alpha$-methyl- $p$-tyrosine and reserpine [199].

In 2002, McKenna et al. performed flow cytometry to confirm the membrane expression of the three D2-like receptors and D5R and the absence of D1R [88]. The existence of D5R in the membrane was later confirmed by RBA using the radioligand $\left[{ }^{3} \mathrm{H}\right]-\mathrm{SCH} 23390$. By RT-PCR, expression of DRD2, DRD3, DRD4, and DRD5-but not DRD1-was observed [93]. DA receptors and DAT, with the exception of $\mathrm{D} 4 \mathrm{R}$, were detected in B lymphocytes and in several malignant B cell lines; also, this report showed higher DRD1 and $D R D 2$ transcript levels versus DRD3 and DRD4 [78]. In 2014, by 5-color flow cytometry, Kustrumovic and colleagues showed that naive $\mathrm{T} \mathrm{CD} 4^{+} \mathrm{T}$ lymphocytes, central memory $\mathrm{CD}^{+}{ }^{+} \mathrm{T}$ lymphocytes (TCM), and effector memory $\mathrm{CD} 4^{+}$ T lymphocytes (TEM) expressed D1R, D2R, D3R, D4R, and D5R in the membrane at various densities between subpopulations. In $\mathrm{CD}^{+}{ }^{+} \mathrm{T}$ lymphocytes that were stimulated with anti-CD3/CD28 $(0.01-0.1 \mu \mathrm{g} / \mathrm{mL})$ for 48 hours, the density of the five DA receptors in the membrane was altered after activation, with increases in the D1-like (71\% to $84 \%$ ) and D2-like (55\% to 97\%) receptors. With regard to the levels of DRs, the frequency of these receptors is higher in apoptotic cells than in viable $\mathrm{T}$ lymphocytes. However, the stimulation of viable $\mathrm{T}$ lymphocytes increases receptor density to similar levels as in apoptotic lymphocytes [85].

4.5.2. Effects of Dopamine in Lymphocytes. The immunomodulatory effects of DA have significant relevance in understanding the relationship between the immune system and CNS. Reports in rodent and human lymphocytes have found that DA receptors in PBMCs are functional and activate signaling cascades that change the phenotype and function of lymphocytes. Some groups have reported the effects of DA on cytokine secretion, cell adhesion, and chemotaxis in human and rodent lymphocytes.

In 2001, Levite and colleagues suggested the importance of DA in integrin-mediated cellular trafficking and extravasation of human $\mathrm{T}$ lymphocytes in the brain and periphery, based on findings that 7-hydroxy-DPAT (a D3R agonist), bromocriptine, and pergolide (D2R agonists) activate T lymphocytes, upregulating $\beta$-integrins expression (mainly $\alpha 4 \beta 1$ and $\alpha 5 \beta 1$ ) and increasing adhesion to fibronectin (FN) [213]. In 2004, Cosentino and colleagues showed that, at various doses, DA has opposing effects on oxidative metabolism and apoptosis in human lymphocytes. At low doses $(0.1-5 \mu \mathrm{M})$, DA decreases the concentration of reactive oxygen species (ROS) and inhibits apoptosis through stimulation of D1-like receptors. However, at high concentrations $(100-500 \mu \mathrm{M})$, DA increases intracellular ROS levels and lymphocyte apoptosis [24]. In 2005, Besser and colleagues demonstrated that human resting $\mathrm{T}$ lymphocytes express D2R, D3R, and D5R on their membrane and that their stimulation upregulates the secretion and expression of cytokines, such as TNF- $\alpha$ and IL10. Stimulation with DA between $10^{-4} \mathrm{M}$ and $10^{-7} \mathrm{M}$ increased TNF- $\alpha$ secretion through D3R and D1-like receptors stimulation, whereas IL-10 secretion was mediated by D2R and D1-like receptors stimulation; in contrast, concentrations of DA between $10^{-9} \mathrm{M}$ and $10^{-14} \mathrm{M}$ did not have any discernible effects [90].

Watanabe and colleagues showed that $\mathrm{CD}^{+} \mathrm{T}$ lymphocytes selectively express D3R and that its stimulation mediates chemotaxis and $\mathrm{CD}^{+} \mathrm{T}$ lymphocyte adhesion. $\mathrm{DA}$ and its agonist, 7-OH-DPAT (100 nM), increase CD45RA ${ }^{+} \mathrm{CD}^{+}$ naive $\mathrm{T}$ lymphocyte chemotaxis, whereas the combination of $\mathrm{DA}$ and other chemokines enhances chemotaxis in CD45RA ${ }^{+}$ 
$\mathrm{CD}^{+}$and $\mathrm{CD}^{+} 5 \mathrm{RA}^{+} \mathrm{CD}^{+}{ }^{+} \mathrm{T}$ lymphocytes. Stimulation with only CCL19 (10 nM), CCL21 (10 nM), and CXCL12 $(0.1 \mathrm{nM})$ significantly induces the migration of $\mathrm{CD}^{+}$and $\mathrm{CD}^{+}$lymphocytes, but the addition of DA $(1 \mathrm{nM})$ induces the selective migration of $\mathrm{CD} 45 \mathrm{RA}^{+} \mathrm{CD} 8^{+} \mathrm{T}$ lymphocytes. In addition, D3R stimulation induces the adhesion of CD45RA ${ }^{+}$ $\mathrm{CD}^{+} \mathrm{T}$ and $\mathrm{CD}^{+} 5 \mathrm{RO}^{+} \mathrm{CD}^{+} \mathrm{T}$ lymphocytes to $\mathrm{FN}$ [86]. Conversely, Strell and colleagues showed that human $\mathrm{CD} 8^{+}$ T lymphocytes expressed D3R and D4R and, to a lower extent, D5R. They also found that these receptors were downregulated on cellular activation, with the exception of D5R. Stimulation with DA $(1 \mu \mathrm{M})$ decreased the activation of these cells by anti-CD3/CD28, decreasing the expression and secretion of IL-2 by reducing ERK1/ERK2 phosphorylation. This stimulation also increased $\mathrm{I} \kappa \mathrm{B}$, which lowers NF- $\kappa \mathrm{B}$ phosphorylation levels. This effect prevents the creation of an autocrine IL-2 loop, which is needed for optimal activation of T lymphocytes [98].

With regard to animal models, Kipnis and colleagues showed that DA regulates the adhesion and chemotaxis of mouse Treg lymphocytes by stimulating D1-like receptors via ERK. CTLA-4 expression decreases in Treg lymphocytes that are incubated with DA or SKF38393, as does IL-10 secretion at concentrations of $10^{-5} \mathrm{M}$. These effects are attributed to ERK phosphorylation. Finally, this group found that DA affects the adhesion and chemotaxis of Treg lymphocytes; adhesion to SPG (extracellular matrix proteins that are associated with injured tissues) decreases dose-dependently $\left(10^{-9}-10^{-5} \mathrm{M}\right)$, and DA downregulates the receptor for CCR-4, affecting the migration of these cells toward macrophage-derived chemokines (MDCs) [84].

Watanabe and colleagues showed by in vivo assays that intraperitoneal administration of DA or 7-OH-DPAT to mice selectively attracts $\mathrm{CD} 44^{\text {low }} \mathrm{CD}^{+} \mathrm{T}$ lymphocytes, effecting their accumulation in the peritoneal cavity. They also reported that DA mediates the homing of naive $\mathrm{CD}^{+} \mathrm{T}$ lymphocytes toward secondary lymphoid tissues through D3R, because U99194A, a D3R antagonist, reduces the number of CD $44^{\text {low }} \mathrm{CD}^{+} \mathrm{T}$ lymphocytes in the inguinal lymph nodes. Similarly, in vitro stimulation of L1.2 pre-B lymphocytes with DA or 7-OH-DPAT (100 nM) increases calcium efflux and elicits a selective chemotactic response for $\mathrm{CD} 44^{\text {low }} \mathrm{CD} 8^{+} \mathrm{T}$ lymphocytes [86].

Other reports have shown that DA modulates the activation, proliferation, and differentiation of lymphocytes in humans and rodents. In human cells, Bergquist and colleagues showed that ConA-activated peripheral blood lymphocytes stimulated in vitro with DA $(10 \mu \mathrm{M}$ and $100 \mu \mathrm{M})$ slow their proliferation, differentiation, and synthesis of IFN$\gamma$ dose-dependently, with complete inhibition reached at $500 \mu \mathrm{M}$. Further, incubation with DA from $10 \mu \mathrm{M}$ to $500 \mu \mathrm{M}$ completely inhibits the production of antibodies in pokeweed mitogen- (PWM-) stimulated B lymphocytes [20]. This group also reported that human lymphocytes (activated with ConA or PWM) stimulated with DA $(10 \mu \mathrm{M}$ and $100 \mu \mathrm{M})$ produce less IL- 4 but experience 2.8-fold greater apoptosis; apoptotic markers, such as Bcl/Bax and Fas/FasL, are also upregulated [125].
In 2001, Saha and colleagues demonstrated that high DA concentrations in serum affect the proliferation of $\mathrm{CD}^{+}$and $\mathrm{CD}^{+} \mathrm{T}$ lymphocytes and the cytotoxicity of lymphocyte activated killer $\mathrm{T}$ cells (LAK-Ts) from patients with lung carcinoma and healthy subjects. The patients had high DA concentrations in plasma compared with healthy subjects $(48.6 \pm 5.1 \mathrm{pg} / \mathrm{mL}$ and $10.2 \pm 0.9 \mathrm{pg} / \mathrm{mL}$, resp.). In vitro, this high concentration $(48 \mathrm{pg} / \mathrm{mL})$ slowed the proliferation of $\mathrm{CD}^{+}$and $\mathrm{CD}^{+} \mathrm{T}$ lymphocytes from patients and healthy donors, which did not occur at physiological concentrations $(10 \mathrm{pg} / \mathrm{mL})$. Similarly, LAK-Ts from patients and healthy subjects had less cytotoxic activity, attributed to D1R stimulation due to the rise in intracellular cAMP [214]. Further, the group performed the same experiments in $\mathrm{CD} 4^{+}, \mathrm{CD} 8^{+}$, and cytotoxic T lymphocytes from patients with uncoping stress and healthy subjects, showing that these patients also had high plasma DA concentrations $(46.6 \pm 3.9 \mathrm{pg} / \mathrm{mL})$ versus the latter $(10 \pm 2.7 \mathrm{pg} / \mathrm{mL})$. The effect of high DA concentration was the same as in patients with lung carcinoma [215].

Ghosh and colleagues reported that DA also affects TCRmediated signaling in $\mathrm{T}$ lymphocytes. Incubation with $\mathrm{DA}$ at $3-5 \mathrm{ng} / \mathrm{mL}$ for 1 to 3 days inhibited the proliferation and secretion of IL-2, IFN- $\gamma$, and IL- 4 in anti-CD3-activated T lymphocytes, due to $\mathrm{D} 2 \mathrm{R}$ and $\mathrm{D} 3 \mathrm{R}$ stimulation. They also showed that DA downregulates the nonreceptor tyrosine kinases Lck and Fyn, which are important in TCR signaling; this effect can decrease lymphocyte activation and cytokine secretion [89]. In 2006, Sarkar and colleagues observed that $\mathrm{D} 4 \mathrm{R}$ stimulation in human $\mathrm{T}$ lymphocytes induces quiescence by upregulating lung Krüppel-like factor 2 through inhibition of ERK1/ERK2 phosphorylation. T lymphocytes that were activated with anti-CD3/CD28 and a D4R-specific agonist (PD168,077 or APT724 at $1 \mu \mathrm{M}$ ) experienced less proliferation, which was not observed in unstimulated $\mathrm{T}$ lymphocytes. Similarly, cells that were activated for 24 hours with PD168,077 $(1 \mu \mathrm{M})$ had equal levels of IL-2 secretion and CD69 and CD25 expression as in nonactivated lymphocytes. PD168,077 also prevented a decline in KFL2 expression, a transcription factor that regulates quiescence and inhibition of ERK1/ERK2 phosphorylation [100].

Studies in rodent cells in vivo and in vitro have demonstrated the effects of DA on lymphocyte activation, proliferation, and differentiation, such as Tsao et al., who observed in vivo that DA governs splenocyte proliferation, based on the intravenous administration of agonists for D1like (SKF38393) and D2R (LY171555) (1, 5, and $10 \mu \mathrm{g} / \mathrm{Kg})$ in $\mathrm{BALB} / \mathrm{cByJ}$ mice. They showed that agonists enhance LPS- or ConA-induced splenocyte proliferation; however, intraperitoneal administration of the neurotoxin MPTP $(20 \mu \mathrm{g} / \mathrm{kg})$ reduced endogenous DA levels and suppressed proliferation [216]. Carr and colleagues determined that chronic administration of L-DOPA $(126 \mathrm{mg} / \mathrm{Kg}$ every 5 days) or L-DOPA combined with domperidone, an agonist of D2R, affects proliferation and cytokine secretion in mouse splenocytes. This group demonstrated that L-DOPA increases the proliferation of spleen cells that have been stimulated with ConA or anti-CD3 by approximately 2.2 -fold [217]. 
In 2011, a study reported that stimulation of D1-like receptors suppresses ovalbumin antigen-induced neutrophilic airway inflammation in OVA TCR-transgenic DO11.10 mice. These mice were nebulized with OVA or LPS and received a D1-like antagonist (SCH23390) by oral administration before OVA administration. SCH23390 significantly inhibited OVAinduced neutrophilic airway inflammation, due primarily to its ability to halt the infiltration of neutrophils, macrophages, and lymphocytes. IL-17 and IL-22 synthesis and infiltration of Th17 cells in the lung were also lower. Conversely, IL-23 production was suppressed in DCllc APCs in response to LPS/anti-CD40 [218].

In vitro, Cook-Mills and colleagues demonstrated that DA $(10 \mu \mathrm{M}$ and $100 \mu \mathrm{M})$ and NE inhibit the activation of splenic lymphocytes from BALB/c mice. However, this effect is not blocked by adrenergic or dopaminergic antagonists, suggesting that the inhibitory effect is mediated by other lymphocyte receptors [219], such as serotonin [7], hormone, and cytokine receptors [193]. According to Josefsson and colleagues, mouse splenocytes produce catecholamines and are stimulated by DA, L-DOPA, and NE, which are enhanced by L-tyrosine and inhibited by $\mathrm{TH}$ inhibitors. L-DOPA and DA $(0-500 \mu \mathrm{M})$ dose-dependently suppress mitogeninduced proliferation and differentiation of mouse splenocytes, even with short treatment times. Moreover, L-DOPA and DA $(500 \mu \mathrm{M})$ also inhibit IL-2, IL-6, and IFN- $\gamma$ synthesis and $\operatorname{IgG}$ and IgM secretion [122].

Bergquist and colleagues reported that, at high concentrations $(100-500 \mu \mathrm{M})$, DA inhibits the proliferation of $\mathrm{T}$ lymphocytes and the secretion of IL-2, IL-6, and IFN- $\gamma$ at $500 \mathrm{nM}$ [125]. Tsao et al. demonstrated that DA promotes the proliferation of splenocytes from BALB/cByJ mice in response to LPS or ConA [216]. Carr and colleagues showed that mouse splenocytes $(\mathrm{BALB} / \mathrm{c})$ that were treated with $\mathrm{L}$ DOPA secreted less IFN- $\gamma$ but produced the same amount of IL-4 [217]. Huang and colleagues found that T lymphocytes from mouse mesenteric lymph nodes, which express the five DA receptors, are polarized toward the Th2 phenotype when D2-like receptors are stimulated, suggesting that this effect involves the CAMP-CREB pathway. In the same lymphocytes, stimulation with the D1-like agonist SFK38393 reduced only IFN- $\gamma$ secretion; in contrast, quinpirole, a D2-like agonist, enhanced IFN- $\gamma$ and IL-4 secretion and decreased proliferation and cAMP and phosphorylated CREB content [87].

DA also has indirect effects on the phenotype and function of lymphocytes. This catecholamine first modulates the function of its target cell, which in turn affects the function and phenotype of the lymphocyte with which it interacts; these effects on human cells have been described by other groups.

In 2007, Cosentino and colleagues demonstrated that DA is released by Treg, allowing them to regulate their activity. However, when Treg do not release DA, they experience autoregulation and lose the ability to suppress Teff proliferation. $\mathrm{CD} 4^{+} \mathrm{CD} 25^{-}$Teff and $\mathrm{CD} 4^{+} \mathrm{CD} 25^{+}$ Treg from healthy donors express the five DA receptors. Treg have detectable mRNA levels of SCL18A1/VMAT1, SCL18A2/VMAT2, DRD2, DRD3, DRD4, and DRD5, whereas
Teff only express SCL18A1/VMAT1 and SCL18A2/VMAT2. When DA release is inhibited by reserpine $(1 \mu \mathrm{M})$ in Treg/Teff cultures, Treg diminish their mRNA levels and secretion of IL-10 and TGF- $\beta$ through stimulation of D1-like receptors. These events significantly reduce the proliferation of $\mathrm{CD} 3 / \mathrm{CD} 28$-activated T lymphocytes but do not affect the secretion of TNF- $\alpha$ and IFN- $\gamma$ [83]. Nakano and colleagues demonstrated that D2-like antagonists induce the differentiation of Th17 cells (in vitro), mediated by DCs, using a mixed lymphocyte reaction (MLR) between human monocyte-derived dendritic cells (Mo-DCs) and naive $\mathrm{CD} 4^{+} \mathrm{T}$ lymphocytes. These antagonists increased the secretion of IL17 in 16-hour cultures of Mo-DCs and $\mathrm{CD}^{+} \mathrm{T}$ lymphocytes that were activated with anti-CD3/CD28; in contrast, D1-like antagonists (SCH23390, SKF83566, and LE300) decreased IL17 levels [124].

A 2004 study by Kipnis et al. in mice showed that Treg from splenic lymph nodes had lower regulatory activity on stimulation of D1-like receptors through ERK activation. Moreover, the incubation of Treg/Teff with DA $\left(10^{-7} \mathrm{M}\right)$ increased Teff proliferation 2-fold, which was also observed in T lymphocytes that were activated with anti-CD3 and IL2. This group also found that the negative regulatory activity of Treg on Teff proliferation is inhibited by genistein, a MEK and ERK inhibitor. This inhibition was also observed with the ERK inhibitor PD98059 [84].

Mori and colleagues reported that D1-like receptors mediate immediate and late-phase skin reactions by promoting Th2 differentiation and mast cell degranulation. In in vivo Th1-type contact hypersensitivity and Th2-type atopic dermatitis models, they observed that $\mathrm{SCH} 23390$ does not affect Th1-type contact hypersensitivity but suppresses immediatetype (ITRs) and late-phase reactions (LPRs) in the atopic dermatitis model. In addition, SCH23390-treated mice had higher IFNG and lower IL-2 mRNA levels in the ear skin versus untreated mice. This report also used bone marrowderived mast cells (BMMCs), fetal skin-derived cultured mast cells (FSMCs), and naive Th2 splenic lymphocytes as in vitro models. Using these models, the group demonstrated that mast cells and $\mathrm{CD} 4^{+} \mathrm{T}$ lymphocytes have D1-like receptors and that DA increases mast cell degranulation and Th2 cell differentiation; both of these activities were abrogated by SCH23390. In T lymphocytes, the ratio of IL-4/IFNG mRNA rose on addition of DA. Also, DA increased the release of $\beta$ hexosaminidase from BMMCs dose-dependently; this effect was also observed when D1-like receptors were stimulated through IgE-triggered FceR1 [220].

4.5.3. Other Approaches. Ilani and colleagues hypothesized that dopaminergic activation of blasts (cells that cross the blood-brain barrier) induces the Thl phenotype and effects changes in membrane surface markers. The authors suggest that these alterations are transferred from blasts to peripheral resting $\mathrm{T}$ lymphocytes by neurotransmitter-mediated brain regulation of peripheral $\mathrm{T}$ lymphocytes. In this work, blast formation was induced from peripheral blood lymphocytes of healthy donors (cells that have been activated with mitogen and IL-2 that express VLA-4 on their membrane); these blasts were incubated with the D2R/D3R agonist quinpirole 
$\left(10^{-5} \mathrm{M}-10^{-7} \mathrm{M}\right)$ for 8 hours. Quinpirole downregulates $I L-4$ and $I L-10$ but increases IFNG expression but has no effects on resting $\mathrm{T}$ lymphocytes.

Further, this group noted differential responses between $\mathrm{CD}^{+}$and $\mathrm{CD}^{+}$blasts. $\mathrm{CD} 4^{+}$blasts had lower $I L-4$ and $I L-10$ mRNA levels, but $I F N G$ mRNA rose. In contrast, $\mathrm{CD} 8^{+}$blasts only upregulated IFNG mRNA. Differences were also noted in adhesion molecules between $\mathrm{T}$ lymphocytes and blastsunchanged in the former during quinpirole stimulation but with the latter upregulating IL-2RA (CD25) mRNA and decreasing CXCR3 levels.

In resting $\mathrm{T}$ lymphocytes, incubation with blast supernatant for 24 hours without quinpirole increased $I L-4$ and $I L-10$ mRNA levels, whereas that with quinpirole upregulated only IFNG. These findings support the hypothesis that blasts that are stimulated with DA in the CNS trigger the phenotype implantation in peripheral blood resting Tlymphocytes [97].

4.6. NK Cells. NK cells constitute less than $10 \%$ of all circulating lymphocytes and have significant functions in the immune response against viruses, intracellular bacteria and in tumor cell destruction [193]. Studies on the effects of DA on NK cells were initially performed in rodents and demonstrated that DA has antitumor effects against Ehrlich ascites carcinoma cells [221]; in Swiss mice with transplantable Ehrlich ascites carcinoma, cancer cells are controlled through increased splenic NK cells [222]. Other studies in NK cells from the spleens of APO-SUS rats with a hyperdopaminergic phenotype [223] and mice with the slc6a3/Dat knockout phenotype [126] reported a decline in NK cell activity and dampened mitogen-induced cytokine responses. Another study has reported that mouse splenic NK cells express the 5 DA receptors in their membrane and that the stimulation of D1like receptors with SKF38393 increases the density of D1R and D5R; SKF38393 also improves the cytotoxic response against YAC-1 lymphoma cells (Moloney leukemia virus-induced mouse lymphoma) through cAMP-PKA-CREB signaling, but stimulation of D2-like receptors with quinpirole impairs NK lymphocyte function [82].

There are differences in the phenotype and function of human and murine NK cells-human NK cells express membrane D2R, D3R, D4R, and D5R but lack D1R [88, 92]. Without activation, human NK cells have no disturbances in phenotype or function when they are exposed to DA; however, stimulation with high concentrations of rIL-2 $(\approx 200 \mathrm{IU})$ for 5 days induces the overexpression of D5R. At concentrations between $10^{-9} \mathrm{M}$ and $10^{-18} \mathrm{M}$, DA reduces NK cell division and inhibits IFN- $\alpha$ secretion dose-dependently, wherein D5R signaling is compromised [92].

\section{Clinical Implications of the Effects on the Dopaminergic System}

Central and peripheral DA can directly or indirectly regulate the immune system in several pathological conditions, such as neurodegenerative (Parkinson disease, Alzheimer disease, and Lesch-Nyhan syndrome), psychiatric (schizophrenia), and immune diseases (multiple sclerosis, encephalomyelitis, and rheumatoid arthritis, among others), and conditions that have an addictive component, such as alcoholism.

In terms of a physiopathological perspective, disturbances in the levels of central DA affect the function of lymphocytes, because DA is supplied by the sympathetic nervous system to primary and secondary lymphoid tissues, modulating a wide range of immune activities, such as the regulation of innate immune and adaptive responses [224]. Several studies have reported disturbances in central DA production under pathological conditions, the most common of which is Parkinson disease, characterized by the selective destruction of dopaminergic neurons in the substantia nigra. However, recent studies indicate that DA production and the expression of dopaminergic receptors are dysregulated in other neurodegenerative and autoimmune diseases, which significantly impacts the immune response.

The expression of dopaminergic receptors in lymphocytes from patients with neurodegenerative and autoimmune diseases has recently been proposed as a diagnostic biomarker and a marker of pathological severity, because the variations in the density of DA receptors on lymphocytes are usually similar to what is observed in the brain. In this section, we catalog the evidence on variations in the expression of DRs on lymphocytes in various pathologies (Table 4).

5.1. Neurodegenerative Diseases. Changes in activation of the immune response in patients and in experimental models of neurodegenerative diseases have been described and implicated in their pathogenesis. Abnormalities in the number and function of circulating lymphocytes are linked to an increase in the production of proinflammatory mediators. The evidence in this section strongly suggests that the DAS participates in the modulation of the immune response.

5.1.1. Parkinson Disease. Parkinson disease is a neurodegenerative pathology that is characterized by the dysfunction and degeneration of dopaminergic neurons in the substantia nigra, neuroinflammation, and motor disturbances. In animal models in which the selective loss of dopaminergic neurons from the substantia nigra is induced by systematic administration of methyl-4-phenyl-1,2,3,6 tetrahydropyridine (MPTP), significant changes in the immune response have been observed. For example, proinflammatory cytokines, such as IFN- $\gamma$, IL-2, IL-17, and IL-22, are upregulated in the spleen and mesenteric lymphatic ganglia; Tbet, a fundamental transcription factor in Thl differentiation, is downregulated in T cells; and the expression of Foxp3, a transcription factor that induces the development and maintains the function of Treg, rises [225].

Regulation by the central DAS modifies peripheral immune functions. For instance, MPTP-induced depletion of DA in the striatum promotes tumor growth, which is associated with dysfunctional cytotoxic activity in T lymphocytes and NK cells $[2,226]$. In this regard, NK cell activity wanes on injury to the nucleus accumbens in animal models [227].

Some studies propose that the activation of circulating lymphocytes is able to regulate the neurodegenerative events 
TABLE 4: Pathology-associated dopaminergic protein expression in immune cells.

\begin{tabular}{|c|c|c|}
\hline Pathology/condition & DA receptors and cell types involved & Reference \\
\hline $\begin{array}{l}\text { Parkinson disease } \\
\text { Patients/MPTP mice }\end{array}$ & $\downarrow$ D3R in lymphocytes & {$[127]$} \\
\hline Lesch-Nyhan disease & $\uparrow \mathrm{D} 5 \mathrm{R}$ in lymphocytes & {$[128]$} \\
\hline Multiple sclerosis & $\downarrow$ D5R in lymphocytes & [129] \\
\hline Multiple sclerosis treatment with IFN- $\beta$ & $\begin{array}{l}\uparrow \mathrm{D} 5 \mathrm{R} \text { in lymphocytes } \\
\downarrow \mathrm{D} 2 \mathrm{R} \text { in lymphocytes }\end{array}$ & {$[129,130]$} \\
\hline Schizophrenia & $\begin{array}{c}\uparrow \mathrm{D} 4 \mathrm{R} \text { in } \mathrm{T} \mathrm{CD} 8^{+} \text {and } \mathrm{T} \text { CD } 4^{+} \text {lymphocytes } \\
\uparrow \mathrm{D} 4 \mathrm{R} \text { in T CD } 8^{+} \text {lymphocytes } \\
\downarrow \mathrm{D} 2 \mathrm{R} \text { in T CD } 4^{+} \text {lymphocytes }\end{array}$ & [131] \\
\hline $\begin{array}{l}\text { Rheumatoid arthritis } \\
\text { type II collagen-induced } \\
\text { arthritis (mice) }\end{array}$ & $\uparrow \mathrm{D} 2 \mathrm{R}$ in lymphocytes & {$[132]$} \\
\hline $\begin{array}{l}\text { Rheumatoid arthritis and } \\
\text { osteoarthritis }\end{array}$ & $\begin{array}{c}\downarrow \text { D5R in B cells } \\
\uparrow \mathrm{D} 2 \mathrm{R} \& \mathrm{D} 3 \mathrm{R} \text { in B cells }\end{array}$ & [133] \\
\hline Systemic lupus erythematosus & $\begin{array}{l}\uparrow \mathrm{D} 4 \mathrm{R} \text { in lymphocytes } \\
\downarrow \mathrm{D} 2 \mathrm{R} \text { in lymphocytes }\end{array}$ & [134] \\
\hline Alcohol dependence syndrome & $\uparrow \mathrm{D} 4 \mathrm{R}$ in lymphocytes & [135] \\
\hline Alcohol withdrawal & $\uparrow \mathrm{D} 1 \mathrm{R}$ in lymphocytes & {$[136]$} \\
\hline Computer game addicts & $\downarrow$ D5R in lymphocytes & [137] \\
\hline
\end{tabular}

in the substantia nigra in Parkinson disease. The stimulation of $\mathrm{D} 3 \mathrm{R}$ in $\mathrm{CD}^{+}{ }^{+} \mathrm{T}$ lymphocytes decreases their synthesis of IL-4 and IL-10 while promoting IFN- $\gamma$ production. Thus, D3R is a relevant target in the physiopathology of Parkinson disease. DRD3-deficient mice that have been treated with MPTP are susceptible to neurodegenerative events in the substantia nigra after receiving $\mathrm{CD}^{+} \mathrm{T}$ lymphocytes from MPTP-treated wild-type mice [127].

Similarly, Drd3KO mice are resistant to MPTP-induced neurodegeneration but become susceptible on transfer of $\mathrm{CD}^{+} \mathrm{T}$ lymphocytes from MPTP-treated wild-type mice. However, they are not prone to MPTP-induced neurodegeneration when they receive $\mathrm{CD} 4^{+} \mathrm{T}$ lymphocytes from D3R-deficient mice [127]. DRD3 expression in lymphocytes is reduced in Parkinson disease patients and correlates with disease severity, possibly due to changes in D3R density in other lymphocyte populations. These data show that D3R in T lymphocytes favors the activation and acquisition of the Th1 phenotype, suggesting that $\mathrm{D} 3 \mathrm{R}$ in $\mathrm{CD} 4^{+} \mathrm{T}$ lymphocytes has an important function in the physiopathology of the murine model of Parkinson disease [127].

5.1.2. Other Neurodegenerative Diseases. Patients with a likely diagnosis of Alzheimer disease have a low density of D2like receptors on lymphocytes. This decrease is also observed in postmortem samples of brains from Alzheimer disease patients [228]. However, Cosentino and colleagues did not observe any differences in the mRNA levels of DRs in lymphocytes in patients with a probable diagnosis of Alzheimer disease [229]. These controversial results might be attributed to the statistical parameters, such as sample size (number of participants), age, gender, and the presumptive diagnosis. With regard to the DAS, the lymphocytes of patients with probable Alzheimer disease experience an increase in the immunoreactivity of dopamine $\beta$-hydroxylase [230]; nevertheless, more studies are needed to determine the function and effects of DA on lymphocytes in the physiopathology of Alzheimer disease.

Studies have reported changes in the expression of DRs in lymphocytes in various pathologies of the CNS. LeschNyhan syndrome is a neurogenetic disorder that is caused by the complete deficiency of hypoxanthine-guanine phosphoribosyltransferase, which effects severe motor disturbances, predominantly dystonia (numbness) and occasionally chorea (involuntary movements); these secondary symptoms are related to disturbances in the production of DA in the CNS. Lesch-Nyhan syndrome patients have higher levels of $D R D 5$ in lymphocytes, rendering it a potential biomarker for the diagnosis of this disease and prompting the use of LDOPA in Lesch-Nyhan patients as an alternative treatment [128].

\subsection{Psychiatric Disorders}

5.2.1. Schizophrenia. Studies on disturbances in the DAS in schizophrenia patients have reported changes in the expression of DA receptors. In the 1980 s, a study examined the binding of $\left[{ }^{3} \mathrm{H}\right]$-spiperone, a specific dopaminergic antagonist, to peripheral blood lymphocytes from healthy volunteers, 27 patients with acute schizophrenia under no treatment, and 16 psychiatric patients as a control group by RBA. The study did not find any differences in binding parameters between the healthy and psychiatric control groups, whereas the binding of $\left[{ }^{3} \mathrm{H}\right]$-spiperone increased significantly in lymphocytes from schizophrenia patients with a slight decrease in affinity [70]. 
At the beginning of the 21st century, Kwak and colleagues performed an 8-week longitudinal study to measure D3R and D5R expression in peripheral blood lymphocytes from 44 patients who had been treated pharmacologically for over three years, 15 drug-naive schizophrenic patients, 28 drug-free patients, and healthy controls. DRD3 mRNA in drug-naive patients climbed significantly compared with medicated patients and healthy controls, and DRD5 mRNA was considerably higher only versus medicated patients. In drug-free and drug-naive patients, the expression of the receptors rose two weeks after antipsychotic treatment was begun, decreasing at 8 weeks of treatment. When the drugnaive and drug-free patients were divided into two groups by $D R D 3$ expression before the treatment, those with higher $D R D 3$ levels presented with more severe psychiatric symptoms [231]. In the same year, Ilani and colleagues observed a significant increase in $D R D 3$, but not $D R D 4$, mRNA in peripheral blood lymphocytes from 14 schizophrenic patients who were not under medication with respect to healthy subjects. This rise was not affected by treatment with typical or atypical antipsychotic drugs. Based on these data, the group implicated DRD3 as an identification and tracking marker [232].

In 2006, Boneberg and colleagues measured DA receptor (D1R-D4R) expression in neutrophils, monocytes, B lymphocytes, NK cells, and $\mathrm{CD}^{+}{ }^{+}$and $\mathrm{CD} 8^{+}$lymphocytes from 10 schizophrenic patients, reporting a significant increase in DRD3 mRNA in $\mathrm{T}$ lymphocytes and downregulation of DRD4 mRNA in $\mathrm{T} \mathrm{CD} 4^{+}$lymphocytes compared with healthy volunteers [233]. In contrast, Vogel and colleagues reported a decrease in DRD3 mRNA in peripheral blood leukocytes from 13 schizophrenic patients and 11 patients with bipolar disorder, subdivided as follows: drug-naive (never having ingested antipsychotics), drug-free (without any treatment for at least four weeks), and drug-treated (under pharmacological treatment). The schizophrenic drug-naive and drug-free patients had significantly less DRD3 mRNA compared with healthy subjects. However, patients who were under treatment had higher DRD3 mRNA levels during the six weeks of treatment; consequently, these levels were similar to those in healthy controls [234].

Another study attempted to identify schizophrenia markers in peripheral blood lymphocytes from 13 drug-naive/ drug-free patients. In a microarray analysis, DRD2 and inwardly rectifying potassium channel (Kir2.3) were overexpressed compared with healthy subjects; this effect was confirmed, based on the elevated mRNA levels of both genes. The group suggested using these genes to predict schizophrenia [235]. Urhan-Kucuk and colleagues studied 55 schizophrenia patients and 51 healthy subjects to determine whether DRD3 expression in peripheral blood lymphocytes could be used as a marker of disease. They noted no significant difference in DRD3 mRNA levels between schizophrenic patients and healthy subjects. However, across schizophrenia subtypes (residual, disorganized, and paranoid), these levels differed between the disorganized and paranoid subtypes and between disorganized schizophrenia and healthy subjects, prompting the authors to conclude that DRD3 mRNA could be used as a peripheral marker of schizophrenia subtype [236].

Recently, Brito-Melo and colleagues used flow cytometry to measure membrane expression of D2R, D4R, and serotonin receptors in $\mathrm{CD}^{+}$and $\mathrm{CD}^{+}$peripheral blood $\mathrm{T}$ lymphocytes from schizophrenic patients who had been treated pharmacologically for ten years. They correlated these levels with several clinimetric scales: Brief Psychiatric Rating (BPRS), Positive and Negative Syndrome (PANSS), and Involuntary Movement (AIMS). The group observed significant overexpression of $\mathrm{D} 4 \mathrm{R}$ in $\mathrm{CD}^{+}$and $\mathrm{CD}^{+} \mathrm{T}$ lymphocytes from schizophrenic patients and upregulation of D2R in $\mathrm{CD}^{+} \mathrm{T}$ lymphocytes; in contrast, D2R levels were lower in $\mathrm{CD}^{+} \mathrm{T}$ lymphocytes. Further, BPRS and PANSS scores correlated with $\mathrm{CD}^{+} \mathrm{D} 2 \mathrm{R}^{+}$lymphocyte levels, and AIMS scores were positively associated with $\mathrm{CD} 4^{+} \mathrm{D} 2 \mathrm{R}^{+} \mathrm{T}$ lymphocytes levels and inversely related to $\mathrm{CD} 4^{+} \mathrm{D} 4 \mathrm{R}^{+} \mathrm{T}$ levels [131].

In 2013, Liu and colleagues measured DRD2 and SLC6A3/DAT expression in peripheral blood leukocytes from 25 patients with acute schizophrenia, 27 patients with chronic schizophrenia, and healthy subjects to determine whether their mRNA levels correlated with PANSS scores. There was no significant difference in DRD2, but SLC6A3/DAT was higher in patients with chronic schizophrenia compared with healthy subjects. In addition, they noted a correlation between DRD2 mRNA levels and positive scores on the PANSS—but only in acute schizophrenia patients [91].

Another study analyzed the DRD3, DRD2, and DARPP32 (dopamine and cyclic adenosine $3^{\prime}, 5^{\prime}$-monophosphateregulated phosphoprotein-32) mRNA levels in peripheral blood lymphocytes from healthy subjects, patients with an unspecified psychotic disorder, and patients with schizophrenia/schizophreniform disorder, examining the relationship between these genes and the psychopathological state of the patients. The study demonstrated that DRD3 mRNA in T lymphocytes differed considerably between the three groups but that DRD2 and DARPP-32 levels were similar. Further, $D R D 3$ expression correlated with the excitement factor on the PANSS in patients with schizophrenia/schizophreniform disorder. According to the authors, DRD3 mRNA levels can be used as a diagnostic marker to differentiate patients with early psychosis from healthy controls [237].

\subsection{Autoimmune Diseases}

5.3.1. Multiple Sclerosis. Multiple sclerosis (MS) is the most common immune-mediated demyelinating disease of the CNS. This condition causes disability in 2.3 million people worldwide. In MS, myelin-reactive $\mathrm{CD} 4^{+}$Th lymphocytes enter the CNS, where they interact with resident cells, promoting inflammation, demyelination, and neurodegeneration [238]. Th cell subsets that are involved in the pathogenesis of MS include Th1 cells, which secrete the proinflammatory cytokines TNF- $\alpha$ and IFN- $\gamma$, and Th17 lymphocytes, which produce IL-17 [239].

The typical treatment for MS is IFN- $\beta$, which induces the production of DA and other catecholamines in human lymphocyte cultures [240]. DA downregulates IL-17 and 
IFN- $\gamma$ production by PBMCs in patients with relapsingremitting MS and healthy controls, strengthening the evidence of the potential benefit of dopaminergic agents in MS [3].

In untreated patients, the expression and activity of D1-like receptors (but perhaps not D2-like receptors) in circulating PBMCs are tempered [238], although untreated MS patients express less DRD 5 mRNA and protein without an increase in D3R $[129,130]$. Immunomodulatory drugs, such as IFN- $\beta$, restore the functional responsiveness of DRs on lymphocytes. Moreover, IFN- $\beta$ therapy appears to shift the balance of DRs in lymphocytes from predominantly D2-like in the cells of untreated patients toward primarily D1-like. D1-like receptors mediate most of the dopamine-dependent inhibition of human T lymphocyte proliferation and cytotoxicity, whereas D2-like receptors induce $\mathrm{T}$ lymphocyte proliferation and adhesion. Upregulation of D1-like receptors is thus expected to be beneficial in MS [129, 130, 238, 241].

Functional dysregulation of Treg contributes to disease pathogenesis and activity in autoimmune mouse models of the CNS and in patients with MS. Thus, the use of DR agonists in MS might suppress Treg via D1-like receptors, with detrimental effects [238]. Notably, treatment with IFN$\beta$ downregulates D1-like receptors on Treg and impedes the ability of DA to inhibit Treg function [3].

These findings suggest that the dopaminergic pathways in circulating lymphocytes have relevant immunomodulatory functions in the pathology of MS, impacting the development of drugs for patients with MS-DR agonists have beneficial effects as an add-on to immunomodulatory treatments with such agents as IFN- $\beta$, and they might act preferentially on D1-like rather than D2-like receptors [238].

5.3.2. Encephalomyelitis. Experimental autoimmune encephalomyelitis (EAE) is an experimental model of human MS. Balkowiec-iskta and colleagues showed that injury to the dopaminergic system modulates the clinical course and inflammatory reaction during EAE; this group studied the effects of dopamine depletion with 1-methyl-4-phenyl1,2,3,4-tetrahydropyridine (MPTP) in C57BL mice with EAE (induced by the MOG 35-55 peptide). They found that MPTP decreased striatal DA levels, and the mean number of inflammatory cells in the spinal cord infiltrate was significantly higher in MPTP + MOG 35-55-treated versus MOG 35-55-treated mice. The mortality rate in mice with a dysfunctional dopaminergic system was lower than in MOG 35-55-treated mice. Also, Illb mRNA was significantly upregulated in the MPTP + MOG 35-55 group, correlating with clinical progression of the disease; this IL- $1 \beta$ increase could be responsible for these changes, causing a more severe course of EAE [242].

Nakano et al. showed that antagonizing D1-like receptors suppresses IL-17 production and prevents EAE in SJL/J mice-animals that were treated with L750667 (a D2-like antagonist) developed hyperacute EAE, the progression of which was accelerated and quickly resulted in death. Conversely, mice that were administered SCH23390 (a D1-like antagonist) did not present with any clinical symptoms. Also, splenocytes from EAE mice that were treated with
SCH23390 for 30 days produced less IL-17, whereas IFN$\gamma$ levels rose. The transfection of BMDCs from SJL/J mice that were treated with antagonists in vitro into SJL/J mice affected the same clinical incidence of EAE. These results suggest that D1-like receptor antagonists ameliorate EAE, an effect that is accompanied by an increase in IFN- $\gamma$ and the suppression of IL-17 in antigen-specific T lymphocytes [124]. In 2012, Prado and colleagues demonstrated in C57BL/6 mice with EAE in vivo that D5R-deficient DCs that were transferred prophylactically into wild-type mice mitigated the severity of EAE. Further, mice into which D5R-deficient DCs were transferred experienced a significant reduction in the percentage of Th17 cells that infiltrated the CNS compared with animals that received wild-type DCs, whereas the percentage of Thl lymphocytes remained in similar levels [75].

5.3.3. Rheumatoid Arthritis. Rheumatoid arthritis (RA) is a chronic inflammatory disease that is characterized by pannus tissue, consisting of synovial fibroblasts (SFs), macrophages, and lymphocytes. The inflammatory milieu in the joint activates resident SFs and transforms them [243]; in particular, SFs increase their expression of D1R and D5R [244]. RA has a high predominance of Th1 and Th17 lymphocytes; further, DA localizes to DCs in the synovial tissue of RA patients and significantly increases its levels in this fluid [244]. In RA patients, DCs release DA during antigen presentation to naive $\mathrm{CD}^{+} \mathrm{T}$ lymphocytes [245], which raises IL-6dependent IL-17 production via D1-like receptors, in response to Tlymphocyte activation by anti-CD3 and anti-CD28 [244].

The involvement of D2R in RA has been demonstrated in several murine models. Its activation mitigates clinical symptoms, and Drd2 knockout (Drd2KO) mice develop severe symptoms of RA; D2R antagonists induce the accumulation of IL- $17^{+}$and IL- $6^{+} \mathrm{T}$ cells in synovial fluid, exacerbating the inflammatory process. Similarly, RA patients express low levels of $D R D 2$ in lymphocytes, which is linked to disease severity [132]. Based on this evidence, D2R agonists have been proposed to be therapeutic agents for RA.

D5R levels in B lymphocytes from RA and osteoarthritis patients are lower than in healthy volunteers, whereas those of D2R and D3R are higher [133]; Nakano and colleagues have suggested that DA that is released by DCs activates the IL-6-Th17 axis, aggravating synovial inflammation in RA [246]. Thus, clinical protocols have been developed in which clinical researchers should use D2R agonists, such as bromocriptine and cabergoline, to lower prolactin synthesis and secretion by infiltrating synovial fibroblasts and lymphocytes in patients with RA-the improvement in RA activity might be attributed to a significant decrease in the secretion of prolactin by immune cells $[247,248]$, although these results are not conclusive.

5.3.4. Systemic Lupus Erythematosus. Systemic lupus erythematosus is an autoimmune disease that is characterized by the dysfunction of several organs, including the liver and brain, due to a dysregulated immune system. In PBMCs of systemic lupus erythematosus patients, $D R D 2$ is downregulated, whereas $D R D 4$ increases compared with a control group. The 
decrease in D2R levels might be associated with the reduction in the function and numbers of Treg cells in this pathology [134].

\subsection{Miscellaneous Clinical Implications}

5.4.1. Glomerulonephritis. Glomerulonephritis encompasses a range of immune-mediated disorders that cause inflammation in the glomerulus and other compartments of the kidney [249]. DA mediates the control of renal sodium excretion, and DRs have been detected in various regions of the nephron-it has been reported that DA is synthesized in the renal proximal tubules. A defect in renal DA receptor function and DA production has been suggested to accelerate the pathogenesis of hypertension [250]. Conversely, in a brain-dead model in rats, the administration of DA reduced monocyte infiltration in renal tissue, indicating that DA has a direct anti-inflammatory effect that is mediated by D1-like and D2-like receptors stimulation [251].

In another study by Hoeger et al. using the same braindead model in rats, the changes in cytokine and chemokine expression were measured to determine the mechanism by which DA lowers renal inflammation. This study evaluated the expression of IL-6, IL-10, macrophage chemoattractant protein 1 (MCP-1), and cytokine-induced neutrophil chemoattractant 1 (CINC-1), a rat homolog of IL-8. No significant changes were observed in IL-6, IL-10, and MCP1 , but CINC-1 was significantly downregulated in the braindead animal group that was treated with DA compared with controls, implicating this change as an anti-inflammatory mechanism that is induced by DA during renal inflammation [252]. Kapper et al. also demonstrated that DA dosedependently inhibits the production of the chemokines Gro$\alpha$, ENA-78, and IL-8 in proximal tubular epithelial cells (PTECs) [253]. Collectively, these findings support the function of DA as an immunomodulator in glomerulonephritis.

5.4.2. Cancer and Angiogenesis. The dopaminergic system has garnered significant interest in angiogenesis and tumor immunity. Endothelial cells express components of the dopaminergic system; thus, DA governs angiogenesis, prompting an examination of the molecular mechanisms that are associated with modulation of tumor immunity, its mechanisms of control, and the link between tumor immunity and angiogenesis [214, 254, 255].

In a murine model, the antitumor effects of DA on Ehrlich ascites carcinoma cells already have been reported [221]. This inhibitory effect suppresses the growth of cancer cells by increasing the number of peripheral large granular lymphocytes (LGLs) and the activity of NK cells. Even in healthy mice (without Ehrlich cells) that have been treated with DA, these effects are also observed [222].

The low incidence of certain types of cancer in schizophrenic patients, in contrast with the high incidence in patients with Parkinson disease, reflects the inhibitory effects of DA on cancer cell growth. This hypothesis is based on the finding that schizophrenic patients express a hyperdopaminergic system, whereas Parkinson patients are hypodopaminergic. However, it is unknown if disruptions in the dopaminergic system in the CNS contribute to the development of tumor angiogenesis outside of the CNS [256-260]. However, the effects of DA on schizophrenic patients might be linked to medication with DR antagonists, suggesting that the development of specific cancers is DR-dependent [261].

Conversely, DA selectively inhibits vascular permeability and the angiogenic activity of VEGF. This inhibitory effect is mediated by the activation of $\mathrm{D} 2 \mathrm{R}$ and the induction of the endocytosis of VEGFR-2 [262, 263]. Further, at low pharmacological doses, DA delays tumor angiogenesis by inhibiting VEGFR-2 phosphorylation in endothelial cells that express D2R, as reported in rat malignant gastric tumors (adenocarcinoma type) and xenotransplanted human gastric cancers in mice. In malignant tumors of the stomach from humans and rats, endogenous DA and TH enzyme are absent compared with normal tissue [264].

Another study demonstrated that DA acts through D2R to inhibit the proliferation of gastric cancer cells that have been induced by insulin-like growth factor receptor-I (IGFIR). This inhibition is mediated by the upregulation of Krüppel-like factor 4 (KLF4) [265]. Also, the ablation of peripheral dopaminergic nerves increases angiogenesis, density, and microvascular permeability, permitting the growth of malignant tumors in mice [266]. Recent reports have demonstrated that the administration of DA stabilizes and normalizes tumor blood vessels by acting on pericytes and endothelial cells, primarily by activation of D2R [254, 267]. Thus, DA has been proposed to be a safe antiangiogenic drug for the control of tumor progression [192].

The relationship between DA, transformed cells, and the immune system is unknown, but it is likely that a link exists with mechanisms of the identification and elimination of abnormal cells, because DA inhibits tumor angiogenesis and stimulates tumor immunity; nevertheless, more studies are needed to examine this issue.

5.4.3. Diabetes Mellitus. The involvement and significance of DA as a neurotransmitter and immunomodulator have been studied, but its effects on glucose homeostasis and pancreatic $\beta$-cell function are unknown [268]. Diabetes mellitus is a group of metabolic diseases that are characterized by hyperglycemia, resulting from defects in insulin secretion, insulin activity, or both. Chronic hyperglycemia in diabetes is associated with long-term damage, dysfunction, and failure of organs, especially the eyes, kidneys, nerve fibers, heart, and blood vessels [269].

DA and its derivatives can act directly in pancreas; the networks between the CNS and pancreatic islets are based on the central vagal connection through the parahypothalamic ventricular nucleus [270]. The pancreas expresses DA receptors, depending on cell type; mRNA of the five DA receptors is expressed in $\beta$-cells [271], but only D1R, D2R, and D4R proteins have been detected in these cells [271-273].

Insulin production depends on the concentration of DA [274]. In humans, neuroleptic drugs cause hyperinsulinemia in normal subjects and are associated with diabetes in psychiatric patients [268]. DA and its agonists modulate $\beta$ cell activity, but it is unknown whether DA promotes or 
inhibits insulin secretion [275]. The activation of $\mathrm{D} 2 \mathrm{R}$ receptor inhibits glucose-stimulated insulin secretion in isolated islets from rodents and $\beta$-cell lines [271], and another study in which D2R was knocked out in the INS-1 832/13 mammalian cell line reported an increase in insulin secretion [276]. García-Tornadú et al., using a global D2R knockout mouse, showed that the disruption in D2R impairs insulin secretion and causes glucose intolerance [277].

One regulatory mechanism that explains the effects of DA states that DA in pancreatic $\beta$-cells involves a dopaminergic negative feedback loop that regulates insulin secretion from human and murine pancreatic islets. According to this model, $\mathrm{DA}$ is stored in $\beta$-cells and is cosecreted with insulin; this endogenous DA acts in an autocrine/paracrine manner on insulin-secreting $\beta$-cells that express D2-like receptors [67, 278].

The effects of DA on the immune system in this disease are not well elucidated. One study showed that the D1-like antagonist SCH-23390 has a preventive effect on diabetes mellitus that occurs naturally in NOD mice. In this in vivo model, Th17 lymphocytes mediate the development of diabetes in NOD mice. The islet infiltrates appear to be composed of mononuclear cells that are positive for IL-23R (a specific Th17 marker), but SCH-23390 significantly decreases the levels of infiltrating cells. This group reported that the antagonism of D1-like receptors suppresses IL-17 production and prevents naturally occurring diabetes in NOD mice, accompanied by an increase in IFN- $\gamma$ production [279].

Diabetes mellitus is a disease with an important inflammatory component; understanding the regulation of DA in the immune system and the significance of the inflammatory condition in the development of this disease will require a more detailed examination of the regulation of DA in this condition with regard to immunity.

5.5. Addictions. The function of the D1R and D2R receptors in the brain is linked to the reward system and might be affected by extended drug use. Several reports indicate that the expression of DRs in immune system cells is altered during addiction. For instance, in patients who suffer from alcohol dependence, $D R D 1$ mRNA levels in lymphocytes are higher compared with healthy controls [136]. Other studies have demonstrated that in alcohol dependence syndrome patients, DRD4 is upregulated in peripheral lymphocytes versus a control group [135].

Similarly, opioid addicts experience an increase in DRD3 expression in circulating lymphocytes compared with healthy controls [280]. On the other hand, a chronic rise in D1R might be a risk factor that predisposes individuals to some type of addiction allowing one to diagnose the severity of the addictive condition [281]. The expression of DA receptors in the immune system might be a valuable biomarker of the risk for pathologies and addictive conducts; thus, it has also been measured in computer game addicts, in whom $D R D 5$ levels in circulating lymphocytes are lower than in control subjects [137]. Notably, the personality of volunteers has been correlated with the expression of the DRD3 and DRD4 receptors [282]. These findings suggest that DA receptor expression in the periphery constitutes a significant link between neurobiological processes and immune system function.

\section{Conclusions}

Based on the activity of DA as a neurotransmitter, studies on the DAS have focused primarily on the CNS. Recently, however, copious experimental evidence indicates that the DAS has important physiological functions in the immune system. The human DAS is complex and comprises many elements; leukocytes have frequently been demonstrated to synthesize, release, perform reuptake of, and metabolize DA. In certain cases, as in Treg cells, DA is released to elicit autocrine effects, implicating the existence of a peripheral DAS that is independent of the CNS.

In this review, we have discussed the immunomodulatory effects of DA by activating DRs, which are differentially expressed in leukocytes, depending on cell type, activation state, DA concentration, and duration of exposure to DA. These effects regulate many cellular processes, such as cell activation, cell adhesion, proliferation, respiratory burst, chemotaxis, apoptosis, cytotoxicity, and cytokine and antibody secretion, and several changes at the phenotypic level and function in certain cell types. All of this activity is linked to the intracellular concentration of cAMP and the activation status of second messengers and transcription factors.

The information that we have here is based on existing reports, but the effects of DA on the immune system require further characterization. The peripheral DAS is dysregulated in patients with psychiatric disorders, neurodegenerative diseases, and other conditions, such as multiple sclerosis. However, more research is needed to demonstrate that peripheral disturbances in the DAS are equivalent to those in the CNS, which will facilitate the identification and characterization of new peripheral biomarkers for diagnostic purposes and the evaluation of the therapeutic efficacy of pharmacological treatments in these illnesses.

\section{Competing Interests}

The authors declare no competing interests with regard to this paper.

\section{Authors' Contributions}

Rodrigo Arreola, Samantha Alvarez-Herrera, Gilberto PérezSánchez, Enrique Becerril-Villanueva, Carlos Cruz-Fuentes, Enrique Octavio Flores-Gutierrez, María Eugenia GarcésAlvarez, Dora Luz de la Cruz-Aguilera, Emilio MedinaRivero, Gabriela Hurtado-Alvarado, Saray Quintero-Fabián, and Lenin Pavón drafted the paper. All authors reviewed the paper and approved the final version.

\section{Acknowledgments}

This work was supported in part by Instituto Nacional de Psiquiatria "Ramón de la Fuente" Project NC-15-0048; SC-152414; SECITI-CM-48/14-SECITI/067/2015; Proyecto Factor de Transferencia-IPN: IC-10-002; PRODEP 14412732; and 
Universidad Nacional Autonoma de México; Programa de Doctorado en Ciencias Biomédicas, CONACYT.

\section{References}

[1] R. Franco, R. Pacheco, C. Lluis, G. P. Ahern, and P. J. O'Connell, "The emergence of neurotransmitters as immune modulators," Trends in Immunology, vol. 28, no. 9, pp. 400-407, 2007.

[2] S. Basu and P. S. Dasgupta, "Dopamine, a neurotransmitter, influences the immune system," Journal of Neuroimmunology, vol. 102, no. 2, pp. 113-124, 2000.

[3] M. Cosentino and F. Marino, "Adrenergic and dopaminergic modulation of immunity in multiple sclerosis: teaching old drugs new tricks?" Journal of Neuroimmune Pharmacology, vol. 8, no. 1, pp. 163-179, 2013.

[4] G. E. Torres, “The dopamine transporter proteome," Journal of Neurochemistry, vol. 97, supplement 1, pp. 3-10, 2006.

[5] R. Pacheco, T. Gallart, C. Lluis, and R. Franco, "Role of glutamate on T-cell mediated immunity," Journal of Neuroimmunology, vol. 185, no. 1-2, pp. 9-19, 2007.

[6] K. F. Atkinson, S. H. Kathem, X. Jin et al., "Dopaminergic signaling within the primary cilia in the renovascular system," Frontiers in Physiology, vol. 6, article 103, 2015.

[7] R. Arreola, E. Becerril-Villanueva, C. Cruz-Fuentes et al., "Immunomodulatory effects mediated by serotonin," Journal of Immunology Research, vol. 2015, Article ID 354957, 21 pages, 2015.

[8] Y. Zhang, S. Cuevas, L. D. Asico et al., "Deficient dopamine D2 receptor function causes renal inflammation independently of high blood pressure," PLoS ONE, vol. 7, no. 6, Article ID e38745, 2012.

[9] D. C. Borcherding, E. R. Hugo, G. Idelman et al., "Dopamine receptors in human adipocytes: expression and functions," PLoS ONE, vol. 6, no. 9, Article ID e25537, 2011.

[10] S. Cuevas, V. A. Villar, P. A. Jose, and I. Armando, "Renal dopamine receptors, oxidative stress, and hypertension," International Journal of Molecular Sciences, vol. 14, no. 9, pp. 1755317572, 2013.

[11] B. Rubí and P. Maechler, "Minireview: new roles for peripheral dopamine on metabolic control and tumor growth: let's seek the balance," Endocrinology, vol. 151, no. 12, pp. 5570-5581, 2010.

[12] J.-H. Baik, "Dopamine signaling in reward-related behaviors," Frontiers in Neural Circuits, vol. 7, article 152, 2013.

[13] N. Ben-Jonathan and R. Hnasko, "Dopamine as a prolactin (PRL) inhibitor," Endocrine Reviews, vol. 22, no. 6, pp. 724-763, 2001.

[14] J. D. Salamone, M. Pardo, S. E. Yohn, L. Lopez-Cruz, N. SanMiguel, and M. Correa, "Mesolimbic dopamine and the regulation of motivated behavior," Current Topics in Behavioral Neurosciences, vol. 27, pp. 231-257, 2016.

[15] J.-M. Beaulieu and R. R. Gainetdinov, "The physiology, signaling, and pharmacology of dopamine receptors," Pharmacological Reviews, vol. 63, no. 1, pp. 182-217, 2011.

[16] J.-M. Beaulieu, S. Espinoza, and R. R. Gainetdinov, "Dopamine receptors-IUPHAR review 13," British Journal of Pharmacology, vol. 172, no. 1, pp. 1-23, 2015.

[17] G. C. Beck, P. Brinkkoetter, C. Hanusch et al., "Clinical review: immunomodulatory effects of dopamine in general inflammation," Critical Care, vol. 8, no. 6, pp. 485-491, 2004.
[18] N. Ayala-Lopez, M. Martini, W. F. Jackson et al., "Perivascular adipose tissue contains functional catecholamines," Pharmacology Research \& Perspectives, vol. 2, no. 3, Article ID e00041, 2014.

[19] E. Nagy, I. Berczi, G. E. Wren, S. L. Asa, and K. Kovacs, "Immunomodulation by bromocriptine," Immunopharmacology, vol. 6, no. 3, pp. 231-243, 1983.

[20] J. Bergquist, A. Tarkowski, R. Ekman, and A. Ewing, "Discovery of endogenous catecholamines in lymphocytes and evidence for catecholamine regulation of lymphocyte function via an autocrine loop," Proceedings of the National Academy of Sciences of the United States of America, vol. 91, no. 26, pp. 12912-12916, 1994.

[21] M. Levite, "Nerve-driven immunity. The direct effects of neurotransmitters on T-cell function," Annals of the New York Academy of Sciences, vol. 917, pp. 307-321, 2000.

[22] I. Berczi, A. Quintanar-Stephano, and K. Kovacs, "Neuroimmune regulation in immunocompetence, acute illness, and healing," Annals of the New York Academy of Sciences, vol. 1153, pp. 220-239, 2009.

[23] I. J. Elenkov, R. L. Wilder, G. P. Chrousos, and E. S. Vizi, “The sympathetic nerve-an integrative interface between two supersystems: the brain and the immune system," Pharmacological Reviews, vol. 52, no. 4, pp. 595-638, 2000.

[24] M. Cosentino, E. Rasini, C. Colombo et al., "Dopaminergic modulation of oxidative stress and apoptosis in human peripheral blood lymphocytes: evidence for a D1-like receptordependent protective effect," Free Radical Biology and Medicine, vol. 36, no. 10, pp. 1233-1240, 2004.

[25] G. Barger and H. H. Dale, "Chemical structure and sympathomimetic action of amines," The Journal of Physiology, vol. 41, no. 1-2, pp. 19-59, 1910.

[26] H. Blaschko, "The activity of 1(-)-dopa decarboxylase," The Journal of Physiology, vol. 101, no. 3, pp. 337-349, 1942.

[27] C. Mannich, W. Jacobsohn, and Hr. C. Mannich, "Über oxyphenyl-alkylamine und dioxyphenyl-alkylamine," Berichte der Deutschen Chemischen Gesellschaft, vol. 43, no. 1, pp. 189-197, 1910.

[28] G. Barger and P. G. Ewins, "Some phenolic derivatives of beta phenylethyl-amine," Journal of the Chemical Society, vol. 97, p. $8,1910$.

[29] O. Hornykiewicz, "Dopamine miracle: from brain homogenate to dopamine replacement," Movement Disorders, vol. 17, no. 3, pp. 501-508, 2002.

[30] D. L. Roe, “The discovery of dopamine's physiological importance," Brain Research Bulletin, vol. 50, no. 5-6, pp. 375-376, 1999.

[31] C. A. Marsden, "Dopamine: the rewarding years," British Journal of Pharmacology, vol. 147, supplement 1, pp. S136-S144, 2006.

[32] Å. Bertler and E. Rosengren, "Occurrence and distribution of dopamine in brain and other tissues," Experientia, vol. 15, no. 1, pp. 10-11, 1959.

[33] K. M. Ashe, W.-L. Chiu, A. M. Khalifa et al., "Vesicular monoamine transporter-1 (VMAT-1) mRNA and immunoreactive proteins in mouse brain," Neuroendocrinology Letters, vol. 32, no. 3, pp. 253-258, 2011.

[34] M. K. Sievert, A. R. Hajipour, and A. E. Ruoho, "Specific derivatization of the vesicle monoamine transporter with novel carrier-free radioiodinated reserpine and tetrabenazine photoaffinity labels," Analytical Biochemistry, vol. 367, no. 1, pp. 6878, 2007. 
[35] A. Carlsson, M. Lindqvist, and T. Magnusson, "3,4-Dihydroxyphenylalanine and 5-hydroxytryptophan as reserpine antagonists," Nature, vol. 180, no. 4596, p. 1200, 1957.

[36] A. Carlsson, M. Lindqvist, T. Magnusson, and B. Waldeck, "On the presence of 3-hydroxytyramine in brain," Science, vol. 127, no. 3296 , p. $471,1958$.

[37] H. Sano, "Biochemistry of the extrapyramidal system Shinkei Kennkyu No Shinpo, Advances in Neurological Sciences. (ISSN 0001-8724) Tokyo, October 1960;5:42-48," Parkinsonism \& Related Disorders, vol. 6, no. 1, pp. 3-6, 1960.

[38] H. Ehringer and O. Hornykiewicz, "Distribution of noradrenaline and dopamine (3-hydroxytyramine) in the human brain and their behavior in diseases of the extrapyramidal system," Parkinsonism and Related Disorders, vol. 4, no. 2, pp. 53-57, 1998.

[39] W. Birkmayer and O. Hornykiewicz, "The effect of L-3,4dihydroxyphenylalanine (=DOPA) on akinesia in parkinsonism," Parkinsonism and Related Disorders, vol. 4, no. 2, pp. 5960, 1998.

[40] C. Leiva, "Madopar: more than 20 years," Revue Neurologique, vol. 25, no. 148, pp. 1957-1963, 1997.

[41] P. J. García Ruiz and E. Meseguer, "Short history of L-Dopa," Neurologia, vol. 17, no. 4, pp. 214-217, 2002.

[42] E. Tolosa, M. J. Marti, and F. Valldeoriola, "History of levodopa and dopamine agonists in Parkinson's disease treatment," Neurology, vol. 50, no. 6, supplement 6, pp. S2-S10, 1998.

[43] R. A. Hauser, "Levodopa: past, present, and future," European Neurology, vol. 62, no. 1, pp. 1-8, 2009.

[44] P. Teismann, K. Tieu, D.-K. Choi et al., "Cyclooxygenase2 is instrumental in Parkinson's disease neurodegeneration," Proceedings of the National Academy of Sciences of the United States of America, vol. 100, no. 9, pp. 5473-5478, 2003.

[45] U. Ungerstedt, L. L. Butcher, S. G. Butcher, N.-E. Andén, and K. Fuxe, "Direct chemical stimulation of dopaminergic mechanisms in the neostriatum of the rat," Brain Research, vol. 14, no. 2, pp. 461-471, 1969.

[46] J. W. Kebabian and P. Greengard, "Dopamine-sensitive adenyl cyclase: possible role in synaptic transmission," Science, vol. 174, no. 4016, pp. 1346-1349, 1971.

[47] J. W. Kebabian, G. L. Petzold, and P. Greengard, "Dopaminesensitive adenylate cyclase in caudate nucleus of rat brain, and its similarity to the 'dopamine receptor," Proceedings of the National Academy of Sciences of the United States of America, vol. 69, no. 8, pp. 2145-2149, 1972.

[48] J. W. Kebabian, "Multiple classes of dopamine receptors in mammalian central nervous system: the involvement of dopamine-sensitive adenylyl cyclase," Life Sciences, vol. 23, no. 5, pp. 479-483, 1978.

[49] P. F. Spano, S. Govoni, and M. Trabucchi, "Studies on the pharmacological properties of dopamine receptors in various areas of the central nervous system," Advances in Biochemical Psychopharmacology, vol. 19, pp. 155-165, 1978.

[50] S. Shimada, S. Kitayama, C.-L. Lin et al., "Cloning and expression of a cocaine-sensitive dopamine transporter complementary DNA," Science, vol. 254, no. 5031, pp. 576-578, 1991.

[51] J. E. Kilty, D. Lorang, and S. G. Amara, "Cloning and expression of a cocaine-sensitive rat dopamine transporter," Science, vol. 254, no. 5031, pp. 578-579, 1991.

[52] B. Giros, S. El Mestikawy, L. Bertrand, and M. G. Caron, "Cloning and functional characterization of a cocaine-sensitive dopamine transporter," FEBS Letters, vol. 295, no. 1-3, pp. 149$154,1991$.
[53] T. B. Usdin, E. Mezey, C. Chen, M. J. Brownstein, and B. J. Hoffman, "Cloning of the cocaine-sensitive bovine dopamine transporter," Proceedings of the National Academy of Sciences of the United States of America, vol. 88, no. 24, pp. 11168-11171, 1991.

[54] B. Giros, S. el Mestikawy, N. Godinot et al., "Cloning, pharmacological characterization, and chromosome assignment of the human dopamine transporter," Molecular Pharmacology, vol. 42, no. 3, pp. 383-390, 1992.

[55] Physiology or Medicine for 2000-Press Release.

[56] A. Baudry, A. Alleaume-Butaux, S. Dimitrova-Nakov et al., "Essential roles of dopamine and serotonin in tooth repair: functional interplay between odontogenic stem cells and platelets," Stem Cells, vol. 33, no. 8, pp. 2586-2595, 2015.

[57] I. Armando, P. Konkalmatt, R. A. Felder, and P. A. Jose, “The renal dopaminergic system: novel diagnostic and therapeutic approaches in hypertension and kidney disease," Translational Research, vol. 165, no. 4, pp. 505-511, 2015.

[58] D. S. Goldstein and C. Holmes, "Neuronal source of plasma dopamine," Clinical Chemistry, vol. 54, no. 11, pp. 1864-1871, 2008.

[59] G. Eisenhofer, Å. Aneman, P. Friberg et al., "Substantial production of dopamine in the human gastrointestinal tract," Journal of Clinical Endocrinology and Metabolism, vol. 82, no. 11, pp. 38643871, 1997.

[60] J. L. Willems, W. A. Buylaert, R. A. Lefebvre, and M. G. Bogaert, "Neuronal dopamine receptors on autonomic ganglia and sympathetic nerves and dopamine receptors in the gastrointestinal system," Pharmacological Reviews, vol. 37, no. 2, pp. 165-216, 1985.

[61] J. Meiser, D. Weindl, and K. Hiller, "Complexity of dopamine metabolism," Cell Communication and Signaling, vol. 11, article 34, 2013.

[62] F. Amenta, A. Ricci, I. Rossodivita, R. Avola, and S. K. Tayebati, "The dopaminergic system in hypertension," Clinical and Experimental Hypertension, vol. 23, no. 1-2, pp. 15-24, 2001.

[63] P. A. Jose, G. M. Eisner, and R. A. Felder, "Regulation of blood pressure by dopamine receptors," Nephron, vol. 95, no. 2, pp. p19-p27, 2003.

[64] C. R. Jackson, G.-X. Ruan, F. Aseem et al., "Retinal dopamine mediates multiple dimensions of light-adapted vision," The Journal of Neuroscience, vol. 32, no. 27, pp. 9359-9368, 2012.

[65] D. E. Hernandez, G. A. Mason, C. H. Walker, and J. E. Valenzuela, "Dopamine receptors in human gastrointestinal mucosa," Life Sciences, vol. 41, no. 25, pp. 2717-2723, 1987.

[66] A. Maffei, A. M. Segal, J. C. Alvarez-Perez, A. Garcia-Ocaña, and P. E. Harris, "Anti-incretin, anti-proliferative action of dopamine on $\beta$-cells," Molecular Endocrinology, vol. 29, no. 4, pp. 542-557, 2015.

[67] N. Simpson, A. Maffei, M. Freeby et al., "Dopamine-mediated autocrine inhibitory circuit regulating human insulin secretion in vitro," Molecular Endocrinology, vol. 26, no. 10, pp. 1757-1772, 2012.

[68] R. Bhattacharya, S. Sinha, S.-P. Yang et al., "The neurotransmitter dopamine modulates vascular permeability in the endothelium," Journal of Molecular Signaling, vol. 3, article 14, 2008.

[69] B. A. Faraj, Z. L. Olkowski, and R. T. Jackson, "Binding of $\left[{ }^{3} \mathrm{H}\right]$-dopamine to human lymphocytes: possible relationship to neurotransmitter uptake sites," Pharmacology, vol. 42, no. 3, pp. 135-141, 1991.

[70] B. Bondy, M. Ackenheil, R. Elbers, and M. Fröhler, "Binding of $3 \mathrm{H}$-spiperone to human lymphocytes: a biological marker in 
schizophrenia?” Psychiatry Research, vol. 15, no. 1, pp. 41-48, 1985.

[71] B. Bondy, M. Ackenheil, and T. Ruppert, "Spiperone binding in lymphocytes: part of a dopamine uptake system?" Annals of the New York Academy of Sciences, vol. 650, pp. 221-225, 1992.

[72] S. Basu, P. Sarathi Dasgupta, T. Lahiri, and J. Roy Chowdhury, "Uptake and biodistribution of dopamine in bone marrow, spleen and lymph nodes of normal and tumor bearing mice," Life Sciences, vol. 53, no. 5, pp. 415-424, 1993.

[73] A. Ricci and F. Amenta, "Dopamine D5 receptors in human peripheral blood lymphocytes: a radioligand binding study," Journal of Neuroimmunology, vol. 53, no. 1, pp. 1-7, 1994.

[74] B. Dean, A. J. McAdam, S. Sundram, G. Pavey, L. C. Harrison, and D. L. Copolov, "Identification of a dopamine-binding protein on the membrane of the human platelet," Biochemical Journal, vol. 287, no. 1, pp. 45-50, 1992.

[75] C. Prado, F. Contreras, H. González et al., "Stimulation of dopamine receptor D5 expressed on dendritic cells potentiates Th17-mediated immunity," The Journal of Immunology, vol. 188, no. 7, pp. 3062-3070, 2012.

[76] B. Basu, C. Sarkar, D. Chakroborty et al., " $\mathrm{D}_{1}$ and $\mathrm{D}_{2}$ dopamine receptor-mediated inhibition of activated normal $\mathrm{T}$ cell proliferation is lost in Jurkat T leukemic cells," The Journal of Biological Chemistry, vol. 285, no. 35, pp. 27026-27032, 2010.

[77] M. Ferrari, M. Cosentino, F. Marino et al., "Dopaminergic D1-like receptor-dependent inhibition of tyrosine hydroxylase mRNA expression and catecholamine production in human lymphocytes," Biochemical Pharmacology, vol. 67, no. 5, pp. 865873, 2004.

[78] E. J. Meredith, M. J. Holder, A. Rosén et al., "Dopamine targets cycling B cells independent of receptors/transporter for oxidative attack: implications for non-Hodgkin's lymphoma," Proceedings of the National Academy of Sciences of the United States of America, vol. 103, no. 36, pp. 13485-13490, 2006.

[79] P. J. Gaskill, L. Carvallo, E. A. Eugenin, and J. W. Berman, "Characterization and function of the human macrophage dopaminergic system: implications for CNS disease and drug abuse," Journal of Neuroinflammation, vol. 9, article 203, 2012.

[80] P. J. Gaskill, T. M. Calderon, A. J. Luers, E. A. Eugenin, J. A. Javitch, and J. W. Berman, "Human immunodeficiency virus (HIV) infection of human macrophages is increased by dopamine: a bridge between HIV-associated neurologic disorders and drug abuse," The American Journal of Pathology, vol. 175, no. 3, pp. 1148-1159, 2009.

[81] H. Liang, X. Wang, H. Chen et al., "Methamphetamine enhances HIV infection of macrophages," American Journal of Pathology, vol. 172, no. 6, pp. 1617-1624, 2008.

[82] W. Zhao, Y. Huang, Z. Liu, B.-B. Cao, Y.-P. Peng, and Y.-H. Qiu, "Dopamine receptors modulate cytotoxicity of natural killer cells via cAMP-PKA-CREB signaling pathway," PLoS ONE, vol. 8, no. 6, Article ID e65860, 2013.

[83] M. Cosentino, A. M. Fietta, M. Ferrari et al., "Human $\mathrm{CD} 4{ }^{+} \mathrm{CD} 25^{+}$regulatory $\mathrm{T}$ cells selectively express tyrosine hydroxylase and contain endogenous catecholamines subserving an autocrine/paracrine inhibitory functional loop," Blood, vol. 109, no. 2, pp. 632-642, 2007.

[84] J. Kipnis, M. Cardon, H. Avidan et al., "Dopamine, through the extracellular signal-regulated kinase pathway, downregulates CD4+CD25+ regulatory T-cell activity: implications for neurodegeneration," The Journal of Neuroscience, vol. 24, no. 27, pp. 6133-6143, 2004.
[85] N. Kustrimovic, E. Rasini, M. Legnaro, F. Marino, and M. Cosentino, "Expression of dopaminergic receptors on human CD4+ T lymphocytes: flow cytometric analysis of naive and memory subsets and relevance for the neuroimmunology of neurodegenerative disease," Journal of Neuroimmune Pharmacology, vol. 9, no. 3, pp. 302-312, 2014.

[86] Y. Watanabe, T. Nakayama, D. Nagakubo et al., "Dopamine selectively induces migration and homing of naive $\mathrm{CD} 8^{+} \mathrm{T}$ cells via dopamine receptor D3," Journal of Immunology, vol. 176, no. 2, pp. 848-856, 2006.

[87] Y. Huang, A.-W. Qiu, Y.-P. Peng, Y. Liu, H.-W. Huang, and Y.H. Qiu, "Roles of dopamine receptor subtypes in mediating modulation of T lymphocyte function," Neuroendocrinology Letters, vol. 31, no. 6, pp. 782-791, 2010.

[88] F. McKenna, P. J. McLaughlin, B. J. Lewis et al., "Dopamine receptor expression on human $\mathrm{T}$ - and B-lymphocytes, monocytes, neutrophils, eosinophils and NK cells: a flow cytometric study," Journal of Neuroimmunology, vol. 132, no. 1-2, pp. 34-40, 2002.

[89] M. C. Ghosh, A. C. Mondal, S. Basu et al., "Dopamine inhibits cytokine release and expression of tyrosine kinases, Lck and Fyn in activated T cells," International Immunopharmacology, vol. 3, no. 7, pp. 1019-1026, 2003.

[90] M. J. Besser, Y. Ganor, and M. Levite, "Dopamine by itself activates either D2, D3 or D1/D5 dopaminergic receptors in normal human T-cells and triggers the selective secretion of either IL-10, TNF $\alpha$ or both," Journal of Neuroimmunology, vol. 169, no. 1-2, pp. 161-171, 2005.

[91] L. Liu, G. Yuan, Z. Cheng, G. Zhang, X. Liu, and H. Zhang, "Identification of the mRNA expression status of the dopamine D2 receptor and dopamine transporter in peripheral blood lymphocytes of schizophrenia patients," PLoS ONE, vol. 8, no. 9, Article ID e75259, 2013.

[92] J. Mikulak, L. Bozzo, A. Roberto et al., "Dopamine inhibits the effector functions of activated NK cells via the upregulation of the D5 receptor," The Journal of Immunology, vol. 193, no. 6, pp. 2792-2800, 2014.

[93] G. P. Kirillova, R. J. Hrutkay, M. R. Shurin, G. V. Shurin, I. L. Tourkova, and M. M. Vanyukov, "Dopamine receptors in human lymphocytes: radioligand binding and quantitative RTPCR assays," Journal of Neuroscience Methods, vol. 174, no. 2, pp. 272-280, 2008.

[94] F. Amenta, E. Bronzetti, L. Felici, A. Ricci, and S. K. Tayebati, "Dopamine D2-like receptors on human peripheral blood lymphocytes: a radioligand binding assay and immunocytochemical study," Journal of Autonomic Pharmacology, vol. 19, no. 3, pp. 151-159, 1999.

[95] Y. Nagai, S. Ueno, Y. Saeki, F. Soga, and T. Yanagihara, "Expression of the D3 dopamine receptor gene and a novel variant transcript generated by alternative splicing in human peripheral blood lymphocytes," Biochemical and Biophysical Research Communications, vol. 194, no. 1, pp. 368-374, 1993.

[96] A. Ricci, E. Bronzetti, L. Felici, S. Greco, and F. Amenta, "Labeling of dopamine $\mathrm{D}_{3}$ and $\mathrm{D}_{4}$ receptor subtypes in human peripheral blood lymphocytes with $\left[{ }^{3} \mathrm{H}\right] 7-\mathrm{OH}-\mathrm{DPAT}$ : a combined radioligand binding assay and immunochemical study," Journal of Neuroimmunology, vol. 92, no. 1-2, pp. 191-195, 1998.

[97] T. Ilani, R. D. Strous, and S. Fuchs, "Dopaminergic regulation of immune cells via D3 dopamine receptor: a pathway mediated by activated T cells," The FASEB Journal, vol. 18, no. 13, pp. 1600$1602,2004$. 
[98] C. Strell, A. Sievers, P. Bastian et al., "Divergent effects of norepinephrine, dopamine and substance $\mathrm{P}$ on the activation, differentiation and effector functions of human cytotoxic $\mathrm{T}$ lymphocytes," BMC Immunology, vol. 10, article 62, 2009.

[99] B. Bondy, S. de Jonge, S. Pander, J. Primbs, and M. Ackenheil, "Identification of dopamine D4 receptor mRNA in circulating human lymphocytes using nested polymerase chain reaction," Journal of Neuroimmunology, vol. 71, no. 1-2, pp. 139-144, 1996.

[100] C. Sarkar, S. Das, D. Chakroborty et al., "Cutting edge: stimulation of dopamine $\mathrm{D}_{4}$ receptors induce $\mathrm{T}$ cell quiescence by upregulating Krüppel-like factor-2 expression through inhibition of ERK1/ERK2 phosphorylation," The Journal of Immunology, vol. 177, no. 11, pp. 7525-7529, 2006.

[101] N. Takahashi, Y. Nagai, S. Ueno, Y. Saeki, and T. Yanagihara, "Human peripheral blood lymphocytes express D5 dopamine receptor gene and transcribe the two pseudogenes," FEBS Letters, vol. 314, no. 1, pp. 23-25, 1992.

[102] A. Ricci, E. Bronzetti, F. Mignini, S. K. Tayebati, D. Zaccheo, and F. Amenta, "Dopamine D1-like receptor subtypes in human peripheral blood lymphocytes," Journal of Neuroimmunology, vol. 96, no. 2, pp. 234-240, 1999.

[103] F. Amenta, E. Bronzetti, F. Cantalamessa et al., "Identification of dopamine plasma membrane and vesicular transporters in human peripheral blood lymphocytes," Journal of Neuroimmunology, vol. 117, no. 1-2, pp. 133-142, 2001.

[104] F. R. Buttarelli, A. Circella, C. Pellicano et al., "Dopamine transporter immunoreactivity in peripheral blood lymphocytes in multiple system atrophy," Journal of Neural Transmission, vol. 116, no. 2, pp. 161-165, 2009.

[105] D. Marazziti, M. Catena Dell'Osso, S. Baroni et al., "Alterations of the dopamine transporter in resting lymphocytes of patients with different psychotic disorders," Psychiatry Research, vol. 175, no. 1-2, pp. 54-57, 2010.

[106] B. Caronti, G. Tanda, C. Colosimo et al., "Reduced dopamine in peripheral blood lymphocytes in Parkinson's disease," NeuroReport, vol. 10, no. 14, pp. 2907-2910, 1999.

[107] X.-Y. Zhao, S.-W. Cui, X.-Q. Wang, Y.-P. Peng, and Y.-H. Qiu, "Tyrosine hydroxylase expression in $\mathrm{CD} 4^{+} \mathrm{T}$ cells is associated with joint inflammatory alleviation in collagen type II-induced arthritis," Rheumatology International, vol. 33, no. 10, pp. 25972605, 2013.

[108] Y.-H. Qiu, C. Cheng, L. Dai, and Y.-P. Peng, "Effect of endogenous catecholamines in lymphocytes on lymphocyte function," Journal of Neuroimmunology, vol. 167, no. 1-2, pp. 45-52, 2005.

[109] I. Kokkinou, E. Nikolouzou, A. Hatzimanolis, E. G. Fragoulis, and D. Vassilacopoulou, "Expression of enzymatically active LDOPA decarboxylase in human peripheral leukocytes," Blood Cells, Molecules, and Diseases, vol. 42, no. 1, pp. 92-98, 2009.

[110] I. Kokkinou, E. G. Fragoulis, and D. Vassilacopoulou, "The U937 macrophage cell line expresses enzymatically active LDopa decarboxylase," Journal of Neuroimmunology, vol. 216, no. 1-2, pp. 51-58, 2009.

[111] R. C. Alaniz, S. A. Thomas, M. Perez-Melgosa et al., "Dopamine $\beta$-hydroxylase deficiency impairs cellular immunity," Proceedings of the National Academy of Sciences of the United States of America, vol. 96, no. 5, pp. 2274-2278, 1999.

[112] U. Grimm, A. Knapp, A. Weber, G. Seidlitz, and M. Wehnert, "Detection of phenylalanine hydroxylase activity in leukocytes and fibroblasts," Biomedica Biochimica Acta, vol. 42, no. 9, pp. 1135-1141, 1983.
[113] G. A. Annenkov and E. E. Safronova, "Presence of active phenylalanine hydroxylase in human leukocytes," Voprosy Meditsinskoj Khimii, vol. 27, no. 2, pp. 266-271, 1981.

[114] G. A. Annenkov, E. E. Safronova, L. M. Gubernieva, and N. M. Volkova, "Detection of phenylalanine hydroxylase activity in human leukocytes and fibroblasts," Voprosy Meditsinskoj Khimii, vol. 26, no. 6, pp. 723-726, 1980.

[115] B. A. Faraj, Z. L. Olkowski, and R. T. Jackson, "Active $\left[{ }^{3} \mathrm{H}\right]-$ dopamine uptake by human lymphocytes: correlates with serotonin transporter activity," Pharmacology, vol. 48, no. 5, pp. 320327, 1994.

[116] F. Marino, M. Cosentino, R. Bombelli, M. Ferrari, S. Lecchini, and G. Frigo, "Endogenous catecholamine synthesis, metabolism, storage, and uptake in human peripheral blood mononuclear cells," Experimental Hematology, vol. 27, no. 3, pp. 489-495, 1999.

[117] J. D. Erickson, M. K.-H. Schäfer, T. I. Bonner, L. E. Eiden, and E. Weihe, "Distinct pharmacological properties and distribution in neurons and endocrine cells of two isoforms of the human vesicular monoamine transporter," Proceedings of the National Academy of Sciences of the United States of America, vol. 93, no. 10, pp. 5166-5171, 1996.

[118] M. Essand, S. Vikman, J. Grawé et al., "Identification and characterization of a novel splicing variant of vesicular monoamine transporter 1," Journal of Molecular Endocrinology, vol. 35, no. 3, pp. 489-501, 2005.

[119] A. Marchese, T. V. Beischlag, T. Nguyen et al., "Two gene duplication events in the human and primate dopamine D5 receptor gene family," Gene, vol. 154, no. 2, pp. 153-158, 1995.

[120] T. Nguyen, R. Sunahara, A. Marchese, H. H. M. Van Tol, P. Seeman, and B. F. O'Dowd, "Transcription of a human dopamine D5 pseudogene," Biochemical and Biophysical Research Communications, vol. 181, no. 1, pp. 16-21, 1991.

[121] D. J. E. Housley, M. Nikolas, P. J. Venta et al., "SNP discovery and haplotype analysis in the segmentally duplicated DRD5 coding region," Annals of Human Genetics, vol. 73, part 3, pp. 274-282, 2009.

[122] E. Josefsson, J. Bergquist, R. Ekman, and A. Tarkowski, "Catecholamines are synthesized by mouse lymphocytes and regulate function of these cells by induction of apoptosis," Immunology, vol. 88, no. 1, pp. 140-146, 1996.

[123] K. Nakano, T. Higashi, R. Takagi, K. Hashimoto, Y. Tanaka, and S. Matsushita, "Dopamine released by dendritic cells polarizes Th2 differentiation," International Immunology, vol. 21, no. 6, pp. 645-654, 2009.

[124] K. Nakano, T. Higashi, K. Hashimoto, R. Takagi, Y. Tanaka, and S. Matsushita, "Antagonizing dopamine D1-like receptor inhibits Th17 cell differentiation: preventive and therapeutic effects on experimental autoimmune encephalomyelitis," Biochemical and Biophysical Research Communications, vol. 373, no. 2, pp. 286-291, 2008.

[125] J. Bergquist, E. Josefsson, A. Tarkovski, R. Ekman, and A. Ewing, "Measurements of catecholamine-mediated apoptosis of immunocompetent cells by capillary electrophoresis," Electrophoresis, vol. 18, no. 10, pp. 1760-1766, 1997.

[126] A. Kavelaars, P. M. Cobelens, M. A. T. Teunis, and C. J. Heijnen, "Changes in innate and acquired immune responses in mice with targeted deletion of the dopamine transporter gene," Journal of Neuroimmunology, vol. 161, no. 1-2, pp. 162-168, 2005.

[127] H. González, F. Contreras, C. Prado et al., "Dopamine receptor D3 expressed on $\mathrm{CD}^{+} \mathrm{T}$ cells favors neurodegeneration of 
dopaminergic neurons duringparkinson's disease," Journal of Immunology, vol. 190, no. 10, pp. 5048-5056, 2013.

[128] M. G. García, J. G. Puig, and R. J. Torres, "Adenosine, dopamine and serotonin receptors imbalance in lymphocytes of LeschNyhan patients," Journal of Inherited Metabolic Disease, vol. 35, no. 6, pp. 1129-1135, 2012.

[129] M. Giorelli, P. Livrea, and M. Trojano, "Dopamine fails to regulate activation of peripheral blood lymphocytes from multiple sclerosis patients: effects of IFN- $\beta$," Journal of Interferon and Cytokine Research, vol. 25, no. 7, pp. 395-406, 2005.

[130] M. Zaffaroni, A. Rizzo, S. M. Baldini, A. Ghezzi, and G. Comi, "Induction and add-on therapy with mitoxantrone and Interferon beta in multiple sclerosis," Neurological Sciences, vol. 29, supplement 2, pp. S230-S232, 2008.

[131] G. E. A. Brito-Melo, R. Nicolato, A. C. P. de Oliveira et al., "Increase in dopaminergic, but not serotoninergic, receptors in T-cells as a marker for schizophrenia severity;" Journal of Psychiatric Research, vol. 46, no. 6, pp. 738-742, 2012.

[132] J.-H. Lu, Y.-Q. Liu, Q.-W. Deng, Y.-P. Peng, and Y.-H. Qiu, "Dopamine D2 receptor is involved in alleviation of type II collagen-induced arthritis in mice," BioMed Research International, vol. 2015, Article ID 496759, 9 pages, 2015.

[133] L. Wei, C. Zhang, H. Y. Chen et al., "Dopamine receptor DR2 expression in $\mathrm{B}$ cells is negatively correlated with disease activity in rheumatoid arthritis patients," Immunobiology, vol. 220, no. 3, pp. 323-330, 2015.

[134] M. Jafari, G. Ahangari, M. Saberi, S. Samangoui, R. Torabi, and M. Zouali, "Distorted expression of dopamine receptor genes in systemic lupus erythematosus," Immunobiology, vol. 218, no. 7, pp. 979-983, 2013.

[135] A. E. Taraskina, M. N. Grunina, A. M. R. Zabotina et al., "The key proteins of dopaminergic neurotransmission of human peripheral blood lymphocytes: changed mRNA level in alcohol dependence syndrome," Bulletin of Experimental Biology and Medicine, vol. 160, no. 2, pp. 271-274, 2015.

[136] T. Biermann, D. Bönsch, U. Reulbach, J. Kornhuber, and S. Bleich, "Dopamine and N-methyl-D-aspartate receptor expression in peripheral blood of patients undergoing alcohol withdrawal," Journal of Neural Transmission, vol. 114, no. 8, pp. 1081-1084, 2007.

[137] N. Vousooghi, S. Z. Zarei, M.-S. Sadat-Shirazi, F. Eghbali, and M. R. Zarrindast, "mRNA expression of dopamine receptors in peripheral blood lymphocytes of computer game addicts," Journal of Neural Transmission, vol. 122, no. 10, pp. 1391-1398, 2015.

[138] V. Dias, E. Junn, and M. M. Mouradian, “The role of oxidative stress in Parkinson's disease," Journal of Parkinson's Disease, vol. 3, no. 4, pp. 461-491, 2013.

[139] Z. Qi, G. W. Miller, and E. O. Voit, "Computational systems analysis of dopamine metabolism," PLoS ONE, vol. 3, no. 6, Article ID e2444, 2008.

[140] T. Hiroi, S. Imaoka, and Y. Funae, "Dopamine formation from tyramine by CYP2D6," Biochemical and Biophysical Research Communications, vol. 249, no. 3, pp. 838-843, 1998.

[141] E. Bromek, A. Haduch, K. Gołembiowska, and W. A. Daniel, "Cytochrome P450 mediates dopamine formation in the brain in vivo," Journal of Neurochemistry, vol. 118, no. 5, pp. 806-815, 2011.

[142] N. R. Musso, S. Brenci, F. Indiveri, and G. Lotti, "L-tyrosine and nicotine induce synthesis of L-Dopa and norepinephrine in human lymphocytes," Journal of Neuroimmunology, vol. 74, no. 1-2, pp. 117-120, 1997.
[143] N. R. Musso, S. Brenci, M. Setti, F. Indiveri, and G. Lotti, "Catecholamine content and in vitro catecholamine synthesis in peripheral human lymphocytes," The Journal of Clinical Endocrinology \& Metabolism, vol. 81, no. 10, pp. 3553-3557, 1996.

[144] P. Uutela, L. Karhu, P. Piepponen, M. Käenmäki, R. A. Ketola, and R. Kostiainen, "Discovery of dopamine glucuronide in rat and mouse brain microdialysis samples using liquid chromatography tandem mass spectrometry," Analytical Chemistry, vol. 81, no. 1, pp. 427-434, 2009.

[145] G. Eisenhofer, M. W. Coughtrie, and D. S. Goldstein, "Dopamine sulphate: an enigma resolved," Clinical and Experimental Pharmacology \& Physiology. Supplement, vol. 26, pp. S41-S53, 1999.

[146] N. T. Buu, J. Duhaime, C. Savard, L. Truong, and O. Kuchel, "Presence of conjugated catecholamines in rat brain: a new method of analysis of catecholamine sulfates," Journal of Neurochemistry, vol. 36, no. 2, pp. 769-772, 1981.

[147] D. Sulzer and L. Zecca, "Intraneuronal dopamine-quinone synthesis: a review," Neurotoxicity Research, vol. 1, no. 3, pp. 181195, 1999.

[148] P. Muñoz, S. Huenchuguala, I. Paris, and J. Segura-Aguilar, "Dopamine oxidation and autophagy," Parkinson's Disease, vol. 2012, Article ID 920953, 13 pages, 2012.

[149] A. Palumbo, M. d'Ischia, G. Misuraca, L. De Martino, and G. Prota, "Iron- and peroxide-dependent conjugation of dopamine with cysteine: oxidative routes to the novel brain metabolite 5S-cysteinyldopamine," Biochimica et Biophysica Acta (BBA)General Subjects, vol. 1245, no. 2, pp. 255-261, 1995.

[150] D. S. Goldstein, C. Holmes, Y. Sharabi, S. Brentzel, and G. Eisenhofer, "Plasma levels of catechols and metanephrines in neurogenic orthostatic hypotension," Neurology, vol. 60, no. 8, pp. 1327-1332, 2003.

[151] L. A. Snyder, J. L. Roberts, and S. C. Sealfon, "Alternative transcripts of the rat and human dopamine D3 receptor," Biochemical and Biophysical Research Communications, vol. 180, no. 2, pp. 1031-1035, 1991.

[152] K. Liu, C. Bergson, R. Levenson, and C. Schmauss, "On the origin of mRNA encoding the truncated dopamine D3-type receptor D3nf and detection of D3nf-like immunoreactivity in human brain," The Journal of Biological Chemistry, vol. 269, no. 46, pp. 29220-29226, 1994.

[153] M. Scarselli, F. Novi, G. U. Corsini, and R. Maggio, "Functional rescue of the inactive splice variant of the dopamine $\mathrm{D}_{3}$ receptor

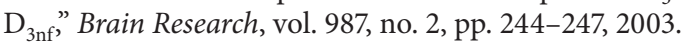

[154] N. M. Richtand, Y. Liu, R. Ahlbrand, J. R. Sullivan, A. H. Newman, and R. K. McNamara, "Dopaminergic regulation of dopamine D3 and D3nf receptor mRNA expression," Synapse, vol. 64, no. 8, pp. 634-643, 2010.

[155] L. M. Pritchard, A. D. Logue, B. C. Taylor et al., "Relative expression of D3 dopamine receptor and alternative splice variant D3nf mRNA in high and low responders to novelty," Brain Research Bulletin, vol. 70, no. 4-6, pp. 296-303, 2006.

[156] D. K. Grandy, Y. Zhang, C. Bouvier et al., "Multiple human D5 dopamine receptor genes: a functional receptor and two pseudogenes," Proceedings of the National Academy of Sciences of the United States of America, vol. 88, no. 20, pp. 9175-9179, 1991.

[157] J. M. Vile and P. G. Strange, "D2-like dopamine receptors are not detectable on human peripheral blood lymphocytes," Biological Psychiatry, vol. 40, no. 9, pp. 881-885, 1996. 
[158] L. Santambrogio, M. Lipartiti, A. Bruni, and R. Dal Toso, "Dopamine receptors on human T- and B-lymphocytes," Journal of Neuroimmunology, vol. 45, no. 1-2, pp. 113-119, 1993.

[159] A. Ricci, E. Bronzetti, L. Felici, S. K. Tayebati, and F. Amenta, "Dopamine D4 receptor in human peripheral blood lymphocytes: a radioligand binding assay study," Neuroscience Letters, vol. 229, no. 2, pp. 130-134, 1997.

[160] A. J. Harmar, R. A. Hills, E. M. Rosser et al., "IUPHAR-DB: the IUPHAR database of $\mathrm{G}$ protein-coupled receptors and ion channels," Nucleic Acids Research, vol. 37, no. 1, pp. D680-D685, 2009.

[161] S. P. H. Alexander, A. P. Davenport, E. Kelly et al., "The Concise Guide to PHARMACOLOGY 2015/16: G protein-coupled receptors," British Journal of Pharmacology, vol. 172, no. 24, pp. 5744-5869, 2015.

[162] S. Brogi, A. Tafi, L. Désaubry, and C. G. Nebigil, "Discovery of GPCR ligands for probing signal transduction pathways," Frontiers in Pharmacology, vol. 5, article 255, 2014.

[163] W. M. Oldham and H. E. Hamm, "Heterotrimeric G protein activation by G-protein-coupled receptors," Nature Reviews Molecular Cell Biology, vol. 9, no. 1, pp. 60-71, 2008.

[164] G. B. Downes and N. Gautam, "The G protein subunit gene families," Genomics, vol. 62, no. 3, pp. 544-552, 1999.

[165] S. Hernádez-López, T. Tkatch, E. Perez-Garci et al., "D2 dopamine receptors in striatal medium spiny neurons reduce L-type $\mathrm{Ca}^{2+}$ currents and excitability via a novel PLC $\beta 1-\mathrm{IP}_{3}-$ calcineurin-signaling cascade," The Journal of Neuroscience, vol. 20, no. 24, pp. 8987-8995, 2000.

[166] S. Ahn, S. K. Shenoy, H. Wei, and R. J. Lefkowitz, "Differential kinetic and spatial patterns of $\beta$-arrestin and $G$ proteinmediated ERK activation by the angiotensin II receptor," The Journal of Biological Chemistry, vol. 279, no. 34, pp. 35518-35525, 2004.

[167] S. Amar, G. Shaltiel, L. Mann et al., "Possible involvement of post-dopamine $\mathrm{D}_{2}$ receptor signalling components in the pathophysiology of schizophrenia," International Journal of Neuropsychopharmacology, vol. 11, no. 2, pp. 197-205, 2008.

[168] K. A. Harrington, S. J. Augood, A. E. Kingsbury, O. J. F. Foster, and P. C. Emson, "Dopamine transporter (DAT) and synaptic vesicle amine transporter (VMAT2) gene expression in the substantia nigra of control and Parkinson's disease," Molecular Brain Research, vol. 36, no. 1, pp. 157-162, 1996.

[169] T. S. Guillot, J. R. Richardson, M. Z. Wang et al., "PACAP38 increases vesicular monoamine transporter 2 (VMAT2) expression and attenuates methamphetamine toxicity," Neuropeptides, vol. 42, no. 4, pp. 423-434, 2008.

[170] E. Floor, S. F. Schaeffer, B. E. Feist, and S. E. Leeman, "Synaptic vesicles from mammalian brain: large-scale purification and physical and immunochemical characterization," Journal of Neurochemistry, vol. 50, no. 5, pp. 1588-1596, 1988.

[171] W. Lu and M. E. Wolf, "Expression of dopamine transporter and vesicular monoamine transporter 2 mRNAs in rat midbrain after repeated amphetamine administration," Molecular Brain Research, vol. 49, no. 1-2, pp. 137-148, 1997.

[172] G. W. Miller, J. D. Erickson, J. T. Perez et al., "Immunochemical analysis of vesicular monoamine transporter (VMAT2) protein in Parkinson's disease," Experimental Neurology, vol. 156, no. 1, pp. 138-148, 1999.

[173] K. Wimalasena, "Vesicular monoamine transporters: structurefunction, pharmacology, and medicinal chemistry," Medicinal Research Reviews, vol. 31, no. 4, pp. 483-519, 2011.
[174] M. B. Larsen, M. S. Sonders, O. V. Mortensen, G. A. Larson, N. R. Zahniser, and S. G. Amara, "Dopamine transport by the serotonin transporter: a mechanistically distinct mode of substrate translocation," The Journal of Neuroscience, vol. 31, no. 17, pp. 6605-6615, 2011.

[175] S. M. Parsons, "Transport mechanisms in acetylcholine and monoamine storage," The FASEB Journal, vol. 14, no. 15, pp. 2423-2434, 2000.

[176] B. Gasnier, "The loading of neurotransmitters into synaptic vesicles," Biochimie, vol. 82, no. 4, pp. 327-337, 2000.

[177] M. Forgac, "Structure and properties of the vacuolar $\left(\mathrm{H}^{+}\right)$ATPases," The Journal of Biological Chemistry, vol. 274, no. 19, pp. 12951-12954, 1999.

[178] N. Nelson and W. R. Harvey, "Vacuolar and plasma membrane proton-adenosinetriphosphatases," Physiological Reviews, vol. 79, no. 2, pp. 361-385, 1999.

[179] D. Marazziti, S. Baroni, M. Catena Dell'Osso et al., "Presence and characterization of the dopamine transporter in human resting lymphocytes," Neurochemical Research, vol. 33, no. 6, pp. 1011-1016, 2008.

[180] J. Mill, P. Asherson, C. Browes, U. D’Souza, and I. Craig, "Expression of the dopamine transporter gene is regulated by the $3^{\prime}$ UTR VNTR: Evidence from brain and lymphocytes using quantitative RT-PCR," American Journal of Medical GeneticsNeuropsychiatric Genetics, vol. 114, no. 8, pp. 975-979, 2002.

[181] F. W. Lohoff, J. P. Dahl, T. N. Ferraro et al., "Variations in the vesicular monoamine transporter 1 gene (VMAT1/SLC18A1) are associated with bipolar I disorder," Neuropsychopharmacology, vol. 31, no. 12, pp. 2739-2747, 2006.

[182] F. W. Lohoff, R. Hodge, S. Narasimhan et al., "Functional genetic variants in the vesicular monoamine transporter 1 modulate emotion processing," Molecular Psychiatry, vol. 19, no. 1, pp.129139,2014

[183] E. Y. T. Chien, W. Liu, Q. Zhao et al., "Structure of the human dopamine D3 receptor in complex with a D2/D3 selective antagonist," Science, vol. 330, no. 6007, pp. 1091-1095, 2010.

[184] V. Olivares-Illana, R. Arreola, A. Gómez-Poyou, and R. PérezMontfort, "Proteins and drug discovery (development)," in Advances in Protien Physical Chemistry, E. García-Hernández and D. A. Fernández-Velasco, Eds., p. 501, Transworld Research Network, Thiruvananthapuram, India, 1st edition, 2008.

[185] M. J. Wasko, K. A. Pellegrene, J. D. Madura, and C. K. Surratt, "A role for fragment-based drug design in developing novel lead compounds for central nervous system targets," Frontiers in Neurology, vol. 6, article 197, 2015.

[186] R. Pacheco, C. E. Prado, M. J. Barrientos, and S. Bernales, "Role of dopamine in the physiology of T-cells and dendritic cells," Journal of Neuroimmunology, vol. 216, no. 1-2, pp. 8-19, 2009.

[187] M. Cosentino, F. Marino, and G. J. M. Maestroni, "Sympathoadrenergic modulation of hematopoiesis: a review of available evidence and of therapeutic perspectives," Frontiers in Cellular Neuroscience, vol. 9, article 302, 2015.

[188] A. Spiegel, A. Kalinkovich, S. Shivtiel, O. Kollet, and T. Lapidot, "Stem cell regulation via dynamic interactions of the nervous and immune systems with the microenvironment," Cell Stem Cell, vol. 3, no. 5, pp. 484-492, 2008.

[189] G. J. M. Maestroni, A. Conti, and E. Pedrinis, "Effect of adrenergic agents on hematopoiesis after syngeneic bone marrow transplantation in mice," Blood, vol. 80, no. 5, pp. 1178-1182, 1992. 
[190] A. Spiegel, S. Shivtiel, A. Kalinkovich et al., "Catecholaminergic neurotransmitters regulate migration and repopulation of immature human $\mathrm{CD}_{3} 4^{+}$cells through Wnt signaling," Nature Immunology, vol. 8, no. 10, pp. 1123-1131, 2007.

[191] M. Cosentino, M. Ferrari, N. Kustrimovic, E. Rasini, and F. Marino, "Influence of dopamine receptor gene polymorphisms on circulating T lymphocytes: a pilot study in healthy subjects," Human Immunology, vol. 76, no. 10, pp. 747-752, 2015.

[192] C. Sarkar, D. Chakroborty, P. S. Dasgupta, and S. Basu, "Dopamine is a safe antiangiogenic drug which can also prevent 5-fluorouracil induced neutropenia," International Journal of Cancer, vol. 137, no. 3, pp. 744-749, 2015.

[193] L. Pavon, M. Jiménez-Martínez, and M. Garces-Alvarez, Inmunología Molecular, Celular y Traslacional, Kluwer Academic Publishers, Philadelphia, Pa, USA, 2016.

[194] M. Cosentino, F. Marino, R. Bombelli, M. Ferrari, S. Lecchini, and G. Frigo, "Endogenous catecholamine synthesis, metabolism, storage and uptake in human neutrophils," Life Sciences, vol. 64, no. 11, pp. 975-981, 1999.

[195] C. Wenisch, B. Parschalk, A. Weiss et al., "High-dose catecholamine treatment decreases polymorphonuclear leukocyte phagocytic capacity and reactive oxygen production," Clinical and Diagnostic Laboratory Immunology, vol. 3, no. 4, pp. 423428, 1996.

[196] S. Sookhai, J. H. Wang, M. McCourt, D. O'Connell, and H. P. Redmond, "Dopamine induces neutrophil apoptosis through a dopamine D-1 receptor-independent mechanism," Surgery, vol. 126, no. 2, pp. 314-322, 1999.

[197] S. Sookhai, J. H. Wang, D. Winter, C. Power, W. Kirwan, and H. P. Redmond, "Dopamine attenuates the chemoattractant effect of interleukin-8: a novel role in the systemic inflammatory response syndrome," Shock, vol. 14, no. 3, pp. 295-299, 2000.

[198] B. Trabold, M. Gruber, and D. Fröhlich, "Functional and phenotypic changes in polymorphonuclear neutrophils induced by catecholamines," Scandinavian Cardiovascular Journal, vol. 41, no. 1, pp. 59-64, 2007.

[199] M. Cosentino, R. Bombelli, M. Ferrari et al., "HPLC-ED measurement of endogenous catecholamines in human immune cells and hematopoietic cell lines," Life Sciences, vol. 68, no. 3, pp. 283-295, 2000.

[200] R. A. Ali, M. A. Qureshi, and F. M. McCorkle, "Profile of chicken macrophage functions after exposure to catecholamines in vitro," Immunopharmacology and Immunotoxicology, vol. 16, no. 4, pp. 611-625, 1994.

[201] G. Haskó, C. Szabó, K. Merkel et al., "Modulation of lipopolysaccharide-induced tumor necrosis factor- $\alpha$ and nitric oxide production by dopamine receptor agonists and antagonists in mice," Immunology Letters, vol. 49, no. 3, pp. 143-147, 1996.

[202] F. Gomez, P. Ruiz, F. Briceño, C. Rivera, and R. Lopez, "Macrophage $F c \gamma$ receptors expression is altered by treatment with dopaminergic drugs," Clinical Immunology, vol. 90, no. 3, pp. 375-387, 1999.

[203] J. Bergquist, B. Ohlsson, and A. Tarkowski, "Nuclear factorkappa B is involved in the catecholaminergic suppression of immunocompetent cells," Annals of the New York Academy of Sciences, vol. 917, pp. 281-289, 2000.

[204] G. Haskó, C. Szabó, Z. H. Németh, and E. A. Deitch, "Dopamine suppresses IL-12 p40 production by lipopolysaccharide-stimulated macrophages via a $\beta$-adrenoceptor-mediated mechanism," Journal of Neuroimmunology, vol. 122, no. 1-2, pp. 34-39, 2002.
[205] O. Rohr, B. E. Sawaya, D. Lecestre, D. Aunis, and E. Schaeffer, "Dopamine stimulates expression of the human immunodeficiency virus type 1 via NF- $\kappa$ B in cells of the immune system," Nucleic Acids Research, vol. 27, no. 16, pp. 3291-3299, 1999.

[206] E. A. Berger, P. M. Murphy, and J. M. Farber, "Chemokine receptors as HIV-1 coreceptors: roles in viral entry, tropism, and disease," Annual Review of Immunology, vol. 17, pp. 657-700, 1999.

[207] J. Wang, K. Crawford, M. Yuan, H. Wang, P. R. Gorry, and D. Gabuzda, "Regulation of CC chemokine receptor 5 and CD4 expression and human immunodeficiency virus type 1 replication in human macrophages and microglia by $\mathrm{T}$ helper type 2 cytokines," Journal of Infectious Diseases, vol. 185, no. 7, pp. 885-897, 2002.

[208] S. Sozzani, S. Ghezzi, G. Iannolo et al., "Interleukin 10 increases CCR5 expression and HIV infection in human monocytes," The Journal of Experimental Medicine, vol. 187, no. 3, pp. 439-444, 1998.

[209] P. J. Gaskill, H. H. Yano, G. V. Kalpana, J. A. Javitch, and J. W. Berman, "Dopamine receptor activation increases HIV entry into primary human macrophages," PLoS ONE, vol. 9, no. 9, Article ID e108232, 2014.

[210] J. Bergquist and J. Silberring, "Identification of catecholamines in the immune system by electrospray ionization mass spectrometry," Rapid Communications in Mass Spectrometry, vol. 12, no. 11, pp. 683-688, 1998.

[211] Y. H. Qiu, Y. P. Peng, J. M. Jiang, and J. J. Wang, "Expression of tyrosine hydroxylase in lymphocytes and effect of endogenous catecholamines on lymphocyte function," Neuroimmunomodulation, vol. 11, no. 2, pp. 75-83, 2004.

[212] A. Ricci, L. Chiandussi, M. Schena, D. Schiavone, F. Veglio, and F. Amenta, "Dopamine D5 receptor expression is unchanged in peripheral blood lymphocytes in essential hypertension," Clinical and Experimental Hypertension, vol. 17, no. 8, pp. 11571172, 1995.

[213] M. Levite, Y. Chowers, Y. Ganor, M. Besser, R. Hershkovits, and L. Cahalon, "Dopamine interacts directly with its D3 and D2 receptors on normal human T cells, and activates $\beta 1$ integrin function," European Journal of Immunology, vol. 31, no. 12, pp. 3504-3512, 2001.

[214] B. Saha, A. C. Mondal, S. Basu, and P. S. Dasgupta, "Circulating dopamine level, in lung carcinoma patients, inhibits proliferation and cytotoxicity of CD4+ and CD8+ T cells by D1 dopamine receptors: an in vitro analysis," International Immunopharmacology, vol. 1, no. 7, pp. 1363-1374, 2001.

[215] B. Saha, A. C. Mondal, J. Majumder, S. Basu, and P. S. Dasgupta, "Physiological concentrations of dopamine inhibit the proliferation and cytotoxicity of human $\mathrm{CD} 4^{+}$and $\mathrm{CD} 8^{+} \mathrm{T}$ cells in vitro: a receptor-mediated mechanism," NeuroImmunoModulation, vol. 9, no. 1, pp. 23-33, 2001.

[216] C.-W. Tsao, Y.-S. Lin, and J.-T. Cheng, "Effect of dopamine on immune cell proliferation in mice," Life Sciences, vol. 61, no. 24, pp. PL361-PL371, 1997.

[217] L. Carr, A. Tucker, and R. Fernandez-Botran, "In vivo administration of L-dopa or dopamine decreases the number of splenic IFN $\gamma$-producing cells," Journal of Neuroimmunology, vol. 137, no. 1-2, pp. 87-93, 2003.

[218] K. Nakagome, M. Imamura, H. Okada et al., "Dopamine D1like receptor antagonist attenuates Th17-mediated immune response and ovalbumin antigen-induced neutrophilic airway inflammation," Journal of Immunology, vol. 186, no. 10, pp. 59755982, 2011. 
[219] J. M. Cook-Mills, R. L. Cohen, R. L. Perlman, and D. A. Chambers, "Inhibition of lymphocyte activation by catecholamines: evidence for a non-classical mechanism of catecholamine action," Immunology, vol. 85, no. 4, pp. 544-549, 1995.

[220] T. Mori, K. Kabashima, S. Fukamachi et al., "D1-like dopamine receptors antagonist inhibits cutaneous immune reactions mediated by Th2 and mast cells," Journal of Dermatological Science, vol. 71, no. 1, pp. 37-44, 2013.

[221] P. S. Dasgupta and T. Lahiri, "Antitumor effect of i.p. dopamine in mice bearing Ehrlich ascites carcinoma," Journal of Cancer Research and Clinical Oncology, vol. 113, no. 4, pp. 363-368, 1987.

[222] S. Basu, P. S. Dasgupta, M. R. Ray, and T. Lahiri, "Stimulation of NK activity in Ehrlich ascites carcinoma-bearing mice following dopamine treatment," Biogenic Amines, vol. 8, article 7, 1992.

[223] M. A. T. Teunis, C. J. Heijnen, A. R. Cools, and A. Kavelaars, "Reduced splenic natural killer cell activity in rats with a hyperreactive dopaminergic system," Psychoneuroendocrinology, vol. 29, no. 8, pp. 1058-1064, 2004.

[224] K. S. Madden, V. M. Sanders, and D. L. Felten, "Catecholamine influences and sympathetic neural modulation of immune responsiveness," Annual Review of Pharmacology and Toxicology, vol. 35, pp. 417-448, 1995.

[225] Y. Huang, Z. Liu, X. Q. Wang, and Y. H. Qiu, "A dysfunction of CD4+ $\mathrm{T}$ lymphocytes in peripheral immune system of Parkinson's disease model mice," Zhongguo Ying Yong Sheng $L i$ Xue Za Zhi, vol. 30, no. 6, pp. 567-576, 2014.

[226] S. Basu, P. S. Dasgupta, and J. R. Chowdhury, "Enhanced tumor growth in brain dopamine-depleted mice following 1-methyl-4phenyl-1,2,3,6-tetrahydropyridine (MPTP) treatment," Journal of Neuroimmunology, vol. 60, no. 1-2, pp. 1-8, 1995.

[227] B. Deleplanque, S. Vitiello, M. Le Moal, and P. J. Neveu, "Modulation of immune reactivity by unilateral striatal and mesolimbic dopaminergic lesions," Neuroscience Letters, vol. 166, no. 2, pp. 216-220, 1994.

[228] P. Barbanti, G. Fabbrini, A. Ricci et al., "Reduced density of dopamine D2-like receptors on peripheral blood lymphocytes in Alzheimer's disease," Mechanisms of Ageing and Development, vol. 120, no. 1-3, pp. 65-75, 2000.

[229] M. Cosentino, C. Colombo, M. Mauri et al., "Expression of Apoptosis-related Proteins and of mRNA for dopaminergic receptors in peripheral blood mononuclear cells from patients with Alzheimer disease," Alzheimer Disease and Associated Disorders, vol. 23, no. 1, pp. 88-90, 2009.

[230] F. Giubilei, C. Calderaro, G. Antonini et al., "Increased lymphocyte dopamine $\beta$-hydroxylase immunoreactivity in Alzheimer's disease: compensatory response to cholinergic deficit?" Dementia and Geriatric Cognitive Disorders, vol. 18, no. 3-4, pp. 338341,2004

[231] Y. T. Kwak, M.-S. Koo, C.-H. Choi, and I. N. Sunwoo, "Change of dopamine receptor mRNA expression in lymphocyte of schizophrenic patients," BMC Medical Genetics, vol. 2, article 3, 2001.

[232] T. Ilani, D. Ben-Shachar, R. D. Strous et al., "A peripheral marker for schizophrenia: increased levels of D3 dopamine receptor mRNA in blood lymphocytes," Proceedings of the National Academy of Sciences of the United States of America, vol. 98, no. 2, pp. 625-628, 2001.

[233] E. M. Boneberg, E. von Seydlitz, K. Pröpster, H. Watzl, B. Rockstroh, and H. Illges, "D3 dopamine receptor mRNA is elevated in $\mathrm{T}$ cells of schizophrenic patients whereas $\mathrm{D} 4$ dopamine receptor mRNA is reduced in CD4 ${ }^{+}$-T cells," Journal of Neuroimmunology, vol. 173, no. 1-2, pp. 180-187, 2006.

[234] M. Vogel, S. Pfeifer, R. T. Schaub et al., "Decreased levels of dopamine D3 receptor mRNA in schizophrenic and bipolar patients," Neuropsychobiology, vol. 50, no. 4, pp. 305-310, 2004.

[235] Á. Zvara, G. Szekeres, Z. Janka et al., "Over-expression of dopamine $\mathrm{D}_{2}$ receptor and inwardly rectifying potassium channel genes in drug-naive schizophrenic peripheral blood lymphocytes as potential diagnostic markers," Disease Markers, vol. 21, no. 2, pp. 61-69, 2005.

[236] M. Urhan-Kucuk, M. E. Erdal, M. E. Ozen, S. Kul, and H. Herken, "Is the dopamine D3 receptor mRNA on blood lymphocytes help to for identification and subtyping of schizophrenia?” Molecular Biology Reports, vol. 38, no. 4, pp. 2569-2572, 2011.

[237] Y. Cui, V. Prabhu, T. B. Nguyen, B. K. Yadav, and Y.-C. Chung, "The mRNA expression status of dopamine receptor D2, dopamine receptor D3 and DARPP-32 in T lymphocytes of patients with early psychosis," International Journal of Molecular Sciences, vol. 16, no. 11, pp. 26677-26686, 2015.

[238] F. Marino and M. Cosentino, "Multiple sclerosis: repurposing dopaminergic drugs for MS-the evidence mounts," Nature Reviews Neurology, vol. 12, no. 4, pp. 191-192, 2016.

[239] J. S. Tzartos, M. A. Friese, M. J. Craner et al., "Interleukin-17 production in central nervous system-infiltrating $\mathrm{T}$ cells and glial cells is associated with active disease in multiple sclerosis," The American Journal of Pathology, vol. 172, no. 1, pp. 146-155, 2008.

[240] M. Cosentino, M. Zaffaroni, M. Ferrari et al., "Interferon- $\gamma$ and interferon- $\beta$ affect endogenous catecholamines in human peripheral blood mononuclear cells: implications for multiple sclerosis," Journal of Neuroimmunology, vol. 162, no. 1-2, pp. 112$121,2005$.

[241] M. Cosentino, M. Zaffaroni, and F. Marino, "Levels of mRNA for dopaminergic receptor $D_{5}$ in circulating lymphocytes may be associated with subsequent response to interferon- $\beta$ in patients with multiple sclerosis," Journal of Neuroimmunology, vol. 277, no. 1-2, pp. 193-196, 2014.

[242] E. Bałkowiec-Iskra, I. Kurkowska-Jastrzebska, I. Joniec et al., "MPTP-induced central dopamine depletion exacerbates experimental autoimmune encephalomyelitis (EAE) in C57BL mice," Inflammation Research, vol. 56, no. 8, pp. 311-317, 2007.

[243] T. Lowin and R. H. Straub, "Synovial fibroblasts integrate inflammatory and neuroendocrine stimuli to drive rheumatoid arthritis," Expert Review of Clinical Immunology, vol. 11, no. 10, pp. 1069-1071, 2015.

[244] S. Capellino, M. Cosentino, A. Luini et al., "Increased expression of dopamine receptors in synovial fibroblasts from patients with rheumatoid arthritis: inhibitory effects of dopamine on interleukin-8 and interleukin-6," Arthritis and Rheumatology, vol. 66, no. 10, pp. 2685-2693, 2014.

[245] M. Levite, "Dopamine and T cells: dopamine receptors and potent effects on $\mathrm{T}$ cells, dopamine production in $\mathrm{T}$ cells, and abnormalities in the dopaminergic system in T cells in autoimmune, neurological and psychiatric diseases," Acta Physiologica, vol. 216, no. 1, pp. 42-89, 2016.

[246] K. Nakano, K. Yamaoka, K. Hanami et al., "Dopamine induces IL-6-dependent IL-17 production via D1-like receptor on CD4 naive $\mathrm{T}$ cells and D1-like receptor antagonist SCH-23390 inhibits cartilage destruction in a human rheumatoid arthritis/ SCID mouse chimera model," Journal of Immunology, vol. 186, no. 6, pp. 3745-3752, 2011. 
[247] M. Mobini, Z. Kashi, A. R. Mohammad Pour, and E. Adibi, “The effect of cabergoline on clinical and laboratory findings in active rheumatoid arthritis," Iranian Red Crescent Medical Journal, vol. 13, no. 10, pp. 749-750, 2011.

[248] R. Pacheco, F. Contreras, and M. Zouali, "The dopaminergic system in autoimmune diseases," Frontiers in Immunology, vol. 5, article 117, 2014.

[249] S. J. Chadban and R. C. Atkins, "Glomerulonephritis," The Lancet, vol. 365, no. 9473, pp. 1797-1806, 2005.

[250] T. Hussain and M. F. Lokhandwala, "Renal dopamine receptor function in hypertension," Hypertension, vol. 32, no. 2, pp. 187$197,1998$.

[251] S. Hoeger, U. Gottmann, Z. Liu et al., "Dopamine treatment in brain-dead rats mediates anti-inflammatory effects: the role of hemodynamic stabilization and D-receptor stimulation," Transplant International, vol. 20, no. 9, pp. 790-799, 2007.

[252] S. Hoeger, A. Reisenbuechler, U. Gottmann et al., "Donor dopamine treatment in brain dead rats is associated with an improvement in renal function early after transplantation and a reduction in renal inflammation," Transplant International, vol. 21, no. 11, pp. 1072-1080, 2008.

[253] S. Kapper, G. Beck, S. Riedel et al., "Modulation of chemokine production and expression of adhesion molecules in renal tubular epithelial and endothelial cells by catecholamines," Transplantation, vol. 74, no. 2, pp. 253-260, 2002.

[254] D. Chakroborty, C. Sarkar, B. Basu, P. S. Dasgupta, and S. Basu, "Catecholamines regulate tumor angiogenesis," Cancer Research, vol. 69, no. 9, pp. 3727-3730, 2009.

[255] H. F. Dvorak, "Angiogenesis: update 2005," Journal of Thrombosis and Haemostasis, vol. 3, no. 8, pp. 1835-1842, 2005.

[256] D. D. Feng, W. Cai, and X. Chen, "The associations between Parkinson's disease and cancer: the plot thickens," Translational Neurodegeneration, vol. 4, article 20, 2015.

[257] C. Sarkar, B. Basu, D. Chakroborty, P. S. Dasgupta, and S. Basu, "The immunoregulatory role of dopamine: an update," Brain, Behavior, and Immunity, vol. 24, no. 4, pp. 525-528, 2010.

[258] R. Hodgson, H. J. Wildgust, and C. J. Bushe, "Cancer and schizophrenia: is there a paradox?" Journal of Psychopharmacology, vol. 24, no. 4, supplement, pp. 51-60, 2010.

[259] M. Asada, S. Ebihara, Y. Numachi et al., "Reduced tumor growth in a mouse model of schizophrenia, lacking the dopamine transporter," International Journal of Cancer, vol. 123, no. 3, pp. 511-518, 2008.

[260] J. A. Driver, G. Logroscino, J. E. Buring, J. M. Gaziano, and T. Kurth, "A prospective cohort study of cancer incidence following the diagnosis of Parkinson's disease," Cancer Epidemiology Biomarkers and Prevention, vol. 16, no. 6, pp. 1260-1265, 2007.

[261] E. Sachlos, R. M. Risueño, S. Laronde et al., "Identification of drugs including a dopamine receptor antagonist that selectively target cancer stem cells," Cell, vol. 149, no. 6, pp. 1284-1297, 2012.

[262] C. Sarkar, D. Chakroborty, R. B. Mitra, S. Banerjee, P. S. Dasgupta, and S. Basu, "Dopamine in vivo inhibits VEGF-induced phosphorylation of VEGFR-2, MAPK, and focal adhesion kinase in endothelial cells," American Journal of PhysiologyHeart and Circulatory Physiology, vol. 287, no. 4, pp. H1554H1560, 2004.

[263] S. Basu, J. A. Nagy, S. Pal et al., "The neurotransmitter dopamine inhibits angiogenesis induced by vascular permeability factor/vascular endothelial growth factor," Nature Medicine, vol. 7, no. 5, pp. 569-574, 2001.
[264] D. Chakroborty, C. Sarkar, R. B. Mitra, S. Banerjee, P. S. Dasgupta, and S. Basu, "Depleted dopamine in gastric cancer tissues: dopamine treatment retards growth of gastric cancer by inhibiting angiogenesis," Clinical Cancer Research, vol. 10, no. 13, pp. 4349-4356, 2004.

[265] S. Ganguly, B. Basu, S. Shome et al., "Dopamine, by acting through Its D2 receptor, inhibits insulin-like growth factorI (IGF-I)-induced gastric cancer cell proliferation via upregulation of Krüppel-like factor 4 through down-regulation of IGF-IR and AKT phosphorylation," American Journal of Pathology, vol. 177, no. 6, pp. 2701-2707, 2010.

[266] S. Basu, C. Sarkar, D. Chakroborty et al., "Ablation of peripheral dopaminergic nerves stimulates malignant tumor growth by inducing vascular permeability factor/vascular endothelial growth factor-mediated angiogenesis," Cancer Research, vol. 64, no. 16, pp. 5551-5555, 2004.

[267] D. Chakroborty, C. Sarkar, H. Yu et al., "Dopamine stabilizes tumor blood vessels by up-regulating angiopoietin 1 expression in pericytes and Krüppel-like factor-2 expression in tumor endothelial cells," Proceedings of the National Academy of Sciences of the United States of America, vol. 108, no. 51, pp. 20730-20735, 2011.

[268] F. Lopez Vicchi, G. M. Luque, B. Brie, J. P. Nogueira, I. Garcia Tornadu, and D. Becu-Villalobos, "Dopaminergic drugs in type 2 diabetes and glucose homeostasis," Pharmacological Research, vol. 109, pp. 74-80, 2016.

[269] American Diabetes Association, "Diagnosis and classification of diabetes mellitus," Diabetes Care, vol. 29, supplement 1, pp. S43-S48, 2006.

[270] B. J. Davis and P. H. Smith, "Effects of substantia nigra lesions on the volumes of A, B, and D cells and the content of insulin and glucagon in the rat pancreas," Diabetologia, vol. 28, no. 10, pp. 756-762, 1985.

[271] B. Rubi, S. Ljubicic, S. Pournourmohammadi et al., "Dopamine D2-like receptors are expressed in pancreatic beta cells and mediate inhibition of insulin secretion," The Journal of Biological Chemistry, vol. 280, no. 44, pp. 36824-36832, 2005.

[272] Y. Zhang, R. Zheng, X. Meng, L. Wang, L. Liu, and Y. Gao, "Pancreatic endocrine effects of dopamine receptors in human islet cells," Pancreas, vol. 44, no. 6, pp. 925-929, 2015.

[273] Y. Chen, F. Hong, H. Chen et al., "Distinctive expression and cellular distribution of dopamine receptors in the pancreatic islets of rats," Cell and Tissue Research, vol. 357, no. 3, pp. 597606, 2014.

[274] E. Shankar, K. T. Santhosh, and C. S. Paulose, "Dopaminergic regulation of glucose-induced insulin secretion through dopamine D2 receptors in the pancreatic islets in vitro," IUBMB Life, vol. 58, no. 3, pp. 157-163, 2006.

[275] K. Melkersson, A. Khan, A. Hilding, and A. L. Hulting, "Different effects of antipsychotic drugs on insulin release in vitro," European Neuropsychopharmacology, vol. 11, no. 5, pp. 327-332, 2001.

[276] W. Wu, J. Shang, Y. Feng et al., "Identification of glucosedependent insulin secretion targets in pancreatic $\beta$ cells by combining defined-mechanism compound library screening and siRNA gene silencing," Journal of Biomolecular Screening, vol. 13, no. 2, pp. 128-134, 2008.

[277] I. García-Tornadú, A. M. Ornstein, A. Chamson-Reig et al., "Disruption of the dopamine D2 receptor impairs insulin secretion and causes glucose intolerance," Endocrinology, vol. 151, no. 4, pp. 1441-1450, 2010. 
[278] A. Ustione, D. W. Piston, and P. E. Harris, "Minireview: dopaminergic regulation of insulin secretion from the pancreatic islet," Molecular Endocrinology, vol. 27, no. 8, pp. 1198-1207, 2013.

[279] K. Hashimoto, T. Inoue, T. Higashi et al., "Dopamine D1-like receptor antagonist, $\mathrm{SCH} 23390$, exhibits a preventive effect on diabetes mellitus that occurs naturally in NOD mice," Biochemical and Biophysical Research Communications, vol. 383, no. 4, pp. 460-463, 2009.

[280] A. Goodarzi, N. Vousooghi, M. Sedaghati, A. Mokri, and M.-R. Zarrindast, "Dopamine receptors in human peripheral blood lymphocytes: changes in mRNA expression in opioid addiction," European Journal of Pharmacology, vol. 615, no. 13, pp. 218-222, 2009.

[281] N. D. Volkow, G.-J. Wang, J. S. Fowler, and D. Tomasi, "Addiction circuitry in the human brain," Annual Review of Pharmacology and Toxicology, vol. 52, pp. 321-336, 2012.

[282] C. Czermak, M. Lehofer, H. Renger et al., "Dopamine receptor D3 mRNA expression in human lymphocytes is negatively correlated with the personality trait of persistence," Journal of Neuroimmunology, vol. 150, no. 1-2, pp. 145-149, 2004. 


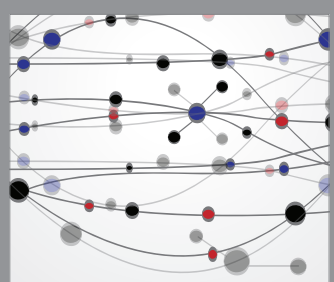

The Scientific World Journal
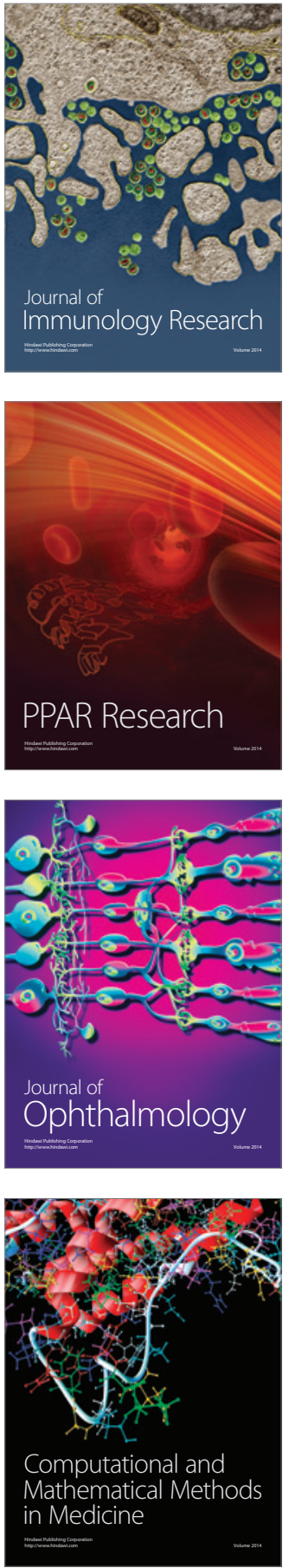

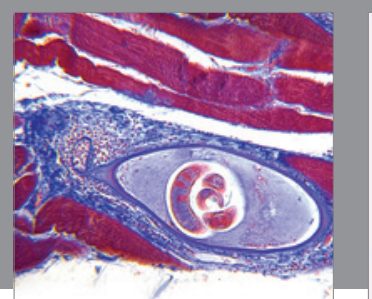

Gastroenterology Research and Practice

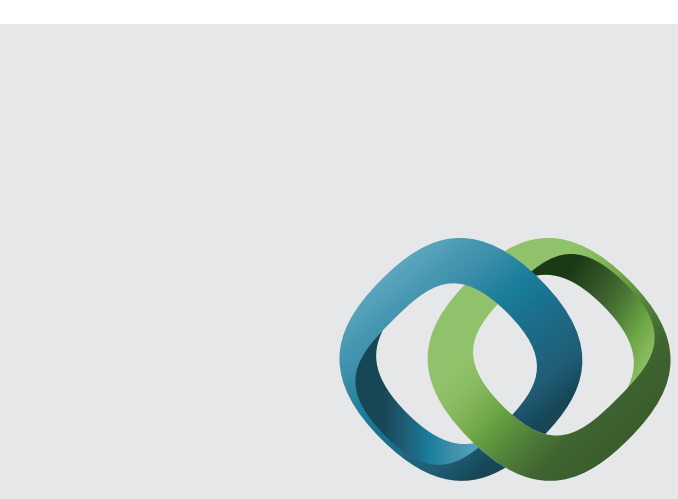

\section{Hindawi}

Submit your manuscripts at

http://www.hindawi.com
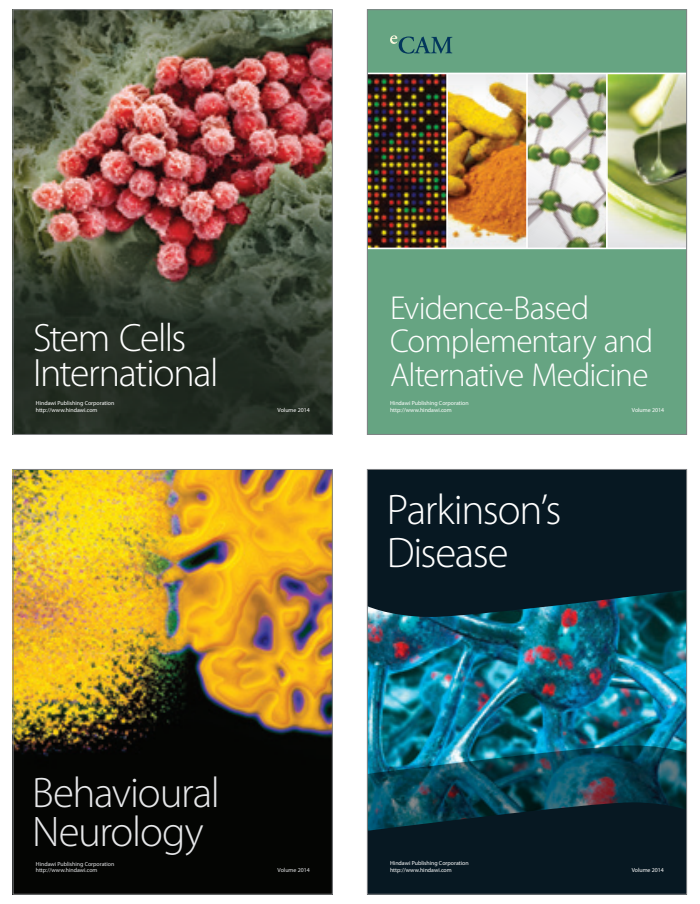
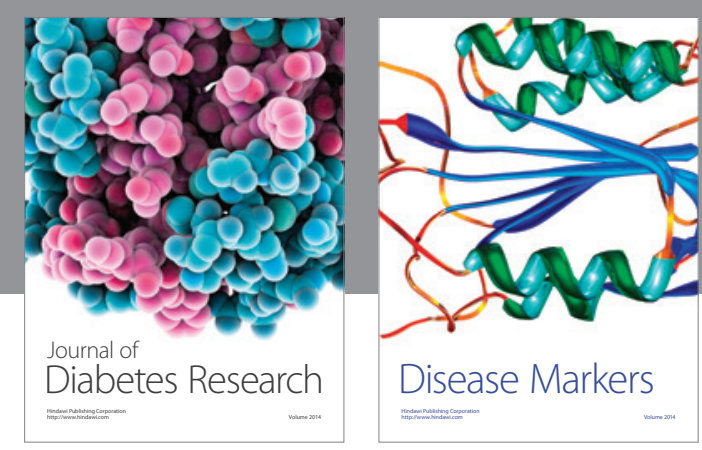

Disease Markers
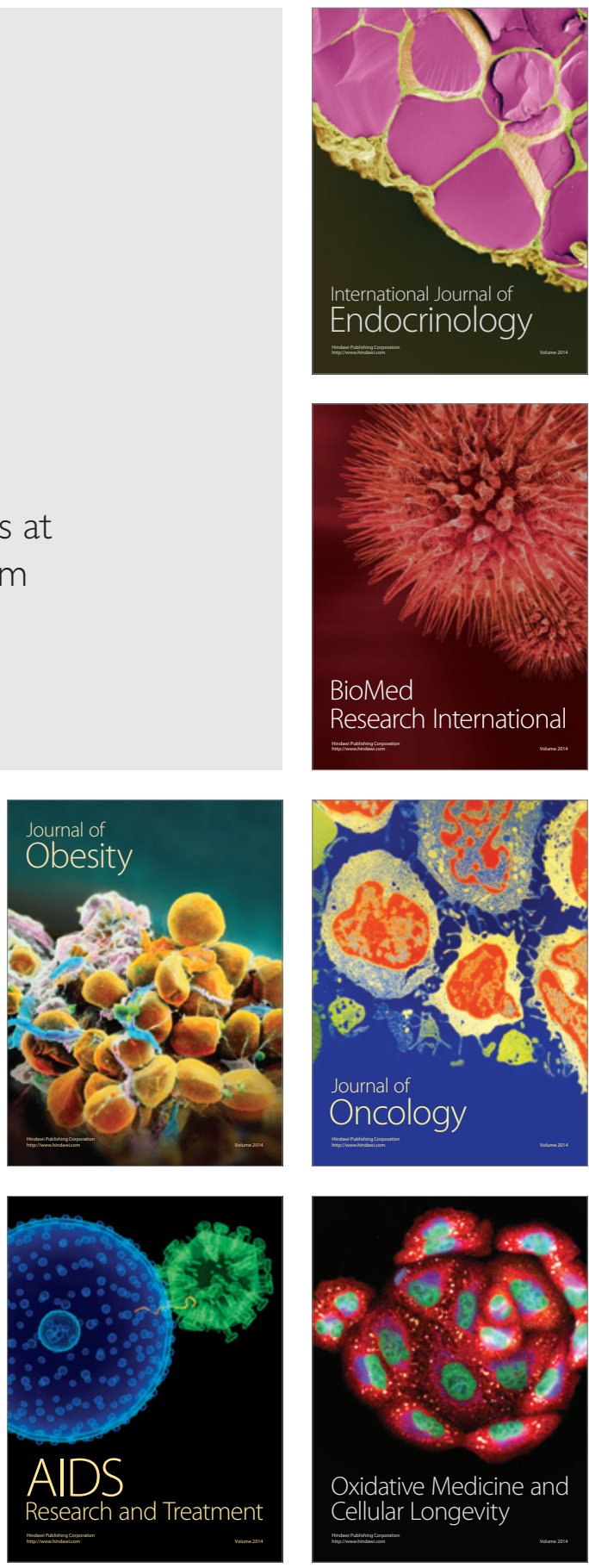